\title{
Vascular access for haemodialysis : a comparative study of brachial-basilic and prosthetic graft arteriovenous fistulas
}

Citation for published version (APA):

Keuter, X. H. A. (2008). Vascular access for haemodialysis : a comparative study of brachial-basilic and prosthetic graft arteriovenous fistulas. [Doctoral Thesis, Maastricht University]. Universiteit Maastricht. https://doi.org/10.26481/dis.20080627xk

Document status and date:

Published: 01/01/2008

DOI:

10.26481/dis.20080627xk

Document Version:

Publisher's PDF, also known as Version of record

Please check the document version of this publication:

- A submitted manuscript is the version of the article upon submission and before peer-review. There can be important differences between the submitted version and the official published version of record.

People interested in the research are advised to contact the author for the final version of the publication, or visit the DOI to the publisher's website.

- The final author version and the galley proof are versions of the publication after peer review.

- The final published version features the final layout of the paper including the volume, issue and page numbers.

Link to publication

\footnotetext{
General rights rights.

- You may freely distribute the URL identifying the publication in the public portal. please follow below link for the End User Agreement:

www.umlib.nl/taverne-license

Take down policy

If you believe that this document breaches copyright please contact us at:

repository@maastrichtuniversity.nl

providing details and we will investigate your claim.
}

Copyright and moral rights for the publications made accessible in the public portal are retained by the authors and/or other copyright owners and it is a condition of accessing publications that users recognise and abide by the legal requirements associated with these

- Users may download and print one copy of any publication from the public portal for the purpose of private study or research.

- You may not further distribute the material or use it for any profit-making activity or commercial gain

If the publication is distributed under the terms of Article $25 \mathrm{fa}$ of the Dutch Copyright Act, indicated by the "Taverne" license above, 


\title{
Vascular access for haemodialysis
}

\author{
A comparative study of brachial-basilic \\ and prosthetic graft arteriovenous fistulas
}





\title{
Vascular access for haemodialysis
}

\author{
A comparative study of brachial-basilic \\ and prosthetic graft arteriovenous fistulas
}

PROEFSCHRIFT

ter verkrijging van de graad van doctor aan de Universiteit Maastricht, op gezag van de Rector Magnificus, Prof. mr. G.P.M.F. Mols

volgens het besluit van het College van Decanen, in het openbaar te verdedigen op vrijdag 27 juni 2008 om 10.00 uur

door

\author{
X.H.A. Keuter
}

Geboren op 28 juni 1978 te Tongeren 
Promotores:

Prof. dr. P.J.E.H.M. Kitslaar

Prof. dr. ir. A.P.G. Hoeks

Copromotores:

Dr. J.H.M. Tordoir

Dr. F.M. van der Sande

Beoordelingscommissie:

Prof. dr. K.M.L. Leunissen (voorzitter)

Prof. dr. F.L. Moll (UMC, Utrecht)

Dr. M.W. de Haan

Dr. L. Hofstra

(C) X.H.A. Keuter, Maastricht 2008

All rights reserved. No part of this book may be translated or reproduced in any form by photo, photo print, microfilm or any other means without written permission from the author.

ISBN: 978-90-808755-5-5

NUR: 883

Layout: B-Point, 's-Hertogenbosch

Druk: Gildeprint, Enschede

Financial support by the Dutch Kidney foundation for this study and the publication of this thesis is gratefully acknowledged.

Additional financial support was generously provided by: Baxter B.V., WL Gore \& Associates, Johnson \& Johnson Medical B.V., Transonic Systems Europe B.V., Fresenius Medical Care Nederland B.V., Bard Benelux N.V.. 


\section{Contents}

$\begin{array}{lll}\text { Chapter } 1 \quad \text { General introduction } & 7\end{array}$

Chapter 2 Autogenous options in secondary and tertiary access for haemodialysis

Chapter 3 Excellent performance of one-stage brachial-basilic arteriovenous fistula

Chapter 4 A randomized multicenter study of the outcome of brachial-basilic arteriovenous fistula and prosthetic brachial-antecubital forearm loop as vascular access for haemodialysis

Chapter 5 Prospective evaluation of ischaemia in brachial-basilic and forearm prosthetic arteriovenous fistulas for haemodialysis

Chapter 6 Effect of upper arm brachial-basilic and prosthetic forearm arteriovenous fistula on left ventricular hypertrophy

Chapter 7 The relation between vascular access flow and different types of vascular access with systemic hemodynamics in haemodialysis patients

Chapter 8 Brachial artery thrombosis due to haemodialysis arteriovenous fistula

Chapter 9 General discussion and conclusions

Chapter 10 Samenvatting 

General introduction 


\section{INTRODUCTION}

Chronic renal disease is a pathophysiologic process with multiple etiologies including arteriosclerosis, diabetes, hypertension, glomerulonephritis and cystic disease, resulting in the loss of nephron number and function, leading to end-stage renal disease (ESRD). In ESRD patients the irreversible loss of endogenous renal function makes the patient permanently dependent upon renal replacement therapy in order to avoid life threatening uremia1. Renal replacement therapy consists of either dialysis or transplantation. For dialysis, the options are haemodialysis and peritoneal dialysis, where both options require an optimal access to the body. For peritoneal dialysis (PD) dialysis fluid is administered through a PD catheter into the peritoneal cavity. The peritoneum acts as a dialysis membrane; after several hours the fluid with the waste products is drained and new fluid is administered. This procedure needs to be done several times a day, or night as preferred by most patients. For haemodialysis a vascular access is a necessity. Blood will be withdrawn from the body through an arterial tube and transferred to the dialysis apparatus, which removes waste products from the blood. Afterwards the blood is returned to the body through a venous tube.

\section{Dialysis population}

In 2005 the number of patients undergoing treatment for ESRD worldwide was estimated 1.9 million, of which 1.5 million patients were treated by dialysis. The number of the total population of ESRD, dialysis and transplant patients has an annual growth rate of 6-7\%. The growth rate for haemodialysis patients is comparable. This means that, if we extrapolate the status of 2005 and the observed growth rates, in 2010 a global population on dialysis treatment approaching 2 million patients is expected ${ }^{2}$. In the Netherlands in 2006 , the prevalence of ESRD patients was 12.038 of which $45 \%$ receives dialysis therapy ${ }^{3}$. Particularly the number of patients in the older age group of above 65 years increased dramatically from 1632 in 1996 to 2515 in 2005. Similar observations are reported in the USA (USRDS) ${ }^{4}$. With regard to the proportion of ESRD patients receiving haemodialysis therapy, the overall percentage is $33.8 \%$. However, in the elderly population, over 75 years of age, this percentage is up to $77 \%$.

\section{History of haemodialysis/vascular access}

The very first type of haemodialysis was performed by Georg Haas in 1924. Initially he used glass cannulae to obtain vascular access, later he performed a 
surgical cut-down to place a cannula into the radial artery and into an adjacent vein. Haemodialysis, in its currently used form, started in 1943 when Willem Kolff constructed a "rotating drum kidney". He used venipuncture needles to obtain blood from the femoral artery and to reinfuse it via a cannulated vein. Later he performed a surgical cut-down of the radial artery, which however caused severe bleeding during heparinisation. It wasn't until 1945 before the first patient of 17 years of age survived haemodialysis. In the following years the dialysis apparatus improved substantially, but reliable access to the circulation remained and remains a major problem 5 .

In 1960, Quintin and Scribner invented an external vascular access for intermittent haemodialysis, also known as the Scribner shunt. Two thin-walled Teflon cannulae with tapered ends were inserted near the wrist into the radial artery and the adjacent cephalic vein. Between dialysis sessions the external ends were connected by a curved Teflon tube ${ }^{6}$. During the following years several modifications were described. In 1961 Stanley Shaldon experimented with hand-made catheters which he introduced into the femoral artery and vein by the percutaneous Seldinger technique for immediate vascular access 7,8 . It wasn't until 1966 when Brescia, Cimino, Appel and Hurwich described the first internal surgically created fistula for the purpose of haemodialysis ${ }^{9}$. Appel, who was the surgeon of the team, performed a side-to-side anastomosis between the radial artery and the cephalic vein at the wrist. Despite the fact that the fistula was first created by him, it is often referred to as a Cimino or Brescia-Cimino-fistula.

Other options of autogenous vascular access are in the antecubital fossa between the brachial artery and suitable veins ${ }^{10,11}$ (brachial-cephalic and cubital), or the transposition of the basilic vein in the upper arm with anastomosis to the brachial artery 12 .

The use of grafts was first described in the seventies, when bovine carotid artery grafts ${ }^{13}$ and expanded polytetrafluoroethylene (ePTFE) ${ }^{14}$ were first used. These grafts are available in different lengths and diameters and can be placed between any suitable artery and vein in the upper or lower extremity. The preferred graft site options are the antecubital forearm loop graft and the upper arm looped graft. The patency of implanted PTFE grafts is superior or equal to other grafts ${ }^{15,16 .}$

\section{Guidelines of vascular access for haemodialysis}

According to the American 16 and European guidelines ${ }^{15,17}$ the sequence of preference for placement of autogenous arteriovenous fistulae (AVF) in patients 
with ESRD is a wrist fistula (radial-cephalic (RC) AVF) and an elbow AVF (brachial-cephalic (BC) AVF). If these options are not possible or when previous RC-AVF have failed, the preferred third choice vascular access is the brachialbasilic (BB) AVF, as it is also an autogenous fistula. However, there is no evidence from a randomised clinical trial demonstrating the superiority of BBAVF to the other third choice options for vascular access. The main other option is an arteriovenous graft using synthetic material (e.g. PTFE) ${ }^{15-17}$. It is important to reach evidence-based consensus about these third option vascular accesses, because better patient care with subsequent increased life expectancy often leads to exhaustion of available access sites with the need for alternative vascular access at different sites ${ }^{18,19}$. Furthermore there is an increase in the number of elderly patients in which arteriosclerosis and/or diabetes is the major cause for renal failure and haemodialysis treatment. In this population, prevalent vascular problems may hamper forearm vascular access creation and maturation 20 .

\section{Complications of arteriovenous fistulas}

Complications of AVF are non-maturation, ischaemia, stenosis formation and thrombosis. Failure to mature is defined as the inability to use the fistula for haemodialysis after 6 weeks ${ }^{21}$. In RC-AVFs non-maturation is reported between 6-34\%21. In BB-AVF studies non-maturation rate has been reported up to $38 \% 22$, although other authors observed lower rates 23 . Prosthetic grafts (PTFE) have shorter and better maturation time and can be instantaneously used for cannulation 24 . On the other hand, they are prone to develop stenoses at the arterial and/or venous anastomosis, leading to flow decrease and eventually thrombosis. In addition, graft infection may lead to access failure and the need for explantation in a considerable number of patients23,24. As a result, long-term patency rates are lower compared to autogenous fistulas $25-27$. Primary patency rates after one year are reported lower for arteriovenous grafts compared to BB-AVF (44-70\% vs. 35-92\%). One year secondary patency rates are more comparable, although slightly in favour of the grafts compared to the BB-AVF (79-87\% vs. 55-96\%)23,24,28-31.

As mentioned before, due to the growing older dialysis population with more co-morbidity and a longer life expectancy the number of upper arm vascular accesses will increase despite the related complications of high output cardiac failure and ischaemia of the hand32-36. Seventy-five percent of the patients with ESRD have left ventricular hypertrophy, a compensatory mechanism of the heart for the increased workload induced by the high blood volume shunting 
through the arteriovenous anastomosis 37 . One should be aware of the associated risk of cardiac failure in this pre-disposed population whenever a highflow fistula is created; selection of a proper intervention strategy is of importance ${ }^{38}$.

Ischaemia of the hand is seen in 1-5\% of all vascular accesses for haemodialysis $^{36}$. In brachial-based accesses this figure increases up to $25 \% 39$. Ischaemia of the hand occurs when blood supply to the hand is impaired. This can be due to obstructed arteries to the hand, usually caused by atherosclerosis, inflow stenosis proximal to the anastomosis or impaired collateral blood flow 36,40 . A steal syndrome occurs when the low pressure in the venous component of the access sucks blood from the distal artery, downstream from the anastomosis. If this steal is not recognised in an early stage and not adequately treated, finger or hand gangrene may lead to minor or major amputation 34 .

\section{OBJECTIVES OF THIS THESIS}

1. To evaluate secondary and tertiary options of vascular access for haemodialysis.

2. To evaluate the brachial-basilic arteriovenous fistula and the prosthetic forearm loop graft as a vascular access for haemodialysis.

3. To determine the incidence of ischaemic complications in brachial-basilic arteriovenous fistulas and prosthetic forearm loop grafts.

4. To detect pre-operative predictors for ischaemia in brachial-basilic arteriovenous fistulas and prosthetic arteriovenous forearm loop grafts.

5. To evaluate cardiac load after creating a brachial-basilic arteriovenous fistula or prosthetic forearm loop graft.

6. To assess the relation between cardiac function and access flow and to compare the haemodynamic effects of elbow/upper arm fistula with those of forearm fistulas.

\section{OVERVIEW OF THIS THESIS}

Chapter 2 provides an overview of the secondary and tertiary vascular access options for haemodialysis. Chapter 3 reports the results of a retrospective study of brachial-basilic arteriovenous fistulas as vascular access for haemodialysis. Chapter 4 addresses a randomized multicenter clinical trial comparing brachial-basilic arteriovenous fistulas and prosthetic arteriovenous 
forearm grafts, focusing on patency rates, complications and interventions. Chapter 5 considers the incidence and pre-operative predictors of ischaemia after brachial-basilic arteriovenous fistula or prosthetic arteriovenous forearm loop graft creation. Chapter 6 evaluates the cardiac load increase after creation of a brachial-basilic arteriovenous fistula or prosthetic arteriovenous forearm loop graft. Chapter 7 discusses the relation between cardiac function and access flow and the haemodynamic effects of elbow/upper arm fistulas compared to forearm fistulas. In Chapter 8 we describe a patient with symptomatic hand ischaemia due to a thrombosed brachial artery in combination with a previous vascular access in the same extremity. Chapter 9 includes a general discussion of the findings of this thesis and those reported in the recent literature, future perspectives, and conclusions. Chapter 10 provides a summary in Dutch.

\section{REFERENCES}

1. Harrison TR, Braunwald E, Fauci AS, et al. Harrison's principles of internal medicine. 15th ed. New York: McGraw-Hill; 2001.

2. Grassmann A, Gioberge S, Moeller S, et al. End-stage renal disease: global demographics in 2005 and observed trends. Artif Organs. Dec 2006;30(12):895-897.

3. Haase BJJM, Hoitsma AJ, Kooman JP, et al. Statistisch Jaarverslag 2007, Renine. Rotterdam: Stichting Renine; 2007.

4. Bethesda. USRDS 2007 Annual Data Report: Atlas of Chronic Kidney Disease and End-Stage Renal Disease in the United States, National Institutes of Health, National Institute of Diabetes and Digestive and Kidney Diseases; 2007.

5. Kolff WJ. First Clinical Experience with the Artificial Kidney. Ann Intern Med. Mar 1965;62:608-619.

6. Scribner BH, Buri R, Caner JE, et al. The treatment of chronic uremia by means of intermittent hemodialysis: a preliminary report. Trans Am Soc Artif Intern Organs. Apr 10-11 1960;6:114-122.

7. Seldinger SI. Catheter replacement of the needle in percutaneous arteriography; a new technique. Acta radiol. May 1953;39(5):368-376.

8. Shaldon S, Chiandussi L, Higgs B. Haemodialysis by percutaneous catheterisation of the femoral artery and vein with regional heparinisation. The Lancet. 14 October 1961 1961;278(7207):857-859.

9. Brescia MJ, Cimino JE, Appel K, et al. Chronic hemodialysis using venipuncture and a surgically created arteriovenous fistula. N Engl J Med. Nov 17 1966;275(20): 1089-1092.

10. Crockett RE. Blood access for haemodialysis. Nephron. 1974;12(5):338-354. 
11. Gracz KC, Ing TS, Soung LS, et al. Proximal forearm fistula for maintenance hemodialysis. Kidney Int. Jan 1977;11(1):71-75.

12. Dagher FJ, Gelber RL, Ramos EJ, et al. Basilic vein to brachial artery fistula: a new access for chronic hemodialysis. South Med J. Nov 1976;69(11):1438-1440.

13. Chinitz JL, Tokoyama T, Bower R, et al. Self-sealing prosthesis for arteriovenous fistula in man. Trans Am Soc Artif Intern Organs. 1972;18(0):452-457.

14. Baker LD, Jr., Johnson JM, Goldfarb D. Expanded polytetrafluoroethylene (PTFE) subcutaneous arteriovenous conduit: an improved vascular access for chronic hemodialysis. Trans Am Soc Artif Intern Organs. 1976;22:382-387.

15. Tordoir J, Canaud B, Haage P, et al. EBPG on Vascular Access. Nephrol Dial Transplant. May 2007;22 Suppl 2:ii88-117.

16. Besarab A, Work J, Brouwer D, et al. Clinical Practice Guidelines for Hemodialysis Adequacy, Update 2006. Am J Kidney Dis. 2006;48:Suppl 1:S176-247.

17. Tordoir JH, Mickley V. European guidelines for vascular access: clinical algorithms on vascular access for haemodialysis. Edtna Erca J. Jul-Sep 2003;29(3):131136.

18. Fitzgerald JT, Schanzer A, Chin Al, et al. Outcomes of upper arm arteriovenous fistulas for maintenance hemodialysis access. Arch Surg. Feb 2004;139(2):201208.

19. Butterworth PC, Doughman TM, Wheatley TJ, et al. Arteriovenous fistula using transposed basilic vein. Br J Surg. May 1998;85(5):653-654.

20. Konner K, Hulbert-Shearon TE, Roys EC, et al. Tailoring the initial vascular access for dialysis patients. Kidney Int. Jul 2002;62(1):329-338.

21. Rooijens PP, Tordoir JH, Stijnen T, et al. Radiocephalic wrist arteriovenous fistula for hemodialysis: meta-analysis indicates a high primary failure rate. Eur J Vasc Endovasc Surg. Dec 2004;28(6):583-589.

22. Rao RK, Azin GD, Hood DB, et al. Basilic vein transposition fistula: a good option for maintaining hemodialysis access site options? J Vasc Surg. May 2004;39(5):1043-1047.

23. Dix FP, Khan Y, Al-Khaffaf H. The Brachial Artery-basilic Vein Arterio-venous Fistula in Vascular Access for Haemodialysis-A Review Paper. Eur J Vasc Endovasc Surg. Oct 132005.

24. Fitzgerald JT, Schanzer A, McVicar JP, et al. Upper arm arteriovenous fistula versus forearm looped arteriovenous graft for hemodialysis access: a comparative analysis. Ann Vasc Surg. Nov 2005;19[6]:843-850.

25. Pisoni RL, Young EW, Dykstra DM, et al. Vascular access use in Europe and the United States: results from the DOPPS. Kidney Int. Jan 2002;61[1]:305-316.

26. Perera GB, Mueller MP, Kubaska SM, et al. Superiority of autogenous arteriovenous hemodialysis access: maintenance of function with fewer secondary interventions. Ann Vasc Surg. Jan 2004;18(1):66-73. 
27. Huber TS, Carter JW, Carter RL, et al. Patency of autogenous and polytetrafluoroethylene upper extremity arteriovenous hemodialysis accesses: a systematic review. J Vasc Surg. Nov 2003;38(5):1005-1011.

28. Coburn MC, Carney WI. Comparison of basilic vein and polytetrafluoroethylene for brachial arteriovenous fistula. Journal of Vascular Surgery. December 1994 1994;20(6):896-904.

29. Dammers R, Planken RN, Pouls KP, et al. Evaluation of 4-mm to 7-mm versus 6$\mathrm{mm}$ prosthetic brachial-antecubital forearm loop access for hemodialysis: results of a randomized multicenter clinical trial. J Vasc Surg. Jan 2003;37(1):143-148.

30. Lemson MS, Tordoir JH, van Det RJ, et al. Effects of a venous cuff at the venous anastomosis of polytetrafluoroethylene grafts for hemodialysis vascular access. J Vasc Surg. Dec 2000;32(6):1155-1163.

31. Rooijens PP, Burgmans JP, Yo TI, et al. Autogenous radial-cephalic or prosthetic brachial-antecubital forearm loop AVF in patients with compromised vessels? A randomized, multicenter study of the patency of primary hemodialysis access. J Vasc Surg. Sep 2005;42(3):481-486; discussions 487.

32. Anderson CB, Codd JR, Graff RA, et al. Cardiac failure and upper extremity arteriovenous dialysis fistulas. Case reports and a review of the literature. Arch Intern Med. Mar 1976;136[3]:292-297.

33. MacRae JM, Pandeya S, Humen DP, et al. Arteriovenous fistula-associated highoutput cardiac failure: a review of mechanisms. Am $J$ Kidney Dis. May 2004;43(5):e17-22.

34. Levine MP. The hemodialysis patient and hand amputation. Am J Nephrol. NovDec 2001;21(6):498-501.

35. Morsy $\mathrm{AH}$, Kulbaski M, Chen $\mathrm{C}$, et al. Incidence and characteristics of patients with hand ischemia after a hemodialysis access procedure. J Surg Res. Jan 1998;74(1):8-10.

36. Tordoir JH, Dammers R, van der Sande FM. Upper extremity ischemia and hemodialysis vascular access. Eur J Vasc Endovasc Surg. Jan 2004;27(1):1-5.

37. Foley RN, Parfrey PS, Sarnak MJ. Clinical epidemiology of cardiovascular disease in chronic renal disease. Am J Kidney Dis. Nov 1998;32(5 Suppl 3):S112-119.

38. Frey N, Olson EN. Cardiac hypertrophy: the good, the bad, and the ugly. Ann Rev Physiol. 2003;65:45-79.

39. van Hoek F, Scheltinga MR, Kouwenberg I, et al. Steal in hemodialysis patients depends on type of vascular access. Eur J Vasc Endovasc Surg. Dec 2006;32(6):710-717.

40. Yeager RA, Moneta GL, Edwards JM, et al. Relationship of hemodialysis access to finger gangrene in patients with end-stage renal disease. J Vasc Surg. Aug 2002;36(2):245-249; discussion 249. 
Autogenous options in secondary and tertiary access for haemodialysis

J.H.M. Tordoir, X.H.A. Keuter, R.N. Planken, M.W. de Haan and F.M. van der Sande

Eur J Vasc Endovasc Surg 2006; 31: 661-666. 


\section{ABSTRACT}

\section{Objectives}

The world's haemodialysis population is growing rapidly so that in 2006 some 1,5 million interventions will be needed for access placement, revision and maintenance. Secondary and tertiary arteriovenous fistulas are becoming an integral part of vascular access especially in the elderly, comorbid population.

\section{Methods}

Venous conduits may have a more favourable outcome with fewer complications and revisions in comparison with accesses using prosthetic implants. Innovative surgical techniques, including vein transposition, translocation and elevation may add to this philosophy of creating exclusively autogenous vascular access. 


\section{INTRODUCTION}

For decades the strategies for access creation have been different in Europe and the USA with the majority of new and incident patients receiving autogenous arteriovenous fistulas (AVF) in Europe, whereas in the USA most have received prosthetic grafts. Although there is still a clear preference for primary autogenous radio-cephalic arteriovenous fistulas (RC-AVF) in European countries, the need for secondary and tertiary procedures in Europe is increasing due the increasing age of dialysis patients and associated comorbidities such as diabetes mellitus, coronary artery disease and peripheral arterial disease, which may hamper the creation of autogenous vascular access conduits. Recently published data still show a high prevalence of autogenous AVFs among European patients, but there seems to be a major shift in secondary and tertiary procedures from forearm fistulas to elbow and upper arm fistulas ${ }^{1}$. In addition, the difficulties encountered by many physicians in creating a functioning vascular access has led to a renewed interest in the exclusive use of the patient's own veins for fistula creation.

In this review the strategies, surgical techniques and outcomes of the creation of secondary and tertiary accesses with the use of upper and lower extremity venous conduits are described.

\section{SECONDARY/TERTIARY AUTOGENOUS FISTULAS IN THE UPPER EXTREMITY}

The upper limb is preferred over the lower extremity for vascular access because of the ease of cannulation, comfort for the patient, and the considerably lower incidence of complications. Similarly, autogenous conduits are also preferable to the use of prosthetic grafts because of improved patency and lower risk of infection.

\section{Forearm venous transposition and elevation}

Superficial vein transposition increases the possibilities for forearm fistulas. When the cephalic vein is unsuitable, the basilic vein can be transposed from the ulnar to the radial side along a straight subcutaneous course from the elbow to the radial artery. Silva et al. advocated different surgical techniques, according to the forearm artery and vein location?2. Of the 89 veins that were of acceptable size and patency, 13 (15\%) were in immediate proximity to the radial artery such that an AVF could be formed through a single incision. Thirty of 89 (33\%) of the veins were located on the dorsal aspect of the fore- 
arm and were transposed to the volar aspect for anastomosis to the appropriate artery (radial in 26, ulnar in two, and brachial in two). The remaining 46 of 89 veins (52\%) were located on the volar aspect of the forearm but were dissected through separate incisions, transposed superficially, and sutured to the appropriate artery (radial in 42, ulnar in two, and brachial in two). Successful cannulation and haemodialysis was accomplished in 81 of the 89 AVFs, giving a maturation rate of $91 \%$. Primary patency rates were $84 \%$ at 1 year and $69 \%$ at 2 years for all AVFs.

When the arterial inflow into a radial fistula is impeded by a distal stenosis in the forearm, it may be enhanced by transposition of the forearm cephalic or basilic vein more proximally to the radial artery or brachial artery at the elbow in a subcutaneous loop ${ }^{3}$.

A cephalic vein that is located too deeply may be made accessible for cannulation by elevation. Four to 9 weeks after the initial operation, the cephalic vein has usually matured sufficiently to allow easy surgical dissection. The subcutaneous fat is approximated beneath the fistula vein, thereby elevating the fistula to a superficial position. An alternative surgical option is cephalic vein dissection and transection $2 \mathrm{~cm}$ proximal to the $\mathrm{AV}$ anastomosis with subcutaneous rerouting along a straight course with reanastomosis to the radial artery. The elevation technique has been described by Cull et al. in 7 patients with RC-AVFs and cannulation difficulties. The failure rate was rather high with 5 out of seven elevated fistulas non-functional for dialysis treatment ${ }^{4}$.

\section{Mid-forearm and elbow AVF}

When the arteries and/or veins are too small or diseased for the creation of a wrist RC-AVF, more proximally located fistulas are indicated with an anastomosis at the mid-forearm or elbow region. Konner et al. have shown that in a high percentage of patients with failed RC-AVFs still a suitable vein can be found proximal in the forearm which can be anastomosed to the radial artery $^{5}$. Bonforte et al. have described the surgical technique of mid-forearm fistula. A total of 112 surgical procedures were performed on 106 patients with primary 24- and 48-month patency rates of $93 \%$ and $83 \%$, respectively, and a low incidence of complications ${ }^{6}$.

In brachial-cubital AVFs (Gracz fistula), the deep perforating branch of the medial cubital vein is dissected, transected and anastomosed to the brachial or proximal radial artery (Figure 2.1). The flow through the AVF will be directed either to the upper arm basilic and/or cephalic vein, which becomes available for cannulation. Brachial-cubital AVFs generate a high blood flow for dialysis. The incidences of non-maturation, thrombosis and infection are low with good 
long-term patency. In 50 patients with brachial-cubital AVFs, the 1- and 3-year patencies were 84 and 78\% respectively. Major complications were distal hypoperfusion, which may lead to symptomatic hand ischaemia, and high-output cardiac failure, especially in patients with heart disease and coronary artery sclerosis?.

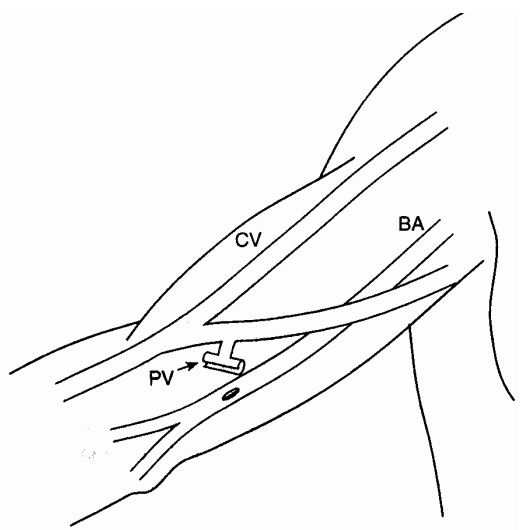

Figure 2.1: Brachio-cubital AVF (Gracz). BA = brachial artery; $P V=$ perforating vein; $C V=$ cephalic vein.

\section{Upper arm brachial-cephalic AVF}

The brachial-cephalic AV fistula is only one of a variety of possible AV anastomoses in the elbow region. Depending on the individual situation, the proximal radial artery, brachial artery or proximal ulnar artery can be used for the AV anastomosis (Figure 2.2). As for forearm fistulas, the vascular access should provide an optimal situation for cannulation along the cephalic vein.

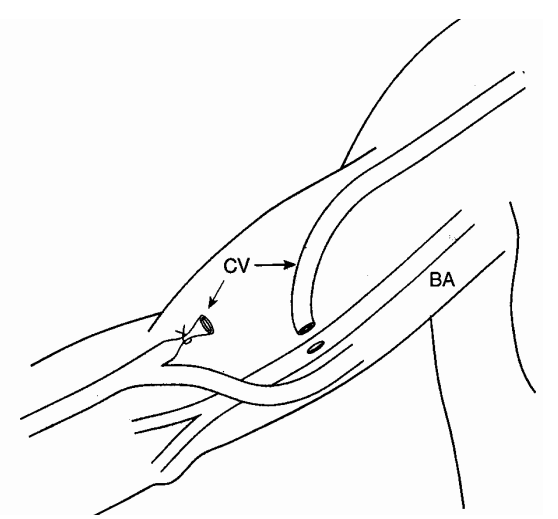

Figure 2.2: Brachial-cephalic AVF. BA = brachial artery; $C V=$ cephalic vein. 
Recently, the results of 100 brachial-cephalic fistulas in 96 patients were reported, with the majority of patients receiving a brachial artery to cubital vein anastomosis. The primary, primary assisted, and secondary patency rates after 1 year were 54.7, 72.3 and $79.2 \%$, and after 2 years 40.4, 59.2 and $67.5 \%$, respectively. Predictors of failure, using Cox regression multivariate analysis, included diabetes mellitus (HR 2.81, $p<0.001)$ and a history of contralateral PTFE loop graft (HR 7.79, $p=0.007$ ). The authors concluded that the primary patency of brachial-cephalic fistulas was comparable to that of radio-cephalic fistulas ${ }^{8}$. Reported early failure and one-year patency rates of brachial-cephalic AVFs are outlined in table 2.18-13.

\begin{tabular}{|c|c|c|c|}
\hline Author & No. AVFs & Early failure (\%) & Patency (\%) \\
\hline Dunlop et al. $^{9}$ & 81 & -- & 70 \\
\hline Zibari et al. ${ }^{10}$ & 48 & -- & 90 \\
\hline Nazzal et al. ${ }^{11}$ & 42 & -- & 91 \\
\hline Murphy et al. ${ }^{12}$ & 208 & 16 & 75 \\
\hline Zeebregts et al. ${ }^{8}$ & 100 & 11 & 79 \\
\hline Lok et al. ${ }^{13}$ & 186 & 9 & 78 \\
\hline
\end{tabular}

Table 2.1: Early failure and one-year patency of brachial-cephalic AVFs.

\section{Upper arm brachial-basilic AVF}

Usually the upper arm basilic vein is inaccessible for dialysis cannulation, because of its medial and deep native position. In 1976 Dagher et al. described the original technique of brachial-basilic anastomosis with a second operation to mobilise the arterialised vein into a subcutaneous position ${ }^{14}$.

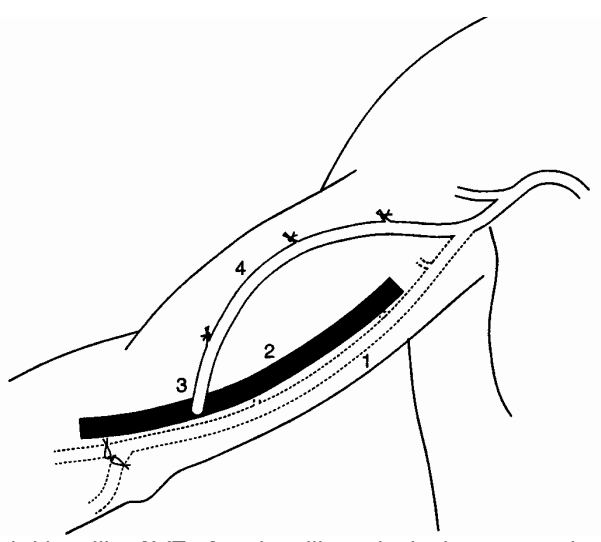

Figure 2.3: Brachial-basilic AVF. 1 = basilic vein in its normal position; 2 = brachial artery; 3 \& 4 = transposed basilic vein. 
There are several surgical options for brachial-basilic AVFs (BB-AVF):

One-stage procedure: The basilic vein is dissected and side branches ligated from the elbow to the axilla. After transection at the elbow it is transposed through a lateral subcutaneous tunnel and reanastomosed end-to-side to the brachial artery (Figure 2.3).

Two-stage procedure: At the first operation a brachial artery to basilic vein anastomosis is performed. Six weeks later a second procedure is performed using one of two alternative techniques for superficialisation of the vein:

a) Elevation: The basilic vein is dissected and the side branches ligated. The fat is sutured beneath the vein, elevating it to a subcutaneous position.

b) Transposition: The basilic vein is dissected out, the sidebranches ligated and transected $2 \mathrm{~cm}$ proximal to the $\mathrm{AV}$ anastomosis. It is then passed laterally through a subcutaneous tunnel and reanastomosed to the brachial artery.

No significant differences in non-maturation and patency rates have been reported between one and two-stage procedures. The elevation and transposition techniques also have similar outcomes. Rivers et al. found that $49 \%$ of one stage BB-AVFs were patent at 30 months ${ }^{15}$. Hossny employed the different techniques of BB-AVF creation in a non-randomised study of 70 patients ${ }^{16}$. High one-year patencies from 86 to $90 \%$ in all groups were reported with only $5-7 \%$ of AVF showing non-maturation. Recent publications report a primary failure rate of $5-40 \%$ with one-year patencies varying from 47 to 90\% (Table 2.2) ${ }^{15-23}$. The technique of subcutaneous placement of the basilic vein seems to have several advantages over forearm or upper arm graft implantation, with less infection and thrombosis. In comparison with brachial-cephalic fistulas, BB-AVFs are more likely to mature, although they are more susceptible to late thrombosis.

\begin{tabular}{lcccc}
\hline Author & Type AVF & No. AVFs & Early failure (\%) & Patency (\%) \\
\hline Rivers et al. $^{15}$ & os/tr & 65 & 2 & 58 \\
Coburn et al. $^{16}$ & os/tr & 59 & -- & 93 \\
El Mallah et al. ${ }^{17}$ & os/tr & 20 & 40 & 50 \\
& ts/el & 20 & 10 & 80 \\
Humphries et al. $^{18}$ & ts/el & 67 & -- & 84 \\
Murphy et al. $^{19}$ & os/tr & 74 & 32 & 73 \\
Segal et al. $^{20}$ & os/tr & 99 & 23 & 64 \\
Taghizadeh et al. $^{21}$ & os/tr & 75 & 8 & 66 \\
Hossny $^{22}$ & os/el & 20 & 5 & 90 \\
& os/tr & 20 & 7 & 86 \\
Rao et al. & & & & \\
& ts/el & 30 & 5 & 87 \\
\hline
\end{tabular}

Table 2.2: Early failure and one-year patency of brachial-basilic AVFs. os = one stage; ts = two stage; $t r=$ transposition; el = elevation. 


\section{Upper arm brachial-brachial vein AVF}

Recently a transposition fistula using the brachial vein in the upper arm has been described for vascular access in two patients 24 . As in basilic vein transposition, the brachial vein is harvested distally about $3 \mathrm{~cm}$ into the forearm beyond the antecubital fossa, in order to gain sufficient length for lateral tunnelling. The vein is ligated at this level, transected and transposed through a subcutaneous tunnel lateral to the incision. The non-distended brachial vein is about 4-5 $\mathrm{mm}$ in diameter and may increase to 6-8 $\mathrm{mm}$ under pressure. A period of 8 weeks is allowed for the fistula to mature prior to its use for haemodialysis.

\section{Upper arm brachial-axillary translocated superficial femoral vein}

The superficial femoral vein is a large autogenous vein that can be translocated to the upper extremity. It is exposed through an incision that extends from the inferior aspect of the femoral triangle over the common femoral vein to the above-knee popliteal fossa on the lateral aspect of the sartorius muscle. The superficial femoro-popliteal vein is then dissected free caudally from its confluence with the profunda femoral vein to the midpopliteal fossa. After removal, the reversed vein is interposed through a subcutaneous tunnel between the brachial artery and axillary vein. Huber et al. reported on the outcome of 30 superficial femoral vein (SFV) translocations ${ }^{25}$. The primary, primary assisted, and secondary patency rates for the SFV were 79, 91, and $100 \%$, respectively, at 12 months; and 67\%, 86\%, and 100\%, respectively, at 18 months. Significant hand ischaemia developed in $43 \%$ of the patients and required a distal revascularisation and interval ligation (DRIL) procedure in $27 \%$. Thigh wound complications developed in $23 \%$ of the patients, and arm wound complications developed in $17 \%$. There was a significant difference in the incidence of thigh complications between obese and non-obese patients (57 vs. 13\%). One patient with peripheral artery occlusive disease (PAOD) required an above-knee amputation ipsilateral to the deep vein harvest, and a second patient with a failing DRIL procedure required a finger amputation.

\section{SECONDARY/TERTIARY AUTOGENOUS FISTULAS IN THE LOWER EXTREMITY}

The lack of potential upper extremity or chest wall AVF sites, due to exhaustion of all upper extremity outflow veins by catheter-induced central venous obstruc- 
tion, makes vascular access at the femoral region inevitable for a growing number of patients. Saphenous and superficial femoral vein transposition are options for thigh AVFs.

\section{Lower extremity femoral-greater saphenous vein access}

The greater saphenous vein can be used for vascular access in either of two ways:

1) It may be transposed in a straight subcutaneous tunnel with anastomosis to the superficial femoral artery above the knee. The main advantage of this technique is its long subcutaneous course available for cannulation26.

2) The second surgical option is transposition in a looped fashion with the AV anastomosis to the groin femoral artery.

\section{Lower extremity femoral-superficial femoral vein access}

Gradman et al. have described the technique of superficial femoral vein (SFV) transposition27. The superficial femoral vein, in continuity with a variable length of supragenicular popliteal vein, is mobilized from the popliteal fossa to the junction of the femoral vein with the profunda femoris vein. The vein is transposed superficially and anastomosed to the distal femoral artery (Figure 2.4). The vein is usually suture banded primarily to avoid distal ischaemia due to steal from the high fistula flow.

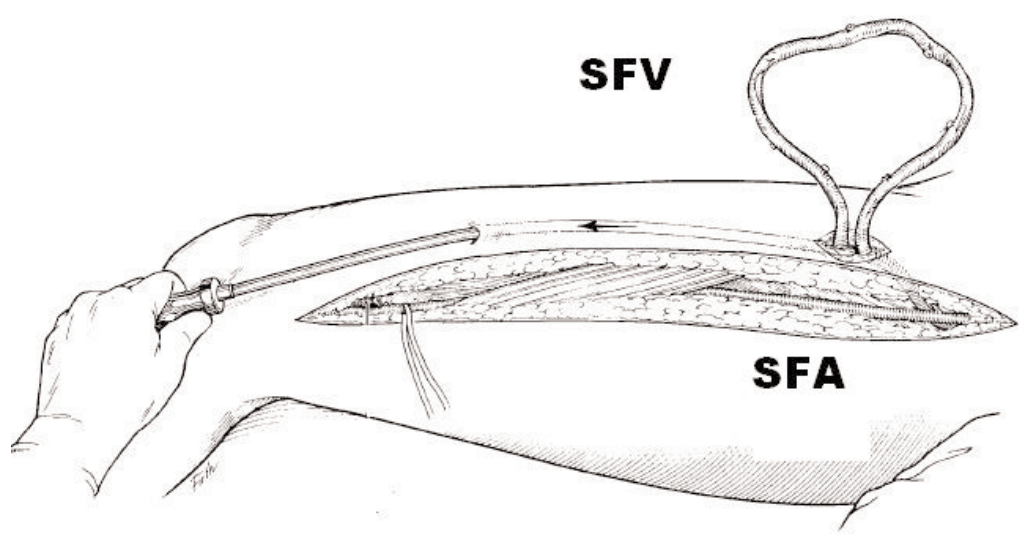

Figure 2.4: Superficial femoral vein transposition. SFA = superficial femoral artery; SFV = superficial femoral vein. 
The results of elective construction of an SFV fistula were reported in 54 patients 27 . The first patients underwent intraoperative access banding and when indicated a femoropopliteal bypass graft or construction of a composite prosthetic-femoral vein to groin femoral artery looped access was performed in patients with PAOD. More recently, patients with known PAOD were excluded. Patients without PAOD that were included underwent a variety of measures to avoid ischaemia, including tapering of the femoral vein at the takeoff from the distal femoral artery and compartment fasciotomies when pulses were very weak or absent immediately after access construction. In the total patient group, 10 accesses were banded either intraoperatively (6) or in the immediate postoperative period (4) to avoid or treat ischaemia. Nine patients (16\%) showed evidence of ischaemia in the postoperative period. Procedures to alleviate ischaemia included various combinations of distal bypass without interval ligation, conversion to a looped access, iliac artery angioplasty, fasciotomy, access banding, and access ligation. One patient eventually had an above-knee amputation. In this study no major wound complications or graft infections were reported. However, in another study there was a rather high incidence of ischaemia and infection (30 and 27\% respectively) 28 .

\section{SUMMARY}

- The percentage of autogenous vascular access in elderly, comorbid and obese patients can be increased considerably by innovative surgical procedures, including elevation and/or transposition of deeply or dorsally positioned veins.

- Upper extremity secondary/tertiary autogenous access conduits with transposed veins have patency rates comparable to primary radial-cephalic AVFs.

- The surgical technique of brachial-basilic AVF (one vs. two-stage procedure; vein transposition vs. elevation) results in similar non-maturation and 1-year patency rates.

- Lower extremity access by femoral vein transposition is an acceptable alternative in case of upper extremity outflow obstruction, but exhibits a high incidence of ischaemia and infection. 


\section{REFERENCES}

1. Pisoni RL, Young EW, Dykstra DM, et al. Vascular access use in Europe and the United States: results from the DOPPS. Kidney Int. Jan 2002;61(1):305-316.

2. Silva MB, Jr., Hobson RW, 2nd, Pappas PJ, et al. Vein transposition in the forearm for autogenous hemodialysis access. J Vasc Surg. Dec 1997;26(6):981986; discussion 987-988.

3. Gefen JY, Fox D, Giangola G, et al. The transposed forearm loop arteriovenous fistula: a valuable option for primary hemodialysis access in diabetic patients. Ann Vasc Surg. Jan 2002;16(1):89-94.

4. Cull DL, Taylor SM, Carsten CG, et al. The fistula elevation procedure: a valuable technique for maximizing arteriovenous fistula utilization. Ann Vasc Surg. Jan 2002;16[1]:84-88.

5. Konner K. Primary vascular access in diabetic patients: an audit. Nephrol Dial Transplant. Sep 2000;15(9):1317-1325.

6. Bonforte G, Zerbi S, Surian M. The middle-arm fistula: A new native arteriovenous vascular access for hemodialysis patients. Ann Vasc Surg. Jul 2004;18(4):448452.

7. Bender MH, Bruyninckx CM, Gerlag PG. The Gracz arteriovenous fistula evaluated. Results of the brachiocephalic elbow fistula in haemodialysis angio-access. Eur J Vasc Endovasc Surg. Oct 1995;10(3):294-297.

8. Zeebregts CJ, Tielliu IF, Hulsebos RG, et al. Determinants of failure of brachiocephalic elbow fistulas for haemodialysis. Eur J Vasc Endovasc Surg. Aug 2005;30(2):209-214.

9. Dunlop MG, Mackinlay JY, Jenkins AM. Vascular access: experience with the brachiocephalic fistula. Ann R Coll Surg Engl. Jul 1986;68(4):203-206.

10. Zibari GB, Rohr MS, Landreneau MD, et al. Complications from permanent hemodialysis vascular access. Surgery. Oct 1988;104(4):681-686.

11. Nazzal MM, Neglen P, Naseem J, et al. The brachiocephalic fistula: a successful secondary vascular access procedure. Vasa. 1990;19(4):326-329.

12. Murphy GJ, Saunders R, Metcalfe M, et al. Elbow fistulas using autogeneous vein: patency rates and results of revision. Postgrad Med J. Aug 2002;78(922):483486.

13. Lok CE, Oliver MJ, Su J, et al. Arteriovenous fistula outcomes in the era of the elderly dialysis population. Kidney Int. Jun 2005;67[6]:2462-2469.

14. Dagher F, Gelber R, Ramos E, et al. The use of basilic vein and brachial artery as an A-V fistula for long term hemodialysis. J Surg Res. Apr 1976;20[4]:373-376.

15. Rivers SP, Scher LA, Sheehan E, et al. Basilic vein transposition: an underused autologous alternative to prosthetic dialysis angioaccess. J Vasc Surg. Sep 1993;18[3]:391-396; discussion 396-397. 
16. Hossny A. Brachiobasilic arteriovenous fistula: different surgical techniques and their effects on fistula patency and dialysis-related complications. J Vasc Surg. Apr 2003;37[4]:821-826.

17. Coburn MC, Carney WI, Jr. Comparison of basilic vein and polytetrafluoroethylene for brachial arteriovenous fistula. J Vasc Surg. Dec 1994;20(6):896-902; discussion 903-894.

18. El Mallah S. Staged basilic vein transposition for dialysis angioaccess. Int Angiol. Jun 1998;17(2):65-68.

19. Humphries AL, Jr., Colborn GL, Wynn JJ. Elevated basilic vein arteriovenous fistula. Am J Surg. Jun 1999;177[6]:489-491.

20. Murphy GJ, Nicholson ML. Autogeneous elbow fistulas: the effect of diabetes mellitus on maturation, patency, and complication rates. Eur J Vasc Endovasc Surg. May 2002;23(5):452-457.

21. Segal JH, Kayler LK, Henke P, et al. Vascular access outcomes using the transposed basilic vein arteriovenous fistula. Am J Kidney Dis. Jul 2003;42(1):151157.

22. Taghizadeh A, Dasgupta P, Khan MS, et al. Long-term outcomes of brachiobasilic transposition fistula for haemodialysis. Eur $J$ Vasc Endovasc Surg. Dec 2003;26[6]:670-672.

23. Rao RK, Azin GD, Hood DB, et al. Basilic vein transposition fistula: a good option for maintaining hemodialysis access site options? J Vasc Surg. May 2004;39(5): $1043-1047$.

24. Bazan HA, Schanzer H. Transposition of the brachial vein: a new source for autologous arteriovenous fistulas. J Vasc Surg. Jul 2004;40(1):184-186.

25. Huber TS, Carter JW, Carter RL, et al. Patency of autogenous and polytetrafluoroethylene upper extremity arteriovenous hemodialysis accesses: a systematic review. J Vasc Surg. Nov 2003;38(5):1005-1011.

26. Pierre-Paul D, Williams S, Lee T, et al. Saphenous vein loop to femoral artery arteriovenous fistula: a practical alternative. Ann Vasc Surg. Mar 2004;18(2):223-227.

27. Gradman WS, Laub J, Cohen W. Femoral vein transposition for arteriovenous hemodialysis access: improved patient selection and intraoperative measures reduce postoperative ischemia. J Vasc Surg. Feb 2005;41(2):279-284.

28. Hazinedaroglu SM, Tuzuner A, Ayli D, et al. Femoral vein transposition versus femoral loop grafts for hemodialysis: a prospective evaluation. Transplant Proc. Jan-Feb 2004;36[1]:65-67. 
Excellent performance of one-stage brachial-basilic arteriovenous fistula

X.H.A. Keuter, F.M. van der Sande, A.G. Kessels, M.W. de Haan, A.P.G. Hoeks, J.H.M. Tordoir

Nephrol Dial Transplant 2005; 20: 2168-2171. 


\section{ABSTRACT}

\section{Introduction}

According to the National Kidney Foundation - Dialysis Outcomes Quality Initiative (NKF-DOQI) and the European Guidelines the first and second choice for vascular access for haemodialysis are the radial-cephalic and brachialcephalic arteriovenous fistula (AVF). Autogenous fistulas have a longer functional lifetime, less thrombotic complications and a lower infection risk compared to prosthetic implants. If it is impossible to create a brachial-cephalic AVF or after failure, either a brachial-basilic (BB) or a prosthetic forearm loop AVF may be considered. To determine the outcome of brachial-basilic AVFs we retrospectively surveyed the results of this type of vascular access.

\section{Methods}

All BB-AVF patient records over a six-year period were subtracted from an academic hospital registry. Primary failure and primary, assisted primary and secondary patency rates were calculated with the Kaplan Meier method. Sex, Diabetes Mellitus (DM), preoperative duplex diameters, complications and interventions were recorded and correlated with the patency rates.

\section{Results}

A total of 31 brachial-basilic arteriovenous fistulas were created in a onestage surgical procedure. Of the patients 36\% were male and 19\% had DM. Only 1 patient had a primary failure, leaving thirty (97\%) of the BB-AVFs functional for dialysis treatment. Four patients died within one year after the operation, one of them from a catheter sepsis. Primary, assisted primary and secondary patency rates after one year were 58\%, 83\%, and 90\%, respectively. Patients' characteristics and preoperative duplex parameters did not influence patency rates.

\section{Conclusion}

From these results we conclude that the brachial-basilic AVF is an excellent third choice option for vascular access. 


\section{INTRODUCTION}

A well functioning vascular access is a major necessity for adequate haemodialysis treatment. However, in the present dialysis population with various comorbidities, it becomes extremely difficult to create an autogenous radial or brachial-cephalic arteriovenous fistula, as recommended by European and American guidelines. Brachial-basilic arteriovenous fistula (BB-AVF) or prosthetic graft implants are considered to be acceptable alternative methods, although the creation of an autogenous fistula still remains in favour1,2.

The basilic vein can be transposed or elevated subcutaneously making it accessible for cannulation and haemodialysis. Both one-staged and twostaged basilic vein transposition procedures have been reported with generally good results 3,4 . However, the risk of non-maturation of BB-AVFs may be considerable as compared to prosthetic graft AVFs 5 .

To elucidate these aspects, we retrospectively studied the performance of BBAVFs.

\section{PATIENTS AND METHODS}

All records of patients with a BB-AVF over a six year period were recalled from a computer data-base. Age, sex, previous access procedures, preoperative arterial and venous dimensions, complications and interventions were recorded. Preoperative Duplex ultrasound investigation (SSD-2000, Aloka Co Ltd, Tokyo, Japan) was performed according to a standard protocol by experienced vascular technicians, measuring the diameters of brachial, radial and ulnar arteries and cephalic and basilic vein in the fore- and upper arm. Patients were operated on using regional or general anaesthesia. A one-stage surgical technique was executed in all patients with vein transposition and arteriovenous anastomosis in one session. In six patients minimal invasive basilic vein dissection was carried out using endoscopy. Intraoperative angiography was performed to exclude technical problems. Cannulation of the fistula was allowed after 4-6 weeks, when wound healing was completed and haematoma had disappeared.

\section{Statistical analysis}

Data were collected in a spreadsheet and analysed. The patency rates were calculated with the Kaplan-Meier life-table method. Clinical criteria were used for non-maturation, e.g. inability to cannulate the AVF or to obtain sufficient 
dialysis flow. We used patency rate definitions as described by Sidawy et al. ${ }^{6}$. The log-rank test was used to search for clinical and duplex parameters that may affect the patency rates. Statistical analyses were performed in SPSS 11.0. A p-value $<0.05$ is considered to be statistically significant.

\section{RESULTS}

Autogenous brachial-basilic arteriovenous fistulas were created in 31 patients. Characteristics of the patient group are outlined in table 3.1. Of the study population $80 \%$ had had a previous vascular access. During the study period, 8 patients died and 2 had kidney transplantation. In these patients the BB-AVF was functioning well. Non-maturation occurred in one BB-AVF [3\%]. This AVF was never used and was abandoned. There were 3 postoperative complications; 2 patients developed haematomas requiring surgical evacuation (one due to a high International Normalized Ratio (INR) caused by oral anticoagulation). One patient died 19 days postoperatively from a catheter sepsis due to a non-tunnelled central vein catheter.

A total of 22 interventions were performed within one year after the operation, including 5 surgical thrombectomies (one after operation, 2 after failed percutaneous transluminal angioplasty (PTA) and 2 late thrombectomies). Only 2 thrombectomies were successful, with salvage of the access site. Eight PTAs were performed for stenosis formation, with in addition 2 stent placements for stenosis recoil and central venous obstruction. Vein rupture occurred during 2 PTAs (68 and 144 days after the creation of the AVF). One was resolved with a covered stent implantation and the other was surgically revised. One surgical intervention for pseudoaneurysm was performed 58

\begin{tabular}{lc}
\hline $\mathbf{N}$ & 31 \\
\hline Male:female ratio & $11: 20$ \\
Mean Age (range) in years & $56.7(23.1-78.0)$ \\
Diabetes Mellitus, (\%) & $6(19)$ \\
Ipsilateral central veincatheter, (\%) & $11(35)$ \\
Location right vs left & 13 vs 18 \\
Mean number (range) of previous AVF & $1.6(0-4)$ \\
Previous ipsilatera I AVF, (\%) & $17(55)$ \\
\hline
\end{tabular}

Table 3.1: Clinical characteristics of patients. 
days postoperatively. Within one year after the operation, 3 (10.3\%) patients developed high-output cardiac failure due to high volume flows in the fistula. Distal radial artery extension ( 2 patients) or interposition of a $4 \mathrm{~mm}$ diameter polytetrafluoroethylene (PTFE) graft (1 patient) was performed to reduce access flow.

Two [6.5\%) patients developed symptoms of ischaemia. Symptoms developed after 69 days and 2.5 years and were due to low flow in diseased radial and ulnar arteries. Conservative treatment and distal revascularisation with interval ligation (DRIL) procedure with in addition a finger amputation was needed, respectively. Symptomatic venous hypertension due to central vein obstruction occurred in 3 patients, necessitating stent implantation in 2 and conservative treatment in 1 patient.

Primary, assisted primary and secondary patency rates after one year were 58\%, 83\% and 90\%, respectively. Two-year patency rates for primary, assisted primary and secondary patencies were $47 \%, 83 \%$ and $90 \%$, respectively (Figure 3.1). The log-rank test for gender, diabetes, previous central vein catheter, previous access, and video-assisted endoscopic method showed no correlation with the patency rate of the BB-AVF. Pre-operative duplex parameters did not influence the patency rates.

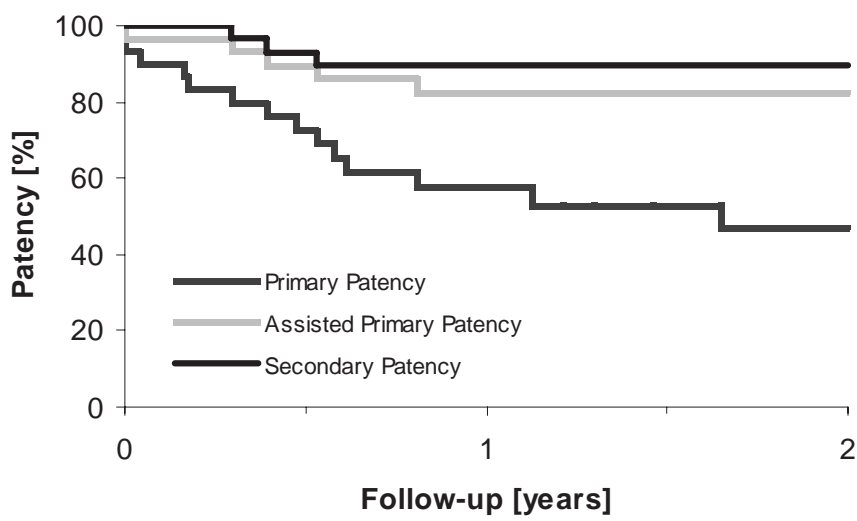

\begin{tabular}{lllll} 
Number at risk & $1 / 2$ year & 1 year & $1 \frac{1 / 2}{2}$ year & 2 years \\
\hline Primary Patency (n) & 20 & 14 & 9 & 7 \\
Assisted Primary Patency (n) & 25 & 20 & 15 & 14 \\
Secondary Patency (n) & 26 & 22 & 17 & 15 \\
\hline
\end{tabular}

Figure 3.1: Primary, assisted primary and secondary patency of the BB-AVF (n=number at risk). 


\section{DISCUSSION}

These results show low non-maturation and high patency rates of the BB-AVF after 1 and 2 years in patients which had previous vascular access in most cases. Today, creation of a functional radial-cephalic or brachial-cephalic AVF becomes difficult due to damaged and/or diseased vessels in patients with various comorbidities. The upper arm basilic vein is usually in a nonharmed condition because of its deep location, protecting it from iatrogenic damage. Therefore the BB-AVF seems to be an attractive alternative conduit to initiate an autogenous arteriovenous fistula.

A BB-AVF can either be created by transposition or elevation of the basilic vein. Due to its more medial location, the elevated basilic vein may be difficult to cannulate, making it prone to haematoma formation and thrombosis? Transposition and elevation can be executed as an one or two-stage procedure ${ }^{4,7}$. In the one-stage technique, the risk of twisting in the subcutaneous tunnel may be considerably, while a small diameter of the vessels may increase the risk of early failure. In the two-stage procedure, the basilic vein has time to enlarge, making it less vulnerable to iatrogenic damage when transposed or elevated. The longer period needed before the newly created fistula can be cannulated in case of the two-stage procedure might be a disadvantage.

Although $80 \%$ of the patients in this study had a previous vascular access, the non-maturation was low (3\%) compared to those reported in the literature (15$38 \%]^{8,9}$. An explanation could be that in case of a previous ipsilateral forearm vascular access the basilic vein diameter has already been increased. On the other hand, high maturation rates were also reported even in diabetics, with only $15 \%$ previous accesses 10 .

Ascher et al. have found a negative correlation between previous vascular access and long-term patency of the BB-AVF11. We could not find this correlation and calculated excellent one- and two-year secondary patencies compared to those reported in the literature $147-92 \%$ and $41-86 \%$, respectively $8,9,12-15$. This high secondary patency underlines the functionality of the BBAVF and may be enhanced by access surveillance. In our study pre-emptive intervention was performed according to certain monitoring parameters [access flow decrease of 25\%], or if patients had significantly longer bleeding time or increased venous pressures. PTA is the first option for stenosis treatment, but is not without risk, since the vessel may rupture. Higher risk of rup- 
ture of upper arm veins (14.9\%), mainly at the entrance of the cephalic vein into the subclavian vein and at the end of the transposition in brachial-basilic fistulas has been reported 16 . Restenosis may occur; in our series, one patient had 16 PTAs in 2.5 years. Surgical revision with patchplasty should be considered if stenosis appears within a few weeks after the creation and when restenosis occurs frequently after PTA. Stenoses of the basilic vein just before the confluence with the deep system are frequently seen. These lesions may be caused by scar formation at the entrance to the subcutaneous tunnel, motion of the arm at that point or iatrogenic damage from vein distention at surgery ${ }^{14}$. Scar formation at the entrance of the subcutaneous tunnel can possibly be prevented if the entrance is created more gradually into the subcutaneous tissue.

The incidence of ischaemia has been reported to be higher in proximal AVFs. Only 2 patients in this study had symptomatic ischaemia, of which one needed to be surgically treated. Limiting the length of the arteriovenous anastomosis may possibly prevent the occurrence of ischaemia 17.

The increased cardiac output (CO) due to the high flow can cause left ventricular hypertrophy and ultimately cardiac decompensation. The CO measured during haemodialysis is a good parameter to review the workload of the heart. It has been shown that left ventricular dilatation can be reversed after ligation of the fistula18. If BB-AVFs do fail, Matsuura et al. showed that it is still possible to implant a prosthetic graft in $89 \%$ of the cases ${ }^{13}$. Therefore we recommend reserving the prosthetic implant as a final option.

In conclusion the BB-AVF is a good option for vascular access, resulting in high primary and long-term functional rates. One of the major disadvantages of the BB-AVF is the high access flow which can cause cardiac failure and ischaemia of the hand.

\section{REFERENCES}

1. III. NKF-K/DOQI Clinical Practice Guidelines for Vascular Access: update 2000. Am J Kidney Dis. Jan 2001;37(1 Suppl 1):S137-181.

2. Tordoir $\mathrm{JH}$, Mickley V. European guidelines for vascular access: clinical algorithms on vascular access for haemodialysis. Edtna Erca J. Jul-Sep 2003;29(3):131136.

3. Dagher FJ, Gelber RL, Ramos EJ, et al. Basilic vein to brachial artery fistula: a new access for chronic hemodialysis. South Med J. Nov 1976;69(11):1438-1440.

4. Zielinski CM, Mittal SK, Anderson P, et al. Delayed superficialization of brachiobasilic fistula: technique and initial experience. Arch Surg. Aug 2001;136(8):929-932. 
5. Patel ST, Hughes J, Mills JL, Sr. Failure of arteriovenous fistula maturation: an unintended consequence of exceeding dialysis outcome quality Initiative guidelines for hemodialysis access. J Vasc Surg. Sep 2003;38(3):439-445; discussion 445.

6. Sidawy AN, Gray R, Besarab A, et al. Recommended standards for reports dealing with arteriovenous hemodialysis accesses. J Vasc Surg. Mar 2002;35(3):603-610.

7. Hossny A. Brachiobasilic arteriovenous fistula: different surgical techniques and their effects on fistula patency and dialysis-related complications. J Vasc Surg. Apr 2003;37[4]:821-826.

8. Murphy GJ, White SA, Knight AJ, et al. Long-term results of arteriovenous fistulas using transposed autologous basilic vein. Br J Surg. Jun 2000;87[6]:819823.

9. Rao RK, Azin GD, Hood DB, et al. Basilic vein transposition fistula: a good option for maintaining hemodialysis access site options? J Vasc Surg. May 2004;39(5): 1043-1047.

10. Hakaim AG, Nalbandian M, Scott T. Superior maturation and patency of primary brachiocephalic and transposed basilic vein arteriovenous fistulae in patients with diabetes. J Vasc Surg. Jan 1998;27(1):154-157.

11. Ascher $E$, Hingoran A, Gunduz $Y$, et al. The value and limitations of the arm cephalic and basilic vein for arteriovenous access. Ann Vasc Surg. Jan 2001;15(1):89-97.

12. Coburn M.C. CWI. Comparison of basilic vein and polytetrafluoroethylene for brachial arteriovenous fistula. Journal of Vascular Surgery. December 1994 1994;20(6):896-904.

13. Matsuura JH, Rosenthal D, Clark M, et al. Transposed basilic vein versus polytetrafluorethylene for brachial-axillary arteriovenous fistulas. Am J Surg. Aug 1998;176[2]:219-221.

14. Rivers SP, Scher LA, Sheehan E, et al. Basilic vein transposition: an underused autologous alternative to prosthetic dialysis angioaccess. J Vasc Surg. Sep 1993;18(3):391-396; discussion 396-397.

15. Taghizadeh A, Dasgupta P, Khan MS, et al. Long-term outcomes of brachiobasilic transposition fistula for haemodialysis. Eur $J$ Vasc Endovasc Surg. Dec 2003;26(6):670-672.

16. Turmel-Rodrigues L, Pengloan J, Baudin S, et al. Treatment of stenosis and thrombosis in haemodialysis fistulas and grafts by interventional radiology. Nephrol Dial Transplant. Dec 2000;15(12):2029-2036.

17. Morsy AH, Kulbaski M, Chen C, et al. Incidence and characteristics of patients with hand ischemia after a hemodialysis access procedure. J Surg Res. Jan 1998;74(1):8-10.

18. Kooman JP, Leunissen KM. Cardiovascular diseases in dialysis patients. Ned Tijdschr Geneeskd. May 22 1999;143(21):1084-1087. 
A randomized multicenter study of the outcome of brachial-basilic arteriovenous fistula and prosthetic brachial-antecubital forearm loop as vascular access for haemodialysis

X.H.A. Keuter, A.A.E.A. de Smet, A.G.H. Kessels, F.M. van der Sande, R.J.Th.J. Welten, J.H.M. Tordoir

Adapted from: J Vasc Surg 2008; 47: 395-401. 


\section{ABSTRACT}

\section{Introduction}

Vascular access is a necessity for patients with end-stage renal disease who need chronic intermittent haemodialysis. According to Kidney Disease Outcomes Quality Initiative (KDOQI) guidelines, radial-cephalic $(R C)$ and brachial-cephalic (BC) arteriovenous fistulas (AVF) are the first and second choice for vascular access, respectively. If these options are not possible, an autogenous brachial-basilic fistula in the upper arm (BB-AVF) or a prosthetic brachial-antecubital forearm loop (PTFE loop) may be considered. Until now it is not clear which access type is preferable. We have performed a randomized study comparing BB-AVF and prosthetic implantation in patients without the possibility for RC-AVF or BC-AVF.

\section{Methods}

Patients with failed primary/secondary access or inadequate arterial and/or venous vessels were randomized for either BB-AVF or PTFE loop creation. The numbers of complications and interventions were recorded. Kaplan-Meier method was used to calculate primary, assisted-primary and secondary patency rates. The patency rates were compared with the log-rank test. Complication and intervention rates were compared with Mann-Whitney test.

\section{Results}

A total of 105 patients were randomized for a BB-AVF or PTFE loop (52 vs 53, respectively]. Primary and assisted-primary 1-year patency rates were significantly higher in the BB-AVF group: $46 \% \pm 7.4 \%$ versus $22 \% \pm 6.1 \%$ (P $=0.005)$ and $87 \% \pm 5.0 \%$ versus $71 \% \pm 6.7 \%(P=0.045)$ for the BB-AVF and PTFE group, respectively. Secondary patencies were comparable for both groups; $89 \% \pm 4.6 \%$ versus $85 \% \pm 5.2 \%$ for the BB-AVF and PTFE group, respectively. The incidence rate of complications was 1.6 per patient-year in the BB-AVF group versus 2.7 per patient-year in the PTFE group. Patients in the BB-AVF group needed a total of 1.7 interventions per patient-year versus 2.7 per patient-year for the PTFE group.

\section{Conclusion}

These data show a significantly better primary and assisted-primary patency in the BB-AVF group compared to the PTFE group. Furthermore, in the BBAVF group, fewer interventions were needed. Therefore we conclude that BBAVF is the preferred choice for vascular access if RC-AVF or BC-AVF creation is impossible, or when these types of access have already failed. 


\section{INTRODUCTION}

As the dialysis population is getting older and has more comorbidities, the creation of an autogenous forearm fistula (radial-cephalic arteriovenous fistula $=$ RC-AVF or brachial-cephalic arteriovenous fistula = BC-AVF] becomes more difficult. Forearm vessels are not suitable for vascular access creation if the diameter is too small, or the vessels are thrombosed or diseased ${ }^{1-5}$.

Whenever forearm vessels are not suitable for RC-AVF/BC-AVF creation or when these AVFs have failed, the options for vascular access are either brachial-basilic arteriovenous fistula (BB-AVF) or the use of a prosthetic implant as recommended by the $\mathrm{KDOQI}$ and European guidelines6,7. Autogenous arteriovenous fistulas are known for their better long-term patencies and lower thrombotic complication rates compared to prosthetic implants $8-10$. The advantages of prosthetic implants are the low primary failure rate, no need for maturation and ease of cannulation ${ }^{9}$. On the other hand, the infection and thrombosis rates are reported higher in the literature compared to the BB-AVF9,11,12. Because there is no consensus on which of these types of vascular accesses is to be preferred, we performed a randomized clinical trial between the BB-AVF and prosthetic brachial-antecubital forearm loop (PTFE loop) graft to elucidate this problem. The purpose of our study was to compare primary and secondary patency rates, complications and interventions in the BB-AVF and prosthetic forearm loop vascular access.

\section{METHODS}

In this multicenter study, all patients in which previous RC-AVF/BC-AVF had failed or in which creation of a forearm fistula was impossible were included in one university and two regional hospitals between October 1, 2003 and May 1, 2006. Patients were randomized between BB-AVF creation and creation of a brachial-antecubital forearm loop graft. Informed consent was obtained from all patients. The study was approved by the Ethical Committee of Maastricht University as well as the regional hospitals.

\section{Preoperative assessment}

All patients in need of vascular access in the three participating hospitals underwent clinical examination and duplex scanning of the upper extremity as a standard investigation before operation. Clinical examination consisted of inspection and palpation of the vessels of the arm, and measurement of blood 
pressure on both sides. Duplex scanning of the arteries and superficial veins was performed according to a standard protocol by experienced vascular technicians. The angle of the emitted Doppler ultrasound wave from the probe was adjusted to 60 degrees to achieve the Doppler signal of the strongest intensity. The antero-posterior internal diameter of the vessel was measured using Bmode technique with a proximal tourniquet to engorge the veins. Vessels were diagnosed as obstructed when no Doppler signal could be obtained. A radial artery and/or cephalic vein diameter of less than $2 \mathrm{~mm}$ at the wrist and less than $3 \mathrm{~mm}$ at the elbow were defined as unsuitable for the creation of a RCAVF or BC-AVF7. Although for the creation of a BB-AVF a diameter of the basilic vein at the elbow of $3 \mathrm{~mm}$ was preferred, the quality of the vein (non-stenotic and non-diseased] was considered more important for the decision whether the basilic vein was suitable for BB-AVF creation. Patients with small diameter or thrombosed vessels, or failed RC-AVF/BC-AVF were asked to participate in the study. Patients with an active local or general infection and/or peripheral ischaemia of the upper extremity were excluded. After informed consent the patients were randomized by a computer system for either a brachial-basilic arteriovenous fistula or a brachial-antecubital forearm loop graft.

\section{Surgical procedure}

All procedures were performed under local/regional or general anaesthesia. All patients received prophylactic antibiotic therapy according to the local hospital standard.

BB-AVFs were constructed by making a continuous or interrupted longitudinal incision at the medial side of the upper arm to dissect the basilic vein. A transverse incision two centimeters proximal to the elbow was made to explore the brachial artery. The basilic vein was mobilized proximally to the confluence with the deep venous system. Side branches were ligated and subsequently the vein was transected as distal as possible. While mobilizing the basilic vein, the medial brachial cutaneous nerve was carefully spared to avoid nervous disturbances. At the proximal end of the basilic vein a bulldog clamp was placed and subsequently the vein was gently dilated with a saline injection. After local heparinization, the vein was marked to prevent twisting. An anterolateral subdermal tunnel was created with the use of a tunneling device at the upper arm, with a diameter of at least $10 \mathrm{~mm}$. Subsequently the basilic vein was pulled through the tunnel and an end-to-side vein-to-artery anastomosis was performed with a running 7-O polypropylene (Prolene, Johnson \& Johnson Medical BV, Amersfoort, Nederland) suture with a limited arteriotomy of seven millimeters. 
For creation of a PTFE loop, thin-walled stretch PTFE grafts (Gore-Tex, WL Gore \& Associates, Flagstaff, Ariz) with a wall thickness of $0.5 \mathrm{~mm}$ and an internal diameter of $6 \mathrm{~mm}$, were positioned in a subcutaneous loop with the use of a tunneling device in the forearm between the brachial artery and a suitable elbow vein. Arterial and venous anastomoses were created with running 7-0 polypropylene sutures.

Access patency was confirmed peroperatively either by palpation, Doppler examination or angiography. All patients received one hundred milligram of aspirin per day unless already on oral anticoagulation. Cannulation of the fistula was allowed after wound healing and maturation (BB-AVF), approximately four to six weeks for the BB-AVF and two weeks after surgery for the PTFE fistula.

\section{Follow-up}

All patients were followed for 12 months after operation. Complications and interventions were recorded for this period. Monitoring (once a month) and indications for interventions of the vascular access were standardized, interventions were done according to the local hospitals standards. Non-maturation (for BB-AVF) was defined as inability to cannulate the AVF. Clinical criteria were used to detect thrombosis. Percutaneous transluminal angioplasty (PTA) was done whenever a flow decrease of more than $25 \%$ or $<600 \mathrm{ml} / \mathrm{min}$ was measured during dialysis (Transonic, Transonic Systems Inc., Ithaca, NY, USA), or if patients had significantly longer bleeding time or an increased venous pressure. A significantly longer bleeding time is defined as a bleeding time of $150 \%$ of the patients' usual bleeding time (which usually varies from 5 to 15 minutes].

\section{End points}

End points were primary, assisted-primary and secondary patency for both types of fistula.

\section{Statistical analysis}

A power calculation was performed before the start of the study to determine the number of patients needed to demonstrate a difference in patency between the two groups after one year follow up of $25 \%$ with a power of $80 \%$ and an $\alpha$ of 0.05. In each group 51 patients were needed. For the definition of incidence rate we used number of complications or interventions per 
patient-year (py), the cumulative follow-up time of all patients and analyzed with the Mann-Whitney test. The different patency rates were defined as described by Sidawy et al. ${ }^{13}$. Primary patency was defined as the interval from the time of access placement until any intervention designed to maintain or reestablish patency, access thrombosis, or the time of measurement of patency. Assisted-primary patency is defined as the interval from the time of access placement until access thrombosis or the time of measurement of patency, including intervening manipulations designed to maintain the functionality of a patent access. Secondary patency was defined as the interval from the time of access placement until access abandonment, thrombosis, or the time of patency measurement including intervening manipulations designed to reestablish functionality in thrombosed access. Patency rates were calculated with the Kaplan-Meier life-table analysis. The log-rank test was used to compare the patencies for the two groups. Differences were considered statistically significant when the P-value was less than 0.05.

Patients with a patent fistula who died, had successful kidney transplantation, or were withdrawn from haemodialysis alive were censored.

\section{RESULTS}

One-hundred-and-seventeen patients were included in this study, 12 of which were withdrawn before the surgical procedure because of possibility to create a RC-AVF after all $(n=7)$, death of the patient $(n=2)$, improvement of kidney function $(n=2)$ and patient withdrawal $(n=1)$. Therefore 105 patients were randomized, 53 of which for a PTFE forearm loop graft. In all patients preoperative evaluation showed that it was possible to create either a BB-AVF or a

\begin{tabular}{lcc}
\hline & BB-AVF (n=52) & Prosthetic AVF (n=53) \\
\hline Male & $26(50 \%)$ & $30(57 \%)$ \\
Mean age $(\mathrm{y})$ & 60 & 66 \\
Diabetes & $20(38 \%)$ & $25(47 \%)$ \\
Hypertension & $21(40 \%)$ & $27(51 \%)$ \\
Ischemic cardiac disease & $21(40 \%)$ & $12(23 \%)$ \\
Peripheral arterial obstructive disease & $12(23 \%)$ & $14(26 \%)$ \\
Cerebrovascular disease & $3(6 \%)$ & $9(16 \%)$ \\
Previously on haemodialysis & $33(63 \%)$ & $29(55 \%)$ \\
Previous vascular access & $27(52 \%)$ & $8(15 \%)$ \\
\hline
\end{tabular}

Table 4.1: Patient characteristics in patients with BB-AVF and prosthetic AVF, BB-AVF, brachialbasilic arteriovenous fistula; AVF, arteriovenous fistula. 
PTFE forearm loop graft. Equal distributions were seen regarding the preoperative patient characteristics and the local risk factors (Table 4.1). In spite of preoperative evaluation, peroperatively basilic vein caliber appeared unsuitable for creation of a basilic vein transposition in two patients and therefore another type of vascular access was created. In the PTFE group it was decided not to create a prosthetic forearm loop in two patients because of low blood pressures.

Therefore, 101 patients were eligible for analysis of survival curves (PTFE forearm loop graft $=51$ ]. Mean follow up time $( \pm S D$ ) was $340( \pm 11)$ versus 325 ( \pm 15) days for the BB-AVF and PTFE group, respectively. Total follow up time was 39.3 py for the PTFE group and 41.0 py for the BB-AVF group. Mean time to cannulation was $51( \pm 9.9)$ days versus $60( \pm 8.5)$ days in the PTFE and BB-AVF group, respectively.

\section{Patency rates}

A significant lower 1-year primary and assisted-primary patency rate $[ \pm \mathrm{SD}$ ] was seen in the PTFE group compared to the BB-AVF group, $22 \% \pm 6.1 \%$ versus $46 \% \pm 7.4 \%(P=0.005$; Figure 4.1$)$ and $71 \% \pm 6.7 \%$ versus $87 \% \pm$

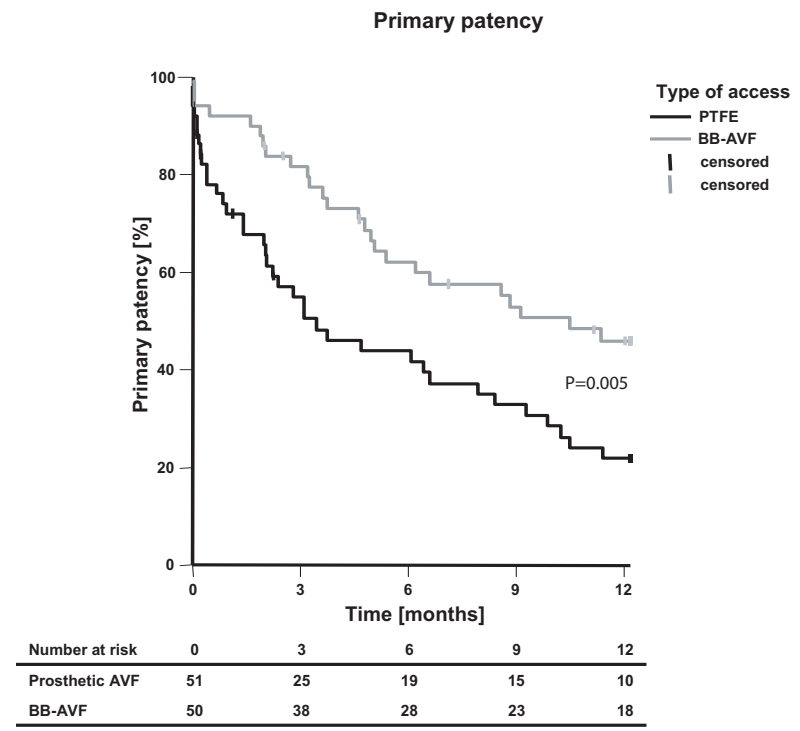

Figure 4.1: Primary patency rates of the brachial-basilic arteriovenous fistula [BB-AVF] and prosthetic arteriovenous fistula. 


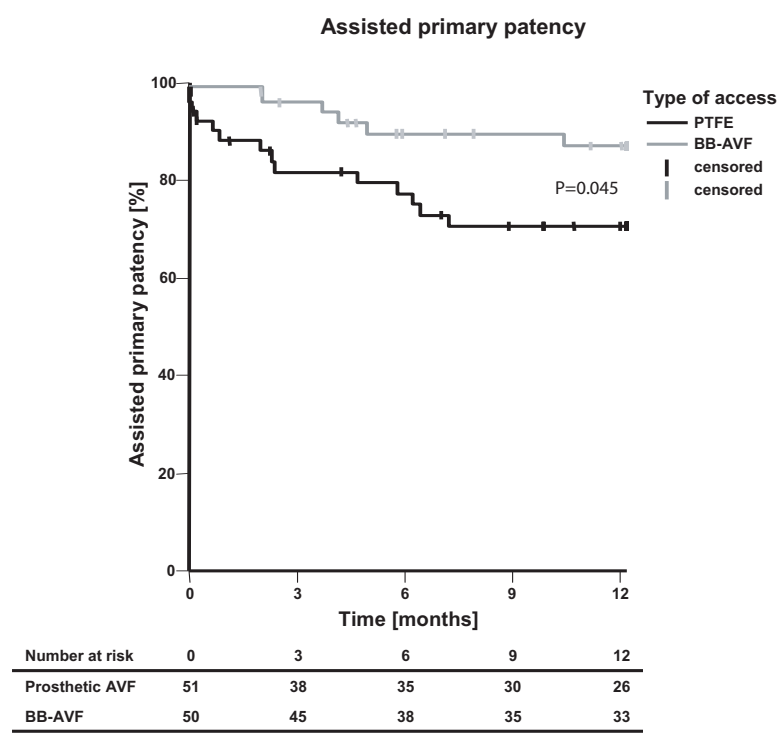

Figure 4.2: Assisted-primary patency rates of the brachial-basilic arteriovenous fistula (BB-AVF] and prosthetic arteriovenous fistula.

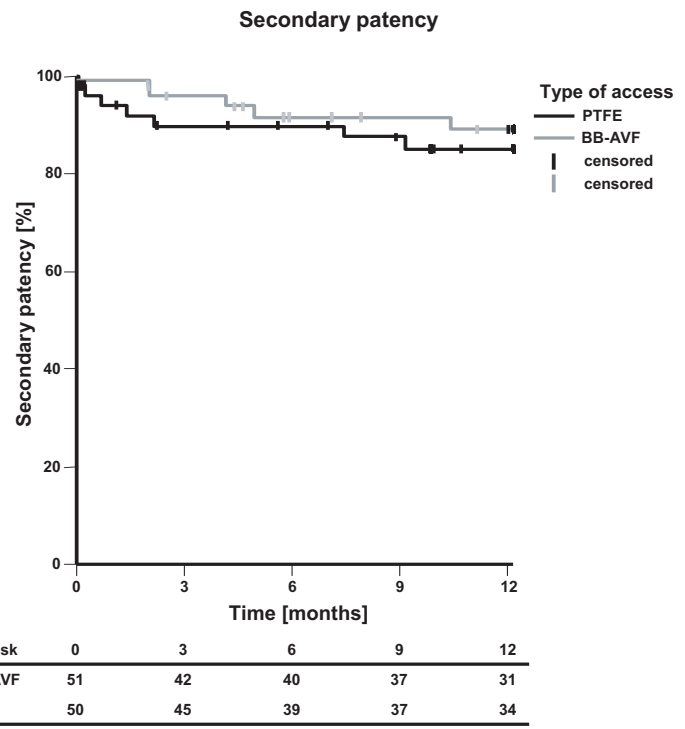

Figure 4.3: Secondary patency rates of the brachial-basilic arteriovenous fistula [BB-AVF] and prosthetic arteriovenous fistula. 
$5.0 \%$ ( $P=0.045$; Figure 4.2), respectively. The secondary patency rate after one year was comparable for the two groups, $85 \% \pm 5.2 \%$ versus $89 \% \pm$ 4.6\% ( $P=0.532$; Figure 4.3) for the PTFE and BB-AVF group, respectively.

Twenty patients in the PTFE (12) and BB-AVF (8) group died of complications of their kidney failure with a patent fistula during the follow up period, three of which died within one week after operation (2 PTFE; 1 BB-AVF). Four patients underwent successful kidney transplantation during the follow-up period, three of which in the BB-AVF group.

\section{Complications}

Twenty-two early complications $[<30$ days of operation) occurred in 18 patients. They consisted of haematoma (PTFE 1; BB-AVF 2), thrombosis (PTFE 8; BB-AVF 2), ischaemia (PTFE 2) and infection (PTFE 6; BB-AVF 1). In two patients (PTFE 1; BB-AVF 1), early thrombosis led to definitive failure of the access.

\begin{tabular}{lccccc}
\hline & $\begin{array}{c}\text { BB-AVF } \\
(\mathbf{n}=\mathbf{5 0})\end{array}$ & IR & $\begin{array}{c}\text { Prosthetic AVF } \\
(\mathbf{n}=\mathbf{5 1})\end{array}$ & IR & P \\
\hline Haematoma & 3 & 0.073 & 1 & 0.026 & 0.200 \\
Infection & 1 & 0.024 & 6 & 0.154 & $0.031^{*}$ \\
Thrombosis & 6 & 0.146 & 33 & 0.846 & $<0.001^{*}$ \\
Aneurysm & 2 & 0.049 & 0 & 0 & 0.131 \\
Ischemia & 4 & 0.098 & 3 & 0.077 & 0.387 \\
Stenosis & 16 & 0.390 & 16 & 0.410 & 0.444 \\
Nonmaturation & 2 & 0.049 & - & - & - \\
Flow decrease & 29 & 0.707 & 41 & 1.051 & 0.051 \\
Venous Hypertension & 2 & 0.049 & 4 & 0.103 & 0.209 \\
Total no. of complications & $\mathbf{6 5}$ & $\mathbf{1 . 5 8 5}$ & $\mathbf{1 0 4}$ & $\mathbf{2 . 6 6 7}$ & $<\mathbf{0 . 0 0 1}$ \\
\hline
\end{tabular}

Table 4.2: Number of complications per patient-year in BB-AVF vs prosthetic AVF group. BB-AVF, brachial-basilic arteriovenous fistula; IR, incidence rate. * Indicates statistical significance.

Non-maturation occurred in two patients. These fistulas could be saved by multiple PTAs and a surgical revision of the anastomosis. Significantly more infections $(P=0.031)$ and thrombotic events $(P<0.001)$ were seen in the PTFE group (Table 4.2). The incidence rate of total complications was significantly higher in the PTFE group with 2.7 complications/py ( $n=104)$ as compared to the BB-AVF group with 1.6 complications/py $(n=65)(P<0.001)$. High output cardiac failure was not seen in these patient groups. 


\begin{tabular}{lccccc}
\hline & $\begin{array}{c}\text { BB-AVF } \\
(\mathbf{n}=\mathbf{5 0})\end{array}$ & IR & $\begin{array}{c}\text { Prosthetic } \\
\text { AVF }(\mathbf{n}=\mathbf{5 1})\end{array}$ & IR & P \\
\hline PTA & 50 & 1.220 & 61 & 1.564 & 0.096 \\
Surgical thrombectomy & 3 & 0.073 & 23 & 0.590 & $<0.001^{*}$ \\
Surgical revision & 9 & 0.220 & 10 & 0.256 & 0.371 \\
Surgical intervention for ischemia & 4 & 0.098 & 2 & 0.051 & 0.245 \\
Ligation & 2 & 0.049 & 0 & 0 & 0.131 \\
Thrombosuction & 0 & 0 & 2 & 0.051 & 0.119 \\
Other interventions & 2 & 0.049 & 6 & 0.154 & 0.079 \\
Total no. of interventions & $\mathbf{7 0}$ & $\mathbf{1 . 7 0 7}$ & $\mathbf{1 0 4}$ & $\mathbf{2 . 6 6 7}$ & $\mathbf{0 . 0 1 8 ^ { * }}$ \\
\hline
\end{tabular}

Table 4.3: Number of interventions per patient-year in BB-AVF vs prosthetic AVF group. BB-AVF, brachial-basilic arteriovenous fistula; AVF, arteriovenous fistula; IR, incidence rate; PTA, percutaneous transluminal angioplasty. * Indicates statistical significance.

\section{Interventions}

The incidence rates for interventions was 2.7 interventions/py $(n=104)$ for the PTFE group versus 1.7 interventions/py $(n=70)$ for the BB-AVF group $(P=$ 0.018). In table 4.3 the different types of interventions are outlined. Significantly more surgical thrombectomies were needed in the PTFE group $(P<0.001)$. Two PTAs (subclavian artery) and two banding procedures with flow reduction were needed for ischaemic complications in the PTFE group. In the BB-AVF group three PTAs (subclavian and brachial artery), one stent placement (subclavian artery), two proximalizations of the arteriovenous anastomosis ${ }^{14}$ and two banding procedures were performed. Eventually one fistula in the BB-AVF group was ligated due to persistent ischaemia after proximalization of the arteriovenous anastomosis.

\section{DISCUSSION}

These data show that a BB-AVF needs fewer interventions to prevent failure compared to prosthetic (PTFE) forearm grafts. In addition, incidence rates for thrombosis and infection are significantly better. As the dialysis population becomes older (with various co-morbidity), the need for secondary and tertiary access, including BB-AVFs and prosthetic implants, will grow. There is still no consensus which type of access is to be preferred as randomized trials on this subject are lacking.

Although the surgical procedure for BB-AVF creation may be more difficult compared to prosthetic graft implantation, in this study only in two patients 
(3.9\%) it was not possible to perform a BB-AVF, because of small brachial artery diameter. Similarly, in the PTFE group it was also impossible to create a forearm loop graft in two patients (3.8\%). The cause for this was low blood pressure in both patients.

One of the main disadvantages of BB-AVFs is maturation failure. The incidence of non-maturation has been reported within the range of $0 \%$ to $38 \%$, although many reports lack information on this issue ${ }^{15}$. Hakaim reported adequate maturation in a population with predominantly diabetics ${ }^{16}$. In our study the nonmaturation rate was low, which is in line with the lowest figures from the literature. Non-maturation of a BB-AVF also has a lower incidence as compared to the RC-AVF15,17, which can be explained by the pristine condition of the basilic vein, which is protected from iatrogenic damage due to its deep location in the upper arm as compared to the cephalic vein which has a more superficial localization. Another advantage of the BB-AVF may be the proximal location; the basilic vein more often has a sufficient diameter (>3 $\mathrm{mm}$ ) for creation of an AV fistula. When the diameter is smaller than $3 \mathrm{~mm}$ a twostage procedure may be advocated, with enhancement of diameters in first instance and superficialization in a second stage. In our study all patients underwent a one-stage procedure with good early and late results. In this study population, infection occurred almost exclusively in the PTFE grafts. Most infections presented within 30 days after operation, indicating peroperative contamination. Cannulation-related infection, as described in the literature, has not been found 18 . In a recent review, infection rate is reported as $3.6 \% 15$. We found similar percentages as seen by Coburn et al. who described a higher infection rate in the PTFE group in their retrospective study of BB-AVF and PTFE grafts ${ }^{8}$.

Surveillance with access flow monitoring has been advocated by recent American and European guidelines. A significant flow decrease [25\%) or low flow $[<600 \mathrm{ml} / \mathrm{min}$ ) was the main reason for pre-emptive PTA. More PTAs were needed in the PTFE group, indicating a high incidence of stenosis formation. With this intensive surveillance and treatment protocol assisted-primary patencies were well acceptable for both BB-AVF and prosthetic grafts.

Ischaemic complications and intervention rates for ischaemia were similar for both groups. These figures are comparable to the rates found in the literature 15,18,19, although incidence rates might be underestimated, as has recently been shown, when using specific questionnaires for patients, focussing on ischaemic complaints 20 . 
High-output cardiac failure is one of the feared complications of upper arm fistulas in this predisposed patient population. Up to 75\% of the end-staged renal disease patients already has left ventricular hypertrophy even before haemodialysis 21 . Due to the high access flows the cardiac load increases and may induce cardiac failure eventually22-24. High-output cardiac failure may occur in high-flow AVFs, but was not observed in our patients ${ }^{15}$.

The primary patency rates of both groups were lower as compared to the literature $9,11,12,16,18,19,25-30$. These low primary patency rates can be explained by before-mentioned pre-emptive interventions which were performed in an early stage due to close monitoring of the arteriovenous fistulas. It is known that interventions with PTA or surgical revision to correct stenosis reduce the rate of AVF thrombosis $31-34$. These interventions have also the supplementary economic impact of reducing emergency admissions due to access thrombosis, reducing the need for central venous catheters with their attendant complications and preventing underdialysis with its associated morbidity and mortality rates ${ }^{35}$. Therefore pre-emptive interventions in fistulas at risk for thrombosis nowadays is more a standard than an acceptance, which results in lower primary but higher assisted-primary and secondary patency rates.

More interventions were needed in the PTFE group compared to the BB-AVF group. This could be partly explained by the pre-emptive interventions, as a result of surveillance and close monitoring. The total number of interventions were done in a smaller group of patients in the BB-AVF group compared to the PTFE group (24 patients versus 36 patients respectively). Some patients needed more interventions than others, but this number of patients was limited. For example two patients needed several PTA's in the BB-AVF group, one seven and the other thirteen. These patients may confound the data. Nevertheless, overall fewer interventions were needed in the BB-AVF group. The median time to intervention is significantly longer in the BB-AVF, with similar secondary patency rates after one year of follow up, but with significantly less interventions needed in the BB-AVF group. Similar results were seen from a randomized study in which prosthetic implants were compared to RCAVFs'12.

It remains discutable whether an autogenous AVF with the risk for non-maturation should always be preferred in an elderly population with various co-morbidities like diabetes and peripheral arterial occlusive disease (PAOD), of which $50 \%$ dies within two years ${ }^{36}$. One could argue to implant PTFE grafts in these patients with accessibility for cannulation within weeks ${ }^{6}$. However, as patients 
are referred in an early stage, and surgical experience with BB-AVF creation is sufficient, our preference would be the BB-AVF because of low intervention rates and long thrombosis-free interval with high secondary patency rates after one year of follow up. In addition, the total costs of access-related hospital admissions and revisions may be lower in patients with BB-AVFs, due to the fewer interventions needed. Whenever BB-AVFs fail, it is still possible to create a prosthetic graft fistula in most patients ${ }^{37}$.

Limitations of the study were the relatively short follow-up time, although a significantly better primary and assisted-primary patency was already shown after one year. It is not known if longer follow-up periods might influence the secondary patency. However, graft deterioration due to repetitive cannulation, might result in significant differences in secondary patency also after a longer follow-up period.

\section{CONCLUSION}

In this prospective, randomized study, we found that after BB-AVF creation, the need for intervention to prevent failure of the access occurs later and the number of interventions needed is less compared to prosthetic graft implantation, which corresponds to a significantly better primary as well as assisted-primary patency for the BB-AVF. Secondary patencies are comparable between both access types. Therefore we conclude that BB-AVF creation is the preferred option for a tertiary vascular access in haemodialysis patients.

\section{REFERENCES}

1. Ascher E, Gade P, Hingorani A, et al. Changes in the practice of angioaccess surgery: impact of dialysis outcome and quality initiative recommendations. J Vasc Surg. Jan 2000;31(1 Pt 1):84-92.

2. Malovrh M. Native arteriovenous fistula: preoperative evaluation. Am J Kidney Dis. Jun 2002;39(6):1218-1225.

3. Malovrh M. Non-invasive evaluation of vessels by duplex sonography prior to construction of arteriovenous fistulas for haemodialysis. Nephrol Dial Transplant. Jan 1998;13(1):125-129.

4. Silva MB, Jr., Hobson RW, 2nd, Pappas PJ, et al. A strategy for increasing use of autogenous hemodialysis access procedures: impact of preoperative noninvasive evaluation. J Vasc Surg. Feb 1998;27(2):302-307; discussion 307-308.

5. Wong V, Ward R, Taylor J, et al. Factors associated with early failure of arteriovenous fistulae for haemodialysis access. Eur J Vasc Endovasc Surg. Aug 1996;12(2):207-213. 
6. Besarab A, Work J, Brouwer D, et al. Clinical practice guidelines for vascular access. Am J Kidney Dis. Jul 2006;48 Suppl 1:S176-247.

7. Tordoir JH, Mickley V. European guidelines for vascular access: clinical algorithms on vascular access for haemodialysis. Edtna Erca J. Jul-Sep 2003;29(3):131136.

8. Coburn MC, Carney WI. Comparison of basilic vein and polytetrafluoroethylene for brachial arteriovenous fistula. Journal of Vascular Surgery. December 1994 1994;20(6):896-904.

9. Fitzgerald JT, Schanzer A, McVicar JP, et al. Upper arm arteriovenous fistula versus forearm looped arteriovenous graft for hemodialysis access: a comparative analysis. Ann Vasc Surg. Nov 2005;19(6):843-850.

10. Pisoni RL, Young EW, Dykstra DM, et al. Vascular access use in Europe and the United States: results from the DOPPS. Kidney Int. Jan 2002;61(1):305-316.

11. Coburn M.C. CWI. Comparison of basilic vein and polytetrafluoroethylene for brachial arteriovenous fistula. Journal of Vascular Surgery. December 1994 1994;20(6):896-904.

12. Rooijens PP, Burgmans JP, Yo TI, et al. Autogenous radial-cephalic or prosthetic brachial-antecubital forearm loop AVF in patients with compromised vessels? A randomized, multicenter study of the patency of primary hemodialysis access. J Vasc Surg. Sep 2005;42(3):481-486; discussions 487.

13. Sidawy AN, Gray R, Besarab A, et al. Recommended standards for reports dealing with arteriovenous hemodialysis accesses. J Vasc Surg. Mar 2002;35(3):603-610.

14. Zanow J, Kruger $U$, Scholz $H$. Proximalization of the arterial inflow: a new technique to treat access-related ischemia. J Vasc Surg. Jun 2006;43(6):12161221 ; discussion 1221.

15. Dix FP, Khan Y, Al-Khaffaf H. The Brachial Artery-basilic Vein Arterio-venous Fistula in Vascular Access for Haemodialysis-A Review Paper. Eur J Vasc Endovasc Surg. Oct 132005.

16. Hakaim AG, Nalbandian M, Scott T. Superior maturation and patency of primary brachiocephalic and transposed basilic vein arteriovenous fistulae in patients with diabetes. J Vasc Surg. Jan 1998;27(1):154-157.

17. Rooijens PP, Tordoir JH, Stijnen T, et al. Radiocephalic wrist arteriovenous fistula for hemodialysis: meta-analysis indicates a high primary failure rate. Eur J Vasc Endovasc Surg. Dec 2004;28(6):583-589.

18. Lemson MS, Tordoir JH, van Det RJ, et al. Effects of a venous cuff at the venous anastomosis of polytetrafluoroethylene grafts for hemodialysis vascular access. J Vasc Surg. Dec 2000;32[6]:1155-1163.

19. Dammers R, Planken RN, Pouls KP, et al. Evaluation of 4-mm to 7-mm versus 6$\mathrm{mm}$ prosthetic brachial-antecubital forearm loop access for hemodialysis: results of a randomized multicenter clinical trial. J Vasc Surg. Jan 2003;37(1):143-148.

20. van Hoek F, Scheltinga MR, Kouwenberg I, et al. Steal in hemodialysis patients depends on type of vascular access. Eur J Vasc Endovasc Surg. Dec 2006;32(6):710-717. 
21. Foley RN, Parfrey PS, Sarnak MJ. Clinical epidemiology of cardiovascular disease in chronic renal disease. Am J Kidney Dis. Nov 1998;32(5 Suppl 3):S112-119.

22. Iwashima Y, Horio T, Takami Y, et al. Effects of the creation of arteriovenous fistula for hemodialysis on cardiac function and natriuretic peptide levels in CRF. Am J Kidney Dis. Nov 2002;40(5):974-982.

23. Ori $Y$, Korzets $A$, Katz $M$, et al. The contribution of an arteriovenous access for hemodialysis to left ventricular hypertrophy. Am J Kidney Dis. Oct 2002;40(4):745-752.

24. Anderson CB, Codd JR, Graff RA, et al. Cardiac failure and upper extremity arteriovenous dialysis fistulas. Case reports and a review of the literature. Arch Intern Med. Mar 1976;136[3]:292-297.

25. Hossny A. Brachiobasilic arteriovenous fistula: different surgical techniques and their effects on fistula patency and dialysis-related complications. J Vasc Surg. Apr 2003;37[4]:821-826.

26. Keuter $X H$, van der Sande FM, Kessels $A G$, et al. Excellent performance of onestage brachial-basilic arteriovenous fistula. Nephrol Dial Transplant. Oct 2005;20(10):2168-2171.

27. Murphy GJ, White SA, Knight AJ, et al. Long-term results of arteriovenous fistulas using transposed autologous basilic vein. Br J Surg. Jun 2000;87[6]:819823.

28. Rao RK, Azin GD, Hood DB, et al. Basilic vein transposition fistula: a good option for maintaining hemodialysis access site options? J Vasc Surg. May 2004;39[5]:1043-1047.

29. Taghizadeh A, Dasgupta P, Khan MS, et al. Long-term outcomes of brachiobasilic transposition fistula for haemodialysis. Eur $J$ Vasc Endovasc Surg. Dec 2003;26[6]:670-672.

30. Tordoir JH, Hofstra L, Leunissen KM, et al. Early experience with stretch polytetrafluoroethylene grafts for haemodialysis access surgery: results of a prospective randomised study. Eur J Vasc Endovasc Surg. Apr 1995;9(3):305-309.

31. Glanz S, Gordon DH, Butt KM, et al. The role of percutaneous angioplasty in the management of chronic hemodialysis fistulas. Ann Surg. Dec 1987;206(6):777781.

32. Safa AA, Valji K, Roberts AC, et al. Detection and treatment of dysfunctional hemodialysis access grafts: effect of a surveillance program on graft patency and the incidence of thrombosis. Radiology. Jun 1996;199(3):653-657.

33. Schwab SJ, Raymond JR, Saeed M, et al. Prevention of hemodialysis fistula thrombosis. Early detection of venous stenoses. Kidney Int. Oct 1989;36[4]:707711.

34. Turmel-Rodrigues L, Pengloan J, Blanchier D, et al. Insufficient dialysis shunts: improved long-term patency rates with close hemodynamic monitoring, repeated percutaneous balloon angioplasty, and stent placement. Radiology. Apr 1993;187(1):273-278. 
35. Wijnen E, Planken N, Keuter X, et al. Impact of a quality improvement programme based on vascular access flow monitoring on costs, access occlusion and access failure. Nephrol Dial Transplant. Dec 2006;21(12):3514-3519.

36. Culp K, Taylor L, Hulme PA. Geriatric hemodialysis patients: a comparative study of vascular access. Anna J. Dec 1996;23(6):583-590, 622; discussion 591582.

37. Matsuura JH, Rosenthal D, Clark M, et al. Transposed basilic vein versus polytetrafluorethylene for brachial-axillary arteriovenous fistulas. Am J Surg. Aug 1998; 176(2):219-221. 
Prospective evaluation of ischaemia in brachial-basilic and forearm prosthetic arteriovenous fistulas for haemodialysis

X.H.A. Keuter, A.G.H. Kessels, M.H. de Haan, F.M. van der Sande, J.H.M. Tordoir

Adapted from: Eur J Vasc Endovasc Surg 2008; 35: 619-624. 


\section{ABSTRACT \\ Introduction}

Ischaemia is a devastating complication after arteriovenous fistula (AVF) creation. When not timely corrected, it may lead to amputation. Symptomatic ischaemia occurs in 3.7-5\% of the haemodialysis population. Upper arm AVFs have a higher incidence of ischaemia compared to forearm AVFs. As more patients may need upper arm AVFs in the growing and older haemodialysis population, occurrence of symptomatic ischaemia may increase. The purpose of this study is to identify predictors for occurrence of ischaemia.

\section{Methods}

A prospective evaluation of ischaemia was performed in patients randomised for either a brachial-basilic (BB) AVF or a prosthetic forearm loop AVF. Clinical parameters, preoperative vessel diameters, access flows, digital blood pressures, digit-to-brachial indices (DBI) and interventions for ischaemia were recorded.

\section{Results}

Sixty-one patients (28 BB-AVF) were studied. Seventeen patients (8 BB-AVF) developed ischaemic symptoms. Six patients (3 BB-AVF) needed interventions for severe symptoms. Age, history of peripheral arterial reconstruction and radial artery volume flow were significant predictors for the occurrence of ischaemia.

\section{Conclusion}

Symptomatic ischaemia occurred in $28 \%$ of patients with brachial-basilic and prosthetic forearm AVFs. Age, history of peripheral arterial reconstruction and radial artery volume flow might be important for prediction of ischaemia. 


\section{INTRODUCTION}

Ischaemia in end-stage renal disease (ESRD) patients on haemodialysis is an uncommon but feared complication of vascular access creation, which can lead to finger and hand amputation ${ }^{1-3}$. Upper extremity ischaemia is reported to be more frequent in elbow and upper arm fistulas as compared to forearm fistulas $^{4}$. It is estimated that 20-25\% of patients with an upper arm fistula will develop hand ischaemia1,5-7. Due to the growing and older haemodialysis population, an increasing number of patients will rely on upper arm vascular access because of the impossibility of forearm arteriovenous fistula (AVF) creation (radial-cephalic AVF) or failure of previous accesses. As a result, an increase in the total number and percentage of patients with symptomatic ischaemia after vascular access creation might be expected 8 . There still is little information on patient-related and noninvasively measured vessel parameters that may predict the occurrence of ischaemia in elbow/upper arm accesses like brachial-basilic and prosthetic forearm loop AVFs.

The primary purpose of this study is therefore to evaluate patient demographics as well as preoperative duplex parameters to identify predictors for occurrence of ischaemia in brachial-basilic and prosthetic forearm loop AVFs. The secondary purpose of this study is to compare the occurrence of ischaemia in these two types of vascular access.

\section{METHODS}

Patients at a single dialysis facility with failed vascular access or insufficient arterial and/or venous vessels (distal radial artery and/or forearm/upper arm cephalic vein $<2.0 \mathrm{~mm}$ in diameter] were included and randomised for creation of a brachial-basilic AVF (BB-AVF) or prosthetic (Polytetrafluoroethylene (PTFE); Gore \& Ass, Flagstaff, USA) brachial-antecubital forearm loop (PTFE loop; prosthetic graft AVF].

This study was part of a larger randomised trial in which patency rates were compared between these two options for vascular access. Approval of the ethical committee was obtained. All patients gave informed consent. Patients received preoperative upper extremity vessel assessment by means of duplex ultrasound investigation (SSD-2000, Aloka Co Ltd, Tokyo, Japan) as a standard procedure. Fore- and upper arm cephalic and basilic vein diameters and brachial, ulnar and radial artery diameters and flow were measured. Bilateral 
systolic and brachial diastolic bloodpressure (Riva-Rocci method) and digital systolic pressure were measured. Finger pressures were measured by photoplethysmography and an inflatable cuff (Nicolet Vascular, Madison, WI, USA) and the digit-to-brachial index (DBI) was calculated by dividing digital systolic blood pressure by brachial systolic blood pressure.

Clinical and duplex parameters were recorded preoperatively. Postoperatively, clinical parameters, flow and DBI were recorded at 6, 12, 26 and 52 weeks. Ischaemic symptoms were defined as pain during exercise and/or haemodialysis (stage 2-3) ${ }^{4}$. The indication for intervention for ischaemia was made on clinical symptoms and the outcome of DBI and duplex measurements. In particular the amount of blood flow through the AV anastomosis was non-invasively measured. All patients underwent pre-intervention angiography with visualisation of the complete arterial inflow, AV anastomosis and outflow veins. In principle all arterial inflow obstructions were treated by radiological intervention, while high blood flow through the vascular access was surgically revised by flow-reducing techniques.

\section{Statistical analysis}

For statistical analysis, SPSS 12.01 program was used. All complications and interventions related to symptomatic ischaemia were recorded. Patients who died, were transplanted, had access failure or were lost to follow up were censored for ischaemia-free survival analysis. No power calculation was used for this study, as the primary aim of this study is to find predictors for ischaemia. The Kaplan-Meier method was used to compare the ischaemia-free period for the two groups. Univariate Cox-regression was used to find predictors for the occurrence of ischaemia. Parameters with $P<0.1$ were included in a multivariate backwards Cox-regression. In this multivariate regression, a P-value of less than 0.05 was considered statistical significant.

\section{RESULTS}

Sixty-one patients were randomised of which 28 had BB-AVF and 33 prosthetic graft AVF creation. Patient characteristics are shown in table 5.1 and 5.2. Mean follow up time was $282 \pm 19.3$ (SD) days for the BB-AVF group and $247 \pm 22$ days for the prosthetic graft group. In one patient, non-maturation of the BB-AVF did occur. There were 14 patients (1 in the BB-AVF group) with 31 thromboses (range: 1-6 per patient). 


\begin{tabular}{lcc}
\hline & PTFE & BB-AVF \\
\hline $\mathrm{N}$ & 33 & 28 \\
$\mathrm{M} / \mathrm{F}$ & $22 / 11$ & $13 / 15$ \\
Previous RC-AVF & 2 & 10 \\
Previous BC-AVF & 1 & 4 \\
Previous graft AVF & 3 & 6 \\
Dominant hand Left/Right & $0 / 33$ & $1 / 27$ \\
Smoking & 8 & 8 \\
Cardiac disease & 4 & 9 \\
Hypertension & 21 & 15 \\
Diabetes & 17 & 7 \\
PAOD & 12 & 10 \\
Previous vascular surgery & 17 & 18 \\
History of central arterial reconstruction & 3 & 2 \\
History of peripheral arterial reconstruction & 2 & 0 \\
Age (years) (SD) & $66.3(11.6)$ & $64.4(16.6)$ \\
Months on CAPD (SD) & $7.0(15.2)$ & $4.5(8.7)$ \\
Months on Haemodialysis (SD) & $6.3(14.0)$ & $20.9(33.5)$ \\
Mean number of pre vious accesses (SD) & $0.3(0.8)$ & $1.0(1.2)$ \\
\hline
\end{tabular}

Table 5.1: Patient characteristics of prosthetic graft (PTFE) and BB-AVF group. PTFE = Polytetrafluoroethylene, graft material; BB-AVF = brachial-basilic arteriovenous fistula; RC-AVF = radial-cephalic arteriovenous fistula; BC-AVF = brachial-cephalic arteriovenous fistula; $P A O D=$ peripheral arterial obstructive disease; CAPD = continuous ambulatory peritoneal dialysis.

Ischaemia occurred earlier after operation in the PTFE group; however, there was no significant difference in occurrence of ischaemic symptoms after one year for both types of access (29\% vs 28\% for the BB-AVF and prosthetic grafts) (Figure 5.1).

\begin{tabular}{lcc}
\hline & PTFE & BB-AVF \\
\hline Brachial artery diameter (mm) (SD) & $4.4(0.8)$ & $4.3(0.9)$ \\
Brachial artery volume flow (ml/min) (SD) & $83.8(61.5)$ & $82.2(63.2)$ \\
Radial artery diameter (mm) (SD) & $2.3(0.5)$ & $2.4(0.5)$ \\
Radial artery volume flow (ml/min) (SD) & $22.7(20.9)$ & $24.0(22.1)$ \\
Ulnar artery diameter (mm) (SD) & $1.9(0.5)$ & $2.0(0.4)$ \\
Systolic digital pressure (mmHg) (SD) & $152(39)$ & $144(41)$ \\
Systolic brachial pressure (mmHg) (SD) & $157(42)$ & $143(44)$ \\
Digit/Brachial Index (SD) & $0.98(0.11)$ & $0.98(0.18)$ \\
\hline
\end{tabular}

Table 5.2: Preoperative vessel characteristics for the prosthetic graft [PTFE] and brachial-basilic arteriovenous fistula (BB-AVF). 


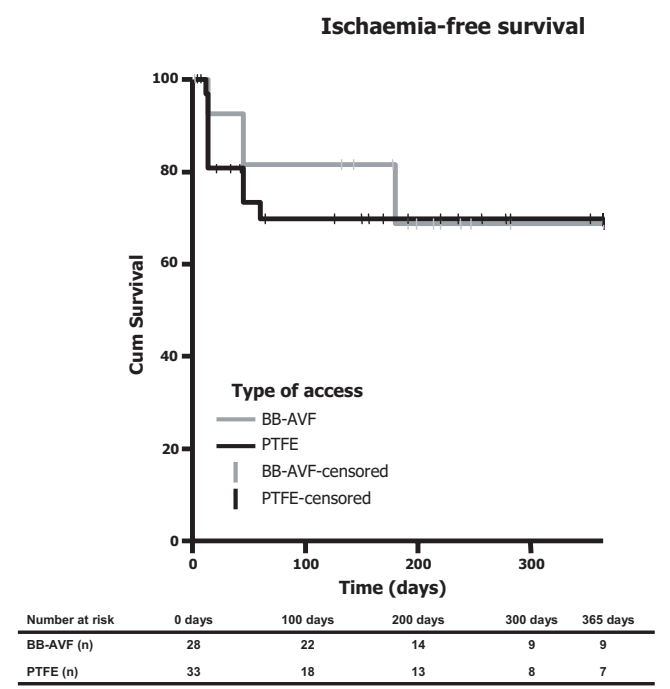

Figure 5.1: Ischaemia-free survival in brachial-basilic (BB-AVF) and prosthetic graft AVF (PTFE).

The mean ischaemia-free period was $280 \pm 26$ and $262 \pm 29$ days for the BB-AVF and prosthetic graft group, respectively. The percentage of patients who did not need intervention for ischaemia after one year was $89 \%$ versus $90 \%$ for the BB-AVF and PTFE group, respectively. Mean intervention-free period for ischaemia was $339 \pm 14$ and $331 \pm 18$ days for the BB-AVF and graft AVF. As can be seen in table 5.3, brachial artery volume flow was at no time significantly different for the BB-AVF and PTFE group as well for the nonischaemia and ischaemia group.

Six patients (3 BB-AVF; 3 prosthetic grafts) needed a total of 12 interventions for salvage of ischaemia. The BB-AVF group underwent 4 percutaneous transluminal angioplasties (PTA) with additional stent implantation (one patient) for subclavian artery obstruction. In addition, distal arterial flow enhancement by proximalisation of the arteriovenous anastomosis with graft implantation ${ }^{9}$ was needed in 2 patients combined with anastomotic patchplas-

\begin{tabular}{lcccccc}
\hline $\begin{array}{l}\text { Brachial artery volume flow } \\
(\mathbf{m l} / \mathbf{m i n})\end{array}$ & BB-AVF & PTFE & P & $\begin{array}{c}\text { Non- } \\
\text { ischaemia }\end{array}$ & Ischaemia & P \\
\hline 6 weeks & 1508 & 1634 & NS & 1574 & 1561 & NS \\
12 weeks & 1569 & 1561 & NS & 1490 & 1761 & NS \\
26 weeks & 1543 & 1519 & NS & 1456 & 1683 & NS \\
52 weeks & 1507 & 1446 & NS & 1505 & 1423 & NS \\
\hline
\end{tabular}

Table 5.3: Brachial artery volume flow for the BB-AVF vs. PTFE and non-ischaemia vs. ischaemia group. 
ty in one. In the end, 2 BB-AVFs had to be surgically ligated to resolve ischaemia, leaving only one patient successfully treated for ischaemia. In the prosthetic graft group, 2 PTAs and 2 banding procedures to reduce high flow were necessary to solve ischaemic complications. There was no graft ligation necessary in the prosthetic group.

Patient and vessel characteristics of the non-ischaemia and ischaemia group are listed in table 5.4 and 5.5. In a univariate Cox-regression analysis age, previous brachial-cephalic AVF, cardiac disease, hypertension, a history of peripheral arterial reconstruction, preoperative brachial artery diameter and volume flow of the distal radial artery were significant parameters for ischaemia $(P<0.01$ ) (Table 5.4 and 5.5). In the backwards multivariate Coxregression analysis with these parameters, a history of peripheral arterial reconstruction and volume flow of the distal radial artery were independent predictors for ischaemic symptoms within one year after operation $(P<0.05)$ (Table 5.5). With a P-value of 0.053, age showed a trend to be a predictor for ischaemia as well.

\begin{tabular}{lcccc}
\hline & $\begin{array}{c}\text { Non- } \\
\text { ischaemia }\end{array}$ & Ischaemia & $\begin{array}{c}\text { P-value } \\
\text { Univariate } \\
\text { analysis }\end{array}$ & $\begin{array}{c}\text { P-value } \\
\text { Multivariate } \\
\text { analysis }\end{array}$ \\
\hline $\mathrm{N}$ & & & & \\
$\mathrm{M}(\%)$ & 44 & 17 & 0.290 & \\
Previous RC-AVF (\%) & 61 & 47 & 0.311 & \\
Previous BC-AVF (\%) & 23 & 12 & 0.094 & 1.000 \\
Previous graft AVF (\%) & 11 & 0 & 0.674 & \\
Dominant hand right (\%) & 16 & 12 & 0.404 & \\
Smoking (\%) & 98 & 100 & 0.316 & \\
Cardiac disease (\%) & 30 & 18 & 0.003 & 0.986 \\
Hypertension (\%) & 30 & 0 & 0.094 & 0.927 \\
Diabetes (\%) & 52 & 76 & 0.285 & \\
PAOD (\%) & 43 & 29 & 0.238 & \\
Previous vascular surgery (\%) & 32 & 47 & 0.633 & \\
History of central arterial reconstruction (\%) & 59 & 53 & 0.582 & \\
History of peripheral arterial reconstruction (\%) & 9 & 6 & 0.039 \\
Age & 0 & 12 & 0.053 \\
Months on CAPD (SD) & 62.0 & 74.2 & 0.001 & $\mathbf{0 . 0 5 3}$ \\
Months on Haemodialysis (SD) & $6.5(12.9)$ & $4.5(13.1)$ & 0.659 & \\
Number of previous accesses (SD) & $14.4(28.3)$ & $9.1(17.2)$ & 0.446 & \\
BB-AVF (\%) & $0.7(1.1)$ & $0.4(0.9)$ & 0.375 & \\
AVF placed in left arm (\%) & 46 & 47 & 0.736 & \\
AVF placed in non -dominant arm (\%) & 77 & 88 & 0.419 & \\
\hline
\end{tabular}

Table 5.4: Patient demographics for the non-ischaemia and ischaemia group. The values in the fourth column represent the p-value found in a univariate Cox-regression analysis for ischaemia. Variables with a p-value < 0.1 were put in a multivariate Cox-regression for ischaemia. Last column represent the $p$-value found in the multivariate backward regression. When P-value is < 0.05, the parameter is considered a statistically significant predictor for ischaemia. Bold numbers indicate (borderline) statistical significance. 


\begin{tabular}{lcccc}
\hline & $\begin{array}{c}\text { Non- } \\
\text { ischaemia }\end{array}$ & Ischaemia & P-value & $\begin{array}{c}\text { P-value } \\
\text { Multivariate } \\
\text { analysis }\end{array}$ \\
\hline Brachial artery diameter (mm) (SD) & $4.2(0.9)$ & $4.7(0.7)$ & 0.063 & 0.359 \\
Brachial artery volume flow (ml/min) (SD) & $78.3(59.0)$ & $95.4(68.7)$ & 0.417 & \\
Radial artery diameter (mm) (SD) & $2.3(0.5)$ & $2.5(0.5)$ & 0.197 & \\
Radial artery volume flow (ml/min) (SD) & $19.3(15.5)$ & $31.9(28.8)$ & 0.078 & $\mathbf{0 . 0 3 4}$ \\
Ulnar artery diameter (mm) (SD) & $1.9(0.5)$ & $2.0(0.6)$ & 0.871 & \\
Systolic finger blood pressure (mmHg) (SD) & $146(42)$ & $154(34)$ & 0.710 & \\
Systolic blood pressure (mmHg) (SD) & $149(47)$ & $154(40)$ & 0.835 & \\
Digit /Brachial Index (SD) & $0.97(0.15)$ & $1.00(0.13)$ & 0.594 & \\
\hline
\end{tabular}

Table 5.5: Preoperative vessel parameters for the non-ischaemia and ischaemia group. The values in the fourth column represent the p-value found in an univariate Cox-regression analysis for ischaemia. Variables with a P-value $<0.1$ were put in a multivariate Cox-regression for ischaemia. Last column represent the p-value found in the multivariate backward regression. When P-value is $<0.05$, the parameter is considered a statistically significant predictor for ischaemia. Bold number indicates the statistical significant parameter.

The increase in brachial arterial diameter from operation until one year after was significantly lower in the ischaemia group compared to the non-ischaemia group $(P<0.001)$, while brachial artery volume flow was not significantly different. The decrease in $\mathrm{DBI}$ after access creation was significantly greater in the ischaemia group compared to the non-ischaemia group $(P=0.03)$. The decrease in $\mathrm{DB}$ in patients who needed intervention was even greater (Figure 5.2).

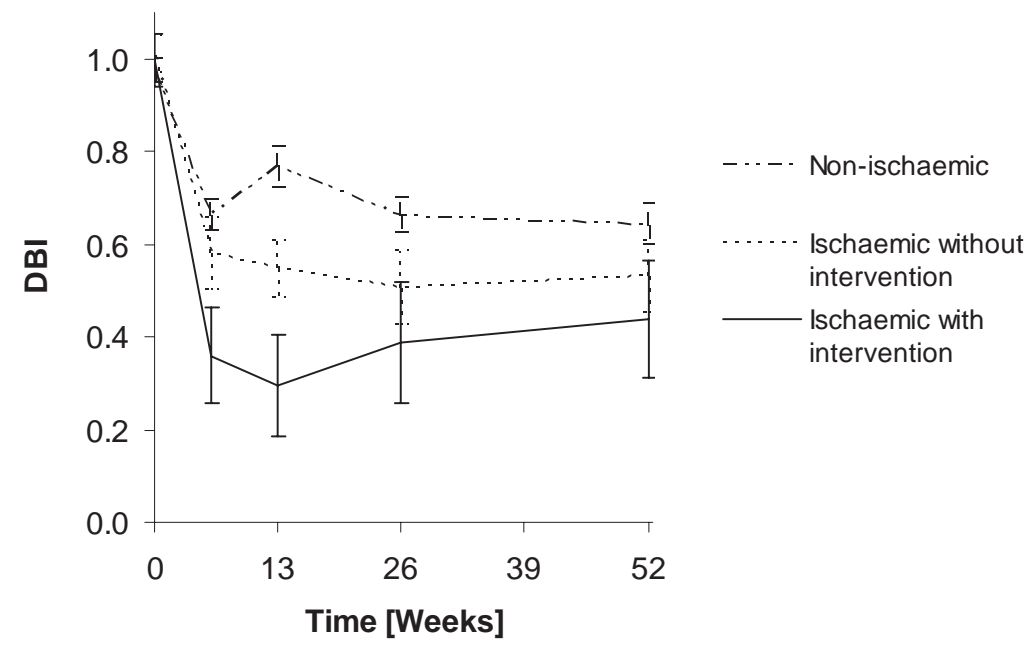

Figure 5.2: Digit-to-brachial index in brachial-basilic (BB-AVF) and prosthetic graft AVF (PTFE). Digit-to-brachial index (DBI) is shown with standard error bars for the non-ischaemia group, the ischaemia group without intervention and the ischaemia group with intervention. There is a significant difference in $\mathrm{DB}$ l between the non-ischaemia group and the ischaemia group $(P=0.03$ ). 


\section{DISCUSSION}

In this study, 28\% of patients with BB-AVF and forearm grafts developed symptoms of ischaemia while $11 \%$ needed intervention within one year after access creation. Similar percentages are reported in the literature, with in particular high percentages in brachial- based arteriovenous fistulas. However, when prospectively evaluated with the use of a questionnaire, steal symptoms are experienced on a much larger scale than previously thought? Not all patients with ischaemic symptoms need intervention, but a carefully wait and see policy is recommended.

Several clinical predictors for ischaemia have been described: age, diabetes, hypertension, peripheral arterial obstructive disease, coronary artery disease, and female gender have been associated with the occurrence of ischaemia3,10-12. A preoperative prediction of ischaemia would be helpful to better outline the strategy for access placement. In the present study a history of peripheral arterial reconstruction and radial artery volume flow are found to be independent predictors of ischaemia. Furthermore, age shows a tendency to significance. It is well appreciated that the aging dialysis population has poor peripheral vessels due to associated cardiovascular morbidities and therefore a priori at risk for deteriorated peripheral hand circulation, in particular when high flow brachial artery-based accesses may induce steal.

Yeager et al. found ischaemia of the hand in ESRD patients with primarily distal atherosclerotic arteries ${ }^{13}$. These poor atherosclerotic arteries have less ability to adapt to higher flows than healthy arteries. Taken this theory into account, in these fistulas less flow will go through the fistula and to the already impaired atherosclerotic peripheral circulation. Thus, a history of peripheral arterial reconstruction of the legs indicates also a poor peripheral circulation in the upper extremity and therefore a higher risk for ischaemia of the hand.

We found volume flows of the distal radial artery to be an independent predictive variable for the occurrence of ischaemia. An explanation for this may be a greater impact of steal on the blood flow to the hand. Another explanation could be that patients with low radial artery volume flows already developed collateral blood flow to the hand, which compensates the steal phenomenon due to the fistula.

Access volume flows were at no time point different between the ischaemia and non-ischaemia group. Therefore this parameter is not useful to discriminate between patients with and without distal hypoperfusion. On the other hand, determination of the access flow is of importance to outline the strate- 
gy for treatment. Flow reduction procedures for instance by access banding is the primary option in high-flow arteriovenous fistulas 8,14 , whereas in normal/low-flow fistulas the distal revascularisation and interval ligation (DRIL) procedure or proximalisation of the arteriovenous anastomosis are recommended $9,15,16$.

The $\mathrm{DBI}$ is described to be a predictor for the occurrence of ischaemia, although different cut-off values $(0.60$ to 1.00$)$ for ischaemia have been proposed $8,11,12,14,17,18$. In this study the $\mathrm{DBI}$ at 6 weeks postoperatively was lower compared to preoperative values and remained unchanged during the follow up in most patients. This is in accordance with the findings of Papasavas et al., who reported a significant change in DBI directly after operation, which remained stable from there on ${ }^{18}$. In the univariate Cox-regression analysis we found the preoperative $\mathrm{DBI}$ not to be a predictor for the occurrence of ischaemia. However a significant decreased DBI was seen six weeks after operation in the ischaemia group, with very low values $[<0.4]$ in patients who needed interventions. Also, Valentine et al. were not able to determine a preoperative $\mathrm{DBI}$ threshold that could indicate the development of postoperative ischaemia12. Others studies reported a DBI of $<0.6$ direct postoperative or $<0.45$ intraoperatively as a predictor for ischaemia, but could not indicate when to intervene on basis of these values ${ }^{11,18}$. Therefore, the DBI measurement might possibly be a method for the diagnosis of patients with suspicion on ischaemic symptoms and might be helpful to support the decision for intervention, although the clinical symptoms prevail in the final decision to treat the patient. Access preservation and relief of symptoms are the ultimate goals of treatment. The major key for a successful outcome is angiography with visualisation of the in- and outflow arterial tree.

Sixty-six percent of the patients with severe ischaemia in this study had an angiographically proven subclavian artery stenosis. After percutaneous dilatation, ischaemic symptoms disappeared in only one patient, despite an adequate PTA with no residual stenosis. In the BB-AVF group we performed distal arterial flow enhancement by proximalisation of the arteriovenous anastomosis with graft implantation as described by Zanow et al. ${ }^{9}$. Although they reported good results with this technique, we had to ligate these two fistulas because of persistent ischaemia. Duplex investigation showed steal in the brachial artery distal of the newly created proximal anastomosis.

In summary, steal is a rather common complication after vascular access creation (28\% in this population). This study showed, in a multivariate Cox' regres- 
sion, age, history of peripheral arterial reconstruction and distal radial artery volume flow to be predictors for the development of symptomatic ischaemia of the hand after vascular access creation. There is no difference in occurrence of ischaemia between brachial-basilic or forearm graft AVF. Furthermore, DBI measurement might be an important surveillance method and can indicate whether a patient will develop ischaemia or not. Future studies on the pre- and postoperative forearm vessel haemodynamics may indicate better predictors for the development of ischaemia after access creation.

\section{REFERENCES}

1. Odland MD, Kelly PH, Ney AL, et al. Management of dialysis-associated steal syndrome complicating upper extremity arteriovenous fistulas: use of intraoperative digital photoplethysmography. Surgery. Oct 1991;110(4):664-669; discussion 669-670.

2. Levine MP. The hemodialysis patient and hand amputation. Am J Nephrol. NovDec 2001;21(6):498-501.

3. Morsy $\mathrm{AH}$, Kulbaski M, Chen $\mathrm{C}$, et al. Incidence and characteristics of patients with hand ischemia after a hemodialysis access procedure. J Surg Res. Jan 1998;74(1):8-10.

4. Tordoir JH, Dammers R, van der Sande FM. Upper extremity ischemia and hemodialysis vascular access. Eur J Vasc Endovasc Surg. Jan 2004;27(1):1-5.

5. Zerbino VR, Tice DA, Katz LA, et al. A 6 year clinical experience with arteriovenous fistulas and bypass for hemodialysis. Surgery. Dec 1974;76(6):1018-1023.

6. Zibari GB, Rohr MS, Landreneau MD, et al. Complications from permanent hemodialysis vascular access. Surgery. Oct 1988;104(4):681-686.

7. van Hoek F, Scheltinga MR, Kouwenberg I, et al. Steal in hemodialysis patients depends on type of vascular access. Eur J Vasc Endovasc Surg. Dec 2006;32(6):710-717.

8. Besarab A, Work J, Brouwer D, et al. Clinical practice guidelines for vascular access. Am J Kidney Dis. Jul 2006;48 Suppl 1:S176-247.

9. Zanow J, Kruger U, Scholz H. Proximalization of the arterial inflow: a new technique to treat access-related ischemia. J Vasc Surg. Jun 2006;43(6):12161221; discussion 1221.

10. Mattson WJ. Recognition and treatment of vascular steal secondary to hemodialysis prostheses. Am J Surg. Aug 1987;154(2):198-201.

11. Tynan-Cuisinier GS, Berman SS. Strategies for predicting and treating access induced ischemic steal syndrome. Eur $J$ Vasc Endovasc Surg. Sep 2006;32(3):309-315. 
12. Valentine RJ, Bouch CW, Scott DJ, et al. Do preoperative finger pressures predict early arterial steal in hemodialysis access patients? A prospective analysis. J Vasc Surg. Aug 2002;36(2):351-356.

13. Yeager RA, Moneta GL, Edwards JM, et al. Relationship of hemodialysis access to finger gangrene in patients with end-stage renal disease. J Vasc Surg. Aug 2002;36[2]:245-249; discussion 249.

14. Tordoir JH, Mickley V. European guidelines for vascular access: clinical algorithms on vascular access for haemodialysis. Edtna Erca J. Jul-Sep 2003;29[3]:131136.

15. Berman SS, Gentile AT, Glickman MH, et al. Distal revascularization-interval ligation for limb salvage and maintenance of dialysis access in ischemic steal syndrome. J Vasc Surg. Sep 1997;26(3):393-402; discussion 402-404.

16. Knox RC, Berman SS, Hughes JD, et al. Distal revascularization-interval ligation: a durable and effective treatment for ischemic steal syndrome after hemodialysis access. J Vasc Surg. Aug 2002;36(2):250-255; discussion 256.

17. Goff CD, Sato DT, Bloch PH, et al. Steal syndrome complicating hemodialysis access procedures: can it be predicted? Ann Vasc Surg. Mar 2000;14[2]:138144.

18. Papasavas PK, Reifsnyder T, Birdas TJ, et al. Prediction of arteriovenous access steal syndrome utilizing digital pressure measurements. Vasc Endovascular Surg. May-Jun 2003;37(3):179-184. 
Effect of upper arm brachial-basilic and prosthetic forearm arteriovenous fistula on left ventricular hypertrophy

\author{
X.H.A. Keuter, J.P. Kooman, J. Habets, \\ F.M. van der Sande, A.G.H. Kessels, \\ E.C. Cheriex, J.H.M. Tordoir
}

Adapted from: J Vasc Access 2007; 8: 296-301. 


\section{ABSTRACT}

\section{Introduction}

Left Ventricular (LV) Hypertrophy is present in up to 75\% of predialysis patients. Creation of an arteriovenous fistula (AVF) may increase left ventricular hypertrophy. Aim of the study was to compare the effects of a brachialbasilic (BB) AVF and the prosthetic brachial-antecubital forearm loop access (PTFE) on cardiac structure.

\section{Methods}

Patients were randomized to receive a BB-AVF or a prosthetic brachial-antecubital forearm loop access. Before and three months after AVF creation patients underwent an echocardiographic examination. The relative increases between the measured parameters for the two groups were compared with a Mann-Whitney U-test.

\section{Results}

A total of 27 patients participated in the study. The relative increase in left ventricular parameters was not significantly different between the two groups. Only left ventricular end-diastolic diameter tended to significance, it increased slightly in the BB-AVF group from $46.18 \pm 1.85$ to $48.00 \pm 2.27$ while it decreased in the PTFE-group from $51.69 \pm 2.29$ to $50.85 \pm 2.28$. Mean blood volume flow through the brachial artery was $1680 \pm 156$ and $1450 \pm$ $221 \mathrm{ml} / \mathrm{min}$ three months after surgery for the PTFE and the BB-AVF group, respectively.

\section{Conclusion}

After three months of follow-up, changes in cardiac structure were comparable between patients with BB- and PTFE AVFs. Also access flow was comparable at this point in time. In general, the effects of creation of a fistula on LV structure were limited. Longer follow up time may be needed to explore the long term effects of different vascular accesses on cardiac function. 


\section{INTRODUCTION}

Creation of a forearm autogenous arteriovenous fistula becomes increasingly difficult due to an increasingly older patient population having various co-morbidities and poor forearm vessels. In a significant percentage of these patients, construction of radial-cephalic fistulas is not possible. According to the K-DOQl and European guidelines, brachial-cephalic (BC), brachial-basilic arteriovenous fistula (BB-AVF) and prosthetic forearm graft (PTFE-loop) are the secondary and tertiary choices for vascular access ${ }^{1,2}$. In general, volume flows are reportedly higher with upper arm fistula.

Left Ventricular Hypertrophy (LVH) is an adaptive response to increased cardiac load, but may lead to systolic or diastolic cardiac failure, and is related to mortality in dialysis patients. LVH is very common in patients with end-stage renal disease (ESRD). Even in a population without a functioning AVF, up to 75 percent of the pre-dialysis patients have $\mathrm{LVH}^{3}$. The cause of $\mathrm{LVH}$ in renal patients is multifactorial and includes factors such as hypertension, anaemia or the uraemic state itself. Presence of an arteriovenous fistula (AVF) may increase risk for or may worsen LVH even further ${ }^{4}$. Two types of LVH are described: concentric LVH, mainly due to pressure overload, in which wall thickness increases more than left ventricular (LV) diameter, and eccentric LVH, mainly due to volume overload, in which wall thickness and LV diameter increase in proportion. In the uraemic patient, concentric LVH is primarily caused by pressure overload secondary to hypertension. Possibly it is also caused by myocardial fibrosis due to the uraemic state ${ }^{5}$. Risk factors for eccentric LVH are volume overload secondary to anaemia, AVF and fluid retention.

Creation of a vascular access in ESRD patients has effect on cardiac performance $^{6-8}$. Due to presence of an AV fistula system, vascular resistance will decrease, resulting in an increased stroke volume and cardiac output in order to maintain blood pressure ${ }^{4}$. High flow fistulas, like upper arm fistulas, will increase cardiac volume load even more. Various case reports have described cardiac failure in high flow $\operatorname{AVFs}^{9}, 10$. Nevertheless, LVH seems to be a reversible process, as several reports showed regression of LVH after AVF closure in renal transplant recipients $5,11,12$.

The contribution of an AVF to cardiac performance has been studied extensively6-8,11,12. There are however only a few prospective evaluations comparing cardiac performance before and after creation of an AVF6-8. Furthermore, difference in cardiac load between different AVFs has never been studied 
prospectively to our knowledge. We hypothesize that due to higher fistula flow rates, cardiac loads will be higher in BB-AVF compared to PTFE forearm loop graft. The aim of this study is to prospectively compare the cardiac performance after creation of BB-AVF and prosthetic forearm loop fistulas.

\section{METHODS}

As part of a prospective randomised trial comparing BB-AVF and prosthetic forearm loop AVFs, echocardiographic examination was performed preoperatively and three months after creation of the vascular access. Patients in which it was not possible to create a RC-AVF or a BC-AVF or in which these AVFs had failed were included. Criteria for RC-AVF creation were forearm radial artery and cephalic vein diameter $>$ 2mm by duplex ultrasound (SSD-2OOO, Aloka Co Ltd, Tokyo, Japan). This study was approved by the local ethical committee. All patients gave informed consent.

Patients received an echocardiography independent of their New York Heart Association (NYHA) classification 13 . After the operation they received $100 \mathrm{mg}$ acetylsalicylic acid per day, unless when already receiving thrombocyt aggregation inhibitor or coumarins. No other changes in medication took place during this period.

Exclusion criteria were active local or general infections or ischaemia of the forearm. Age, Body Surface Area (BSA), Body Mass Index (BMI), systolic and diastolic blood pressure, heart rate and levels of haemoglobin and serum creatinine were evaluated before the creation of an AVF and approximately 3 months after the operation. The glomerular filtration rate was calculated using the Modification of Diet in Renal Disease (MDRD) formula $G \mathrm{R}_{\mathrm{mdrd}}=$ $186 \times$ (S-Cre/88.4) $]^{-1.154} \times$ (age $]^{-0.203} \times$ [0.742 if female) $\times$ (1.212 if African American) (SI units) ${ }^{14}$.

Two-dimensional echocardiographic examination was performed pre-operatively as well as three months postoperatively using a Philips sonos 5500 (Philips Nederland B.V./Medical Systems, Eindhoven, The Netherlands] ultrasound system with standard imaging transducers (S3). The following parameters were assessed: left atrial diameter (LAD), left ventricular end-diastolic diameter (LVEDD), posterior wall end-diastolic wall thickness (PW-EDWT), interventricular septal end-diastolic wall thickness (IVS-EDWT), left ventricular ejection fraction (LVEF), stroke volume (SV) and cardiac output (CO) and the diameter of the inferior vena cava (IVC). Left ventricular mass (LVM) was calculated with 
the following formula: LVM $=0.8 *\left\{1.04\left[\right.\right.$ [LVEDD + PW-EDWT + IVS-EDWT] ${ }^{3}$ - (LVEDD) $\left.\left.{ }^{3}\right]\right\}+0.6 \mathrm{~g}$. LVM index was calculated as LVM divided by heigth2.7 as recommended for ESRD patients. Indexing LVM to heigth2.7, rather than body surface area, reduced possible error caused by changes in volume. LVH was defined as LVM/heigth2.7 $>44 \mathrm{~g} / \mathrm{m}^{2.7}$ for women and $>48 \mathrm{~g} / \mathrm{m}^{2.7}$ for men ${ }^{15}$. The diameter of the IVC was expressed as an index to the body surface area (IVCi)16. Fractional shortening (FS) was calculated as (LVEDD LVESD)/LVEDD. Relative Wall Thickness was calculated by the formula (2 * PVEDWT]/LVEDD.

To compare the two groups, relative increase of the different parameters, as a representation of cardiac load, was used. The relative increase was defined as $\left(X_{\text {after }}-X_{\text {before }}\right) / X_{\text {before }}$.

Fistula flow was measured using duplex ultrasound (SSD-2000, Aloka Co Ltd, Tokyo, Japan) with a linear-array transducer operating at $5 \mathrm{MHz}$ in Doppler mode and $7.5 \mathrm{MHz}$ in imaging mode. Flow in the brachial artery was measured five centimetres proximal to the elbow level for both the BB-AVF and the PTFE forearm loop.

\section{Statistical analysis}

Statistical analysis was performed using SPSS for windows, version 12.0.1 [SPSS Inc, Chicago, IL). Differences in relative changes before and after creation of an arteriovenous fistula for the two groups were analyzed with the Mann Whitney U-test. Difference between access flows for the two groups after surgery were analyzed with a two sample independent T-test. A P-value less than 0.05 was considered significant.

\section{RESULTS}

Twenty-seven patients underwent an echocardiographic examination before operation, fifteen of which received a PTFE forearm loop and twelve a BB-AVF in the upper arm. In each group one patient did not show up for post-operative control for unknown reason. In the PTFE group one patient died of cardiac failure seven days after operation. Medical history revealed angina pectoris and multi-vessel coronary disease for which a percutaneous transluminal coronary angioplasty was done in the right coronary artery. 


\begin{tabular}{lcc}
\hline & BB-AVF & PTFE \\
\hline Age (years $\pm \mathrm{SD})$ & $65 \pm 13$ & $64 \pm 11$ \\
M/V & $7 / 4$ & $5 / 8$ \\
Body Mass Index $\left(\mathrm{kg} / \mathrm{m}^{2} \pm \mathrm{SD}\right)$ & $22.9 \pm 3.5$ & $26.9 \pm 7.4$ \\
Body Surface area $\left(\mathrm{m}^{2} \pm \mathrm{SD}\right)$ & $1.67 \pm 0.19$ & $1.90 \pm 0.29$ \\
NYHA clas. I & 6 & 6 \\
NYHA clas. II & 3 & 3 \\
NYHA clas. III & 2 & 3 \\
NYHA clas. IIV & 0 & 1 \\
Previous shunt & 3 & 1 \\
\hline
\end{tabular}

Table 6.1: Clinical characteristics.

\begin{tabular}{lcc}
\hline Cause & BB-AVF & PTFE \\
\hline Chronic glomerulonefritis & 1 & 1 \\
Nefrosclerosis/systemic vascular disease & 5 & 4 \\
Diabetes & 0 & 5 \\
Interstitial n efritis & 1 & 2 \\
Others & 4 & 1 \\
\hline
\end{tabular}

Table 6.2: Causes of end-stage renal failure in patients.

Mean age, gender, body mass index (BMI), body surface area (BSA), NYHA classification and number of previous shunts are described in table 6.1. Only BSA was higher in the PTFE group. The cause of end stage renal disease for the two groups is described in table 6.2. Four patients had had a previous arteriovenous fistula, three of which in the BB-AVF group. Twelve patients had central vein catheters for dialysis before operation, seven of which in the BBAVF group. Eleven and six patients, in the PTFE and BB-AVF group respectively, used erythropoietin. Six and two patients, in the PTFE and BB-AVF group respectively, used ACE inhibitors.

Three months post-operatively eleven and ten patients were on dialysis in the PTFE and BB-AVF group, respectively.

LVM could not be calculated accurately because of clear wall-motion abnormalities with scar formation in two patients of the PTFE group. Due to excessive pleural effusion IVS-EDWD, PW-EDWD an LVM could not be measured postoperatively in one patient in the BB-AVF group. SV and CO could not be calculated in three patients before and in another 3 patients after operation in the PTFE-group because of incomplete data. 
Haemoglobin levels, serum creatinine levels and glomerular filtration rate did not differ between the two groups (Table 6.3). Systolic and diastolic blood pressures were higher in the PTFE-group after surgery compared to the BBAVF group: $154.3 \pm 24.4$ (SD) versus $127.7 \pm 29.8(p=0.03$ ) and $78.0 \pm$ 11.4 versus $66.2 \pm 13.4$ ( $p=0.03$ ), respectively. Heart rate did not differ between the two groups.

\begin{tabular}{lcccc}
\hline & \multicolumn{2}{c}{ BB-AVF } & \multicolumn{2}{c}{ PTFE } \\
& Before (SD) & After (SD) & Before (SD) & After (SD) \\
\hline LAD (mm) & $40.4(5.5)$ & $42.0(5.6)$ & $43.5(4.7)$ & $44.5(5.9)$ \\
LVEDD (mm) & $46.2(6.1)$ & $48.0(7.5)$ & $51.7(8.3)$ & $50.9(8.2)$ \\
PW-EDWT (mm) & $9.8(1.8)$ & $10.1(1.4)$ & $9.5(1.5)$ & $9.7(1.3)$ \\
IVS-EDWT (mm) & $10.6(1.9)$ & $10.9(2.2)$ & $9.9(1.1)$ & $10.2(1.4)$ \\
LVEF (\%) & $54.8(11.2)$ & $57.9(10.2)$ & $51.5(13.6)$ & $52.9(13.2)$ \\
FS (\%) & $30.0(5.3)$ & $32.4(5.3)$ & $28.9(7.3)$ & $29.4(6.8)$ \\
LVM (g) & $169.9(58.4)$ & $193.7(60.7)$ & $186.8(46.8)$ & $191.2(61.8)$ \\
LVMi (g/m $\left.{ }^{2}\right)$ & $100.4(30.0)$ & $113.5(34.5)$ & $99.9(24.9)$ & $104.5(30.9)$ \\
LVMi $\left(\mathrm{g} / \mathrm{m}^{2.7}\right)$ & $44.4(14.1)$ & $50.0(15.7)$ & $44.4(11.1)$ & $45.2(16.0)$ \\
SV $(\mathrm{cc})$ & $69.0(13.2)$ & $74.8(17.3)$ & $79.3(16.6)$ & $76.8(20.9)$ \\
CO (L/min) & $4.8(0.8)$ & $5.2(1.2)$ & $5.8(1.3)$ & $5.5(1.2)$ \\
Cl (L/min/m $\left.{ }^{2}\right)$ & $2.9(0.5)$ & $3.0(0.7)$ & $3.2(0.8)$ & $3.2(0.7)$ \\
IVC (mm) & $16.2(5.7)$ & $17.1(3.8)$ & $17.2(3.2)$ & $18.4(4.9)$ \\
IVCi (mm/m $\left.{ }^{2}\right)$ & $9.7(3.1)$ & $10.4(2.1)$ & $9.1(1.6)$ & $10.0(2.4)$ \\
Systolic blood pressure (mmHg) & $126.5(28.0)$ & $127.7(29.8)$ & $148.5(23.1)$ & $154.3(24.4)$ \\
Diastolic blood pressure (mmHg) & $68.1(20.3)$ & $66.2(13.4)$ & $75.1(16.1)$ & $78.0(11.4)$ \\
Heart rate (beats/min) & $71(13)$ & $71(12)$ & $77(13)$ & $76(15)$ \\
Haemoglobin (mmol/l) & $6.7(0.8)$ & $7.0(0.8)$ & $6.4(0.9)$ & $7.1(1.3)$ \\
Serum creatinine (ì mol/l) & $469(234)$ & $571(213)$ & $475(164)$ & $562(224)$ \\
MDRD (ml/min/1.73 m $\left.{ }^{2}\right)$ & $12.54(7.5)$ & & $13.31(10.5)$ & \\
\hline
\end{tabular}

Table 6.3: Parameters before and after fistula creation. Left atrial diameter (LAD), left ventricular end-diastolic diameter (LVEDD), posterior wall end-diastolic wall thickness (PW-EDWT), interventricular septal end-diastolic wall thickness (IVS-EDWT), left ventricular ejection fraction (LVEF), fractional shortening (FS), left ventricular mass (LVM), left ventricular mass index (LVMi) either by body surface area $\left(\mathrm{g} / \mathrm{m}^{2}\right)$ or height ${ }^{2.7}\left(\mathrm{~g} / \mathrm{m}^{2.7}\right.$ ), stroke volume [SV], cardiac output (CO), cardiac index (CI), inferior vena cava (IVC), IVC indexed for body surface area (IVCi].

There were no significant differences in relative increase for the measured cardiac parameters between the two groups (Table 6.4). Only LVEDD tended to significant difference. LVEDD increased slightly in the BB-AVF group from $46.2 \pm 6.1$ to $48.0 \pm 7.5$, while it decreased in the PTFE-group from $51.7 \pm$ 8.3 to $50.9 \pm 8.2$ (Table 6.3). IVCi did not differ significantly between the two groups and limited increase was seen three month after the operation for each group. Fistula flow measured in the brachial artery was $1680 \pm 563$ 
$\mathrm{ml} / \mathrm{min}$ in the PTFE-group and $1450 \pm 733 \mathrm{ml} / \mathrm{min}$ in the BB-AVF group (NS). When patients with history of a previous access were excluded, this did not influence results on (lack of) difference in relative increase between two groups. Before operation $38 \%$ and $45 \%$ had $\mathrm{LVH}$ and after the operation $38 \%$ and 60\% had LVH in the PTFE and BB-AVF group respectively.

\begin{tabular}{|c|c|c|c|}
\hline & BB-AVF (SD) & PTFE (SD) & $\mathbf{P}$ \\
\hline $\mathrm{LAD}(\mathrm{mm})$ & $0.032(0.117)$ & $0.023(0.053)$ & NS \\
\hline LVEDD (mm) & $0.039(0.078)$ & $-0.014(0.086)$ & NS \\
\hline PW-EDWT (mm) & $0.004(0.086)$ & $0.020(0.062)$ & NS \\
\hline IVS-EDWT (mm) & $-0.005(0.062)$ & $0.033(0.111)$ & NS \\
\hline $\operatorname{LVEF}(\%)$ & $0.065(0.079)$ & $0.035(0.134)$ & NS \\
\hline FS (\%) & $0.083(0.144)$ & $0.036(0.166)$ & NS \\
\hline LVM $(g)$ & $0.092(0.148)$ & $0.020(0.178)$ & NS \\
\hline LVMi $\left(\mathrm{g} / \mathrm{m}^{2}\right)$ & $0.100(0.150)$ & $0.063(0.225)$ & NS \\
\hline LVMi $\left(\mathrm{g} / \mathrm{m}^{2.7}\right)$ & $0.092(0.148)$ & $0.014(0.168)$ & NS \\
\hline $\mathrm{SV}(\mathrm{cc})$ & $0.081(0.154)$ & $-0.027(0.168)$ & NS \\
\hline $\mathrm{CO}(\mathrm{L} / \mathrm{min})$ & $0.086(0.210)$ & $0.023(0.221)$ & NS \\
\hline $\mathrm{Cl}\left(\mathrm{L} / \mathrm{min} / \mathrm{m}^{2}\right)$ & $0.056(0.197)$ & $0.063(0.228)$ & NS \\
\hline IVC $(\mathrm{mm})$ & $0.151(0.413)$ & $0.068(0.203)$ & NS \\
\hline IVCi $\left(\mathrm{mm} / \mathrm{m}^{2}\right)$ & $0.163(0.418)$ & $0.111(0.254)$ & NS \\
\hline Systolic blood pressure (mmHg) & $0.030(0.217)$ & $0.051(0.178)$ & NS \\
\hline Diastolic blood pressure $(\mathrm{mmHg})$ & $0.031(0.290)$ & $0.086(0.289)$ & NS \\
\hline Heart rate (beats/min) & $0.006(0.098)$ & $-0.001(0.193)$ & NS \\
\hline
\end{tabular}

Table 6.4: Relative increase between before and after creation of AVF (Xafter - Xbefore / Xbefore). Left atrial diameter ( $L A D$ ), left ventricular end-diastolic diameter (LVEDD), posterior wall end-diastolic wall thickness (PW-EDWT), interventricular septal end-diastolic wall thickness (IVS-EDWT), left ventricular ejection fraction (LVEF), fractional shortening (FS), left ventricular mass (LVM), left ventricular mass index (LVMi) either by body surface area $\left(\mathrm{g} / \mathrm{m}^{2}\right)$ or height.7 $\left(\mathrm{g} / \mathrm{m}^{2.7]}\right.$, stroke volume (SV), cardiac output (CO), cardiac index (CI), inferior vena cava (IVC), IVC indexed for body surface area (IVCi).

\section{DISCUSSION}

In this study we have shown that the relative difference between the diastolic LV parameters did not differ significantly after three months between BB-AVF and prosthetic forearm graft implants. Access flow was also comparable at three months postoperatively. The effect of fistula creation on LV structure was limited; no significant increase in left ventricular parameters was seen.

It was hypothesized that due to the high flow in a BB-AVF cardiac load would be higher. However, similar blood volume flows were measured in the BB-AVF group compared to the PTFE forearm loop. An explanation for this observa- 
tion might be the fact that volume flow in the BB-AVF will enhance in time and that the observation period might have been too short, although the great majority of the flow increase of an arteriovenous fistula already occurs within the first three months after construction ${ }^{17}$.

In contrast to other studies, we did not find significant differences in cardiac parameters before and after creation of an AVF, especially shortly after creation of the AVF 6-8. Previous reports about LV function after fistula creation or ligation show that changes in LVM are mainly influenced by LVEDD. Most studies only assessed cardiac parameters shortly after fistula construction $^{6,8,12}$. As is suggested by lwashima et al. the increase in $\mathrm{CO}$ after creation of an AV fistula is induced directly by the increased volume flow of the fistula ${ }^{6}$. It has been shown that venous vessel diameter and blood volume flow increase occur within the first 2 weeks ${ }^{17}$ and can therefore explain the early increase seen in LV parameters. In a study with a comparable follow-up time compared to our study, Ori et al. observed a significantly elevated LVEDD shortly after fistula construction, which decreased again after one month and three months ${ }^{7}$. These data suggest that the heart adapts in the first few days by significant increase of the different left ventricular echocardiographic parameters, after which they decrease again to baseline values after several month. Therefore, the cardiac effects of the AV fistula may partly dissipate in the course of time. Another possible explanation for the absence of cardiac changes after fistula creation is an improvement in fluid state after initiation of dialysis, which would counteract the cardiac effects of the arteriovenous fistula. However, vena cava diameter, as a parameter of volume status, was not significantly different at the two time points. Besides, the changes in left ventricular end diastolic diameters and volumes after shunt creation are minor. This is clear when one calculates the net effect of adding two millimetres to a diameter in the Teichholtz formula. For example, when increasing LVEDD from 48 to $50 \mathrm{~mm}$, while all other parameters remain stable, stroke volume will increase $10 \mathrm{cc}$ per heartbeat. Multiplied by 70 heartbeats per min., this equals an increase of cardiac output of $700 \mathrm{ml}$. Adding some minor decrease in LVESD and increase in heart-rate and the shunt flow is reached. With access flows of $1500 \mathrm{ml} / \mathrm{min}$ it is therefore possible, that no significant cardiac changes are detected, especially in small groups like these combined with a small intra- and inter-observer variability.

The absence of changes in cardiac parameters after fistula creation is in contrast to the decrease in LVM observed after fistula ligation in renal transplant patients 5 . On the other hand, Hüting described that LVH did not regress after 
renal transplantation even in patients whose arteriovenous fistulas were thrombosed. This suggests that the stressors traditionally associated with AV fistula may be less important than was previously assumed ${ }^{18}$. Also Sheashaa et al. and De Lima et al. found no significant influence on LV mass and little impact on cardiac morphology and function in transplant patients with persistence of even large, high flow AVFs for prolonged periods of time ${ }^{19,20}$.

However, as in individual patients the cardiac effects of access may be clinically significant, even leading to high-output cardiac failure, we advice regular surveillance of both fistula flow and cardiac parameters.

Limitations of the study are the relative small number of patients, and the use of echocardiography instead of MRI to assess changes in cardiac parameters.

In conclusion, after creation of BB-AVF versus prosthetic forearm loop access changes in cardiac structure were limited and comparable three months postoperatively. Access flow was also comparable for the two groups at this time point. To elucidate the long term effects of different vascular accesses on cardiac status a longer follow up time may be needed. Despite our findings it is advisable to monitor the cardiac status of the individual patient to prevent high output cardiac failure.

\section{REFERENCES}

1. III. NKF-K/DOQI Clinical Practice Guidelines for Vascular Access: update 2000. Am J Kidney Dis. Jan 2001;37(1 Suppl 1):S137-181.

2. Tordoir JH, Mickley V. European guidelines for vascular access: clinical algorithms on vascular access for haemodialysis. Edtna Erca J. Jul-Sep 2003;29(3):131136.

3. Foley RN, Parfrey PS, Sarnak MJ. Clinical epidemiology of cardiovascular disease in chronic renal disease. Am J Kidney Dis. Nov 1998;32(5 Suppl 3):S112-119.

4. Kooman JP, Leunissen KM. Cardiovascular aspects in renal disease. Curr Opin Nephrol Hypertens. Sep 1993;2(5):791-797.

5. van Duijnhoven EC, Cheriex EC, Tordoir JH, et al. Effect of closure of the arteriovenous fistula on left ventricular dimensions in renal transplant patients. Nephrol Dial Transplant. Feb 2001;16(2):368-372.

6. Iwashima Y, Horio T, Takami Y, et al. Effects of the creation of arteriovenous fistula for hemodialysis on cardiac function and natriuretic peptide levels in CRF. Am J Kidney Dis. Nov 2002;40(5):974-982. 
7. Ori $\mathrm{Y}$, Korzets $A$, Katz $\mathrm{M}$, et al. The contribution of an arteriovenous access for hemodialysis to left ventricular hypertrophy. Am J Kidney Dis. Oct 2002;40(4):745-752.

8. Ori Y, Korzets A, Katz M, et al. Haemodialysis arteriovenous access-a prospective haemodynamic evaluation. Nephrol Dial Transplant. Jan 1996;11(1):94-97.

9. Anderson CB, Codd JR, Graff RA, et al. Cardiac failure and upper extremity arteriovenous dialysis fistulas. Case reports and a review of the literature. Arch Intern Med. Mar 1976;136[3]:292-297.

10. MacRae JM, Pandeya S, Humen DP, et al. Arteriovenous fistula-associated highoutput cardiac failure: a review of mechanisms. Am $J$ Kidney Dis. May 2004;43(5):e17-22.

11. Unger P, Velez-Roa S, Wissing KM, et al. Regression of left ventricular hypertrophy after arteriovenous fistula closure in renal transplant recipients: a long-term follow-up. Am J Transplant. Dec 2004;4[12):2038-2044.

12. Unger P, Wissing KM, de Pauw $L$, et al. Reduction of left ventricular diameter and mass after surgical arteriovenous fistula closure in renal transplant recipients. Transplantation. Jul 15 2002;74(1):73-79.

13. The Criteria Committee of the New York Heart Association. Nomenclature and criteria for diagnosis of diseases of the heart and great vessels. 9th ed. Boston, Massachusetts: Little, Brown \& Co; 1994:253-256.

14. Levey AS, Greene T, Kusek JW, et al. A simplified equation to predict glomerular filtration rate from serum creatinine [abstract]. J Am Soc Nephrol. 2000; 11:155A.

15. Lang RM, Bierig M, Devereux RB, et al. Recommendations for chamber quantification: a report from the American Society of Echocardiography's Guidelines and Standards Committee and the Chamber Quantification Writing Group, developed in conjunction with the European Association of Echocardiography, a branch of the European Society of Cardiology. J Am Soc Echocardiogr. Dec 2005;18(12):1440-1463.

16. Cheriex EC, Leunissen KM, Janssen $\mathrm{JH}$, et al. Echography of the inferior vena cava is a simple and reliable tool for estimation of 'dry weight' in haemodialysis patients. Nephrol Dial Transplant. 1989;4(6):563-568.

17. Wong V, Ward R, Taylor J, et al. Factors associated with early failure of arteriovenous fistulae for haemodialysis access. Eur J Vasc Endovasc Surg. Aug 1996;12(2):207-213.

18. Huting J. Course of left ventricular hypertrophy and function in end-stage renal disease after renal transplantation. Am J Cardiol. Dec 1 1992;70(18):14811484.

19. Sheashaa H, Hassan N, Osman Y, et al. Effect of Spontaneous Closure of Arteriovenous Fistula Access on Cardiac Structure and Function in Renal Transplant Patients. Am J Nephrol. Aug 11 2004;24[4]:432-437. 
20. De Lima JJ, Vieira ML, Molnar LJ, et al. Cardiac effects of persistent hemodialysis arteriovenous access in recipients of renal allograft. Cardiology. 1999;92(4):236-239. 
The relation between vascular access flow and different types of vascular access with systemic haemodynamics in haemodialysis patients

E. Wijnen, X.H.A. Keuter, R.N. Planken, F.M. van der Sande, J.H.M. Tordoir, K.M. Leunissen, J.P. Kooman

Artif Organs 2005; 29: 960-964. 


\section{ABSTRACT}

\section{Introduction}

Access flow $[Q a]$ has an important effect on systemic haemodynamics in dialysis patients. A Qa:cardiac output (CO) ratio higher than 0.3 is considered a risk factor for high-output cardiac failure. However, the effect of different types of vascular access in haemodialysis patients has not yet been studied. Aim of the present study was to assess the relationship between $Q$ a and systemic haemodynamics and to compare systemic haemodynamics between patients with elbow/upperarm access with forearm access types.

\section{Methods}

Qa, cardiac output (CO), cardiac index (Cl), central blood volume and peripheral vascular resistance (PVR) were studied by the saline dilution technique in 58 haemodialysis patients (18 elbow/upperarm access; 40 with forearm access types].

\section{Results}

Qa was significantly and positively related to $\mathrm{CO}$ and $\mathrm{Cl}$, and inversely to PVR. Central blood volume, $\mathrm{Q}$ a and presence of cardiac failure were independent determinants of $\mathrm{Cl}$. Qa and the Qa:CO ratio were significantly higher and PVR significantly lower in patients with elbow/upper arm access compared to forearm access types. When patients with cardiac failure were excluded, $\mathrm{CO}$ and $\mathrm{Cl}$ were also significantly higher in patients with elbow/upper arm access types. $11 \%$ of patients with elbow/upperarm fistula had a Qa:CO ratio above 0.3.

\section{Conclusion}

Qa is strongly related to systemic haemodynamics in dialysis patients. In patients without cardiac failure, $\mathrm{CO}$ and $\mathrm{Cl}$ are significantly higher in patients with elbow/upperarm access compared to patients with forearm access types. However, only a small percentage of patients with elbow/upperarm fistulae appeared to be in the risk zone for development of high-output cardiac failure. 


\section{INTRODUCTION}

Recent guidelines have advocated the construction of vascular access with native blood vessels instead of the use of artificial materials such as polytetrafluoroethylene (PTFE), because of the reduced graft survival and the increased incidence of stenotic and thrombotic complications associated with the latter approach. However, in various patients, construction of CiminoBrescia fistula may fail because of bad quality of the forearm vasculature. In such patients, construction of elbow (brachial-cephalic) or transposed brachial-basilic fistula, which is associated with long-term fistula patency, is often a good option? 1 .

Due to their generally higher access flow [Qa], elbow/upper arm fistula may have different haemodynamic effects on the heart compared to forearm fistula and grafts, leading to a hyperdynamic state ${ }^{2}$. Several case reports showed high-output cardiac failure in patients with high-flow fistula and improvement of cardiac function after closure of the fistula2-6. Moreover, in previous studies, a significant relation between cardiac output ( $\mathrm{CO}$ ) and Qa was observed ${ }^{7-9}$. To the best of our knowledge, the haemodynamic effects of forearm versus elbow/upper arm access types have not yet been investigated in larger patient groups. Moreover, with the introduction of the saline dilution technique, it has become possible to assess systemic haemodynamics during dialysis in an easy way ${ }^{10}$.

The aim of the present study was first, to assess the relation between cardiac function and access flow, and second, to compare the haemodynamic effects of elbow/upperarm fistula with those of forearm access types.

\section{PATIENTS AND METHODS}

\section{Patients}

After informed consent, 58 patients in our dialysis center were included in this study. Our haemodialysis population consists of 68 patients. Nine patients were dialyzed with central venous catheters and were thus not eligible for study. One patient had a thoracic loop and was also not included in the analysis. Forty patients had a forearm access, of whom 21 had radial-cephalic arteriovenous fistulas and 19 PTFE grafts. Eighteen patients had an elbow/upper arm access types, of whom 9 had brachial-cephalic and 9 transposed brachial-basilic arteriovenous fistulas. Mean age, weight, and height did 
not differ between patients with forearm and upper arm/elbow access types (Table 7.1), nor did the presence of diabetes mellitus. However, the prevalence of (pre-existent) cardiac failure (NYHA class III or higher) was higher in patients with elbow/upper arm access. In patients with cardiac failure, age was significantly higher compared to patients without cardiac failure $[80.0 \pm$ 9.5 versus $67.5 \pm 11.6$ years; $p<0.001$ ), whereas time on dialysis was shorter in patients with cardiac failure $(1.2 \pm 0.4$ years versus $3.9 \pm 2.6$ years; $p<0.001$ ).

\begin{tabular}{lccc}
\hline & Forearm access & $\begin{array}{c}\text { Elbow/upperarm } \\
\text { access }\end{array}$ & $\mathbf{P}$ \\
\hline $\mathrm{N}$ & 40 & 18 & \\
Age & $71 \pm 11$ & $67 \pm 14$ & n.s. \\
Predialytic systolic BP & $139 \pm 28$ & $129 \pm 27$ & n.s. \\
Height $(\mathrm{cm})$ & $168 \pm 9$ & $170 \pm 7$ & n.s. \\
Weight $(\mathrm{kg})$ & $67 \pm 12$ & $67 \pm 13$ & n.s. \\
Diabetes mellitus & $6(15 \%)$ & $2(11 \%)$ & n.s. \\
Cardiac failure & $3(8 \%)$ & $6(33 \%)$ & P $<0.05$ \\
Time on dialysis (years) & $3.7 \pm 2.7$ & $2.9 \pm 2.6$ & n.s. \\
\hline
\end{tabular}

Table 7.1: Patient characteristics. Values expressed as mean $\pm S D$. BP = blood pressure.

\section{Dialysis strategy}

Patients were treated with bicarbonate haemodialysis with low flux polysulfone membranes (F8HPS; Fresenius; Bad Homburg or Polyflux 8L; Gambro; Lund; Sweden). Fresenius 4008H dialysis modules (Bad Homburg; Germany) were used. Sodium concentration of the dialysate was 138 or $140 \mathrm{mmol} / \mathrm{l}$, calcium concentration was $1.5 \mathrm{mmol} / \mathrm{l}$ and temperature of the dialysate was 35.5, 36 or 36.5 $\square$ C. Ultrapure dialysate was used, achieved by double reverse osmosis, electric deionisation, ozone sanitisation and filtration through Diasafe (Fresenius Bad Homburg; Germany) or U8000 (Gambro; Lund: Sweden) membranes.

\section{Study protocol}

Measurements were performed on a midweek dialysis. Immediately after the start of dialysis, cardiac function was assessed by the saline dilution method (Transonic; Ithaca; USA). Hereafter, access flow was assessed, also by the saline dilution technique. 


\section{Statistical analysis}

The relation between access flow and cardiac function was assessed by Pearson's r. The relation between $\mathrm{Qa}$ and $\mathrm{Cl}$ was also studied using multiregression analysis (enter method), with presence of (pre-existent) cardiac failure, age, sex, systolic blood pressure, $\mathrm{Qa}$, diabetes mellitus and central blood volume index (central blood volume indexed for body weight) as independent variables. Differences between patients with elbow/upperarm access and those with forearm access was assessed by the unpaired Student t-test [SPSS 12.0]. A p-value below 0.05 was considered significant.

Access flow measurements and assessment of systemic haemodynamic parameters by the saline dilution technique

Qa was assessed as described previously and expressed as the mean of three measurements ${ }^{11}$. CO, cardiac index (Cl), central blood volume and peripheral vascular resistance (PVR) were assessed by the saline dilution technique (Transonic HD 01; Transonic Systems; Ithaca NY; USA) as described in detail elsewhere 10,12 . In short: a heated $\left(37^{\circ} \mathrm{C}\right.$ ) bolus of $30 \mathrm{ml} \mathrm{NaCl} 0.9 \%$ (indicator) is injected into the venous line with the blood pump speed set at 200 $\mathrm{ml} / \mathrm{min}$, and the change in velocity of ultrasound waves produced by the returning dilution curve (S) is detected by a probe attached to the arterial line.

By comparing the dilution curve with a calibration curve (Scal), produced by injecting $10 \mathrm{ml}$ of isotonic saline in the venous bubble trap, $\mathrm{CO}$ is calculated by the formula: 3 * blood flow * (S/Scal). CBV, which is considered to be the blood in the heart, great vessels (pulmonary artery and veins and ascending aorta) and the lung capillaries, is calculated by multiplication of $\mathrm{CO}$ with the mean transit time of the indicator, corrected for travel time in the arterial and venous blood line. Peripheral vascular resistance (PVR) was calculated by dividing mean arterial pressure, assessed by an oscillometric method (Omron M4-I; Omron Healthcare; West Sussex; UK) by CO. PVR was also corrected for body surface area (PVRI = peripheral vascular resistance index).

Coefficient of variation of $\mathrm{CO}$ between subsequent measurements, obtained in 12 patients, was $8.3 \%{ }^{10}$. Coefficient of variation for $\mathrm{CO}$ performed at the start of two dialysis sessions, separated by a one week period, was $17.6 \%$. 


\section{RESULTS}

\section{Relation between Qa and systemic haemodynamics}

Qa, measured directly after the start of haemodialysis, was significantly different between patients with forearm access and elbow/upper arm access types (Table 7.2). Of the patients with elbow/upper arm access types, Qa was not different between patients with brachio-cephalic $(1245 \pm 539 \mathrm{ml} / \mathrm{min})$ or transposed brachial-basilic fistulas (1454 $\pm 539 \mathrm{ml} / \mathrm{min}$ ). Of the patients with forearm access types, Qa was also not different between patients with radialcephalic fistulas (935 $\pm 415 \mathrm{ml} / \mathrm{min}$ ) or PTFE grafts $(814 \pm 408 \mathrm{ml} / \mathrm{min}$ ).

Two patients (11\%) with elbow/upper arm access and none of the patients with forearm had a Qa:CO ratio above 30\% (highest value 32\%).

Pooling all patients, Qa was significantly related to $C O(r=0.53 ; p<0.001)$, $\mathrm{Cl}(r=0.56 ; p<0.001)$ (Figure 7.1), stroke volume $(r=0.43 ; p<0.01)$, peripheral vascular resistance and resistance index $(r=-0.26$ and $r=-0.26$; $p<0.05$ ), systolic and diastolic blood pressure ( $r=0.36$ and $r=0.43 ; p<0.01$ ). With multiregression analysis (strength of model: $r^{2}=0.63 ; p<0.001$ ), cen-

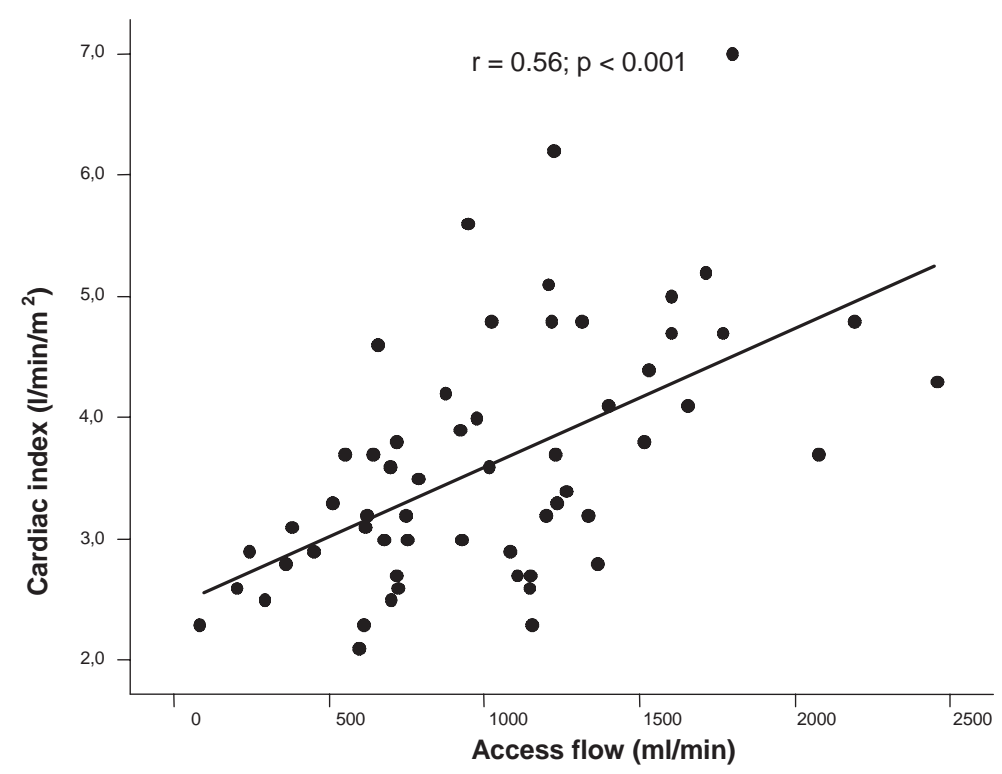

Figure 7.1: Relation between cardiac index and access flow. 


\begin{tabular}{lccc}
\hline & Forearm access & $\begin{array}{c}\text { Elbow/upperarm } \\
\text { access }\end{array}$ & $\mathbf{P}$ \\
\hline $\mathrm{N}$ & 40 & 18 & \\
Systolic BP $(\mathrm{mm} \mathrm{Hg})$ & $139 \pm 28$ & $129 \pm 27$ & n.s. \\
Diastolic BP $(\mathrm{mm} \mathrm{Hg})$ & $70 \pm 13$ & $66 \pm 19$ & n.s. \\
PVR $(\mathrm{mm} \mathrm{Hg} / \mathrm{min} / \mathrm{L})$ & $15.4 \pm 4.4$ & $13.0 \pm 2.0$ & $\mathrm{P}<0.05$ \\
$\mathrm{PVRI}\left(\mathrm{mm} \mathrm{Hg} / \mathrm{min} / \mathrm{L} / \mathrm{m}^{2}\right)$ & $27.1 \pm 7.5$ & $23.0 \pm 5.0$ & $\mathrm{P}<0.05$ \\
Qa $(\mathrm{mL} / \mathrm{min})$ & $878 \pm 411$ & $1350 \pm 560$ & $\mathrm{P}<0.001$ \\
$\mathrm{CO}(\mathrm{L} / \mathrm{min})$ & $6.4 \pm 1.9$ & $6.9 \pm 2.1$ & n.s. \\
$\mathrm{Cl}\left(\mathrm{L} / \mathrm{min} / \mathrm{m}^{2}\right)$ & $3.6 \pm 1.0$ & $3.9 \pm 1.0$ & n.s. \\
$\mathrm{CBV}(\mathrm{L})$ & $1.52 \pm 0.53$ & $1.48 \pm 0.67$ & n.s. \\
$\mathrm{CBVI}(\mathrm{L} / \mathrm{kg})$ & $23.7 \pm 7.5$ & $22.7 \pm 11.0$ & $\mathrm{n} . \mathrm{s}$. \\
$\mathrm{Qa}: \mathrm{CO}(\%)$ & $14.0 \pm 6.0$ & $20.0 \pm 7.6$ & $\mathrm{P}<0.01$ \\
$\mathrm{CO}(\mathrm{L} / \mathrm{min})$ & $6.5 \pm 2.0$ & $7.7 \pm 1.9$ & $\mathrm{P}=0.05$ \\
$\mathrm{Cl}\left(\mathrm{L} / \mathrm{min} / \mathrm{m}^{2}\right)$ & $3.6 \pm 1.0$ & $4.3 \pm 1.0$ & $\mathrm{P}<0.05$ \\
\hline
\end{tabular}

Table 7.2: Differences in systemic haemodynamic between patients with forearm and elbow/upperarm access types. Values expressed as mean $\pm S D$. * Patients with cardiac failure excluded. BP, blood pressure; PVR, peripheral vascular resistance; PVRI, peripheral vascular resistance index; $\mathrm{Qa}$, access flow; $\mathrm{CO}$, cardiac output; $\mathrm{Cl}$, cardiac index; CBV, central blood volume; CBVI, central blood volume index.

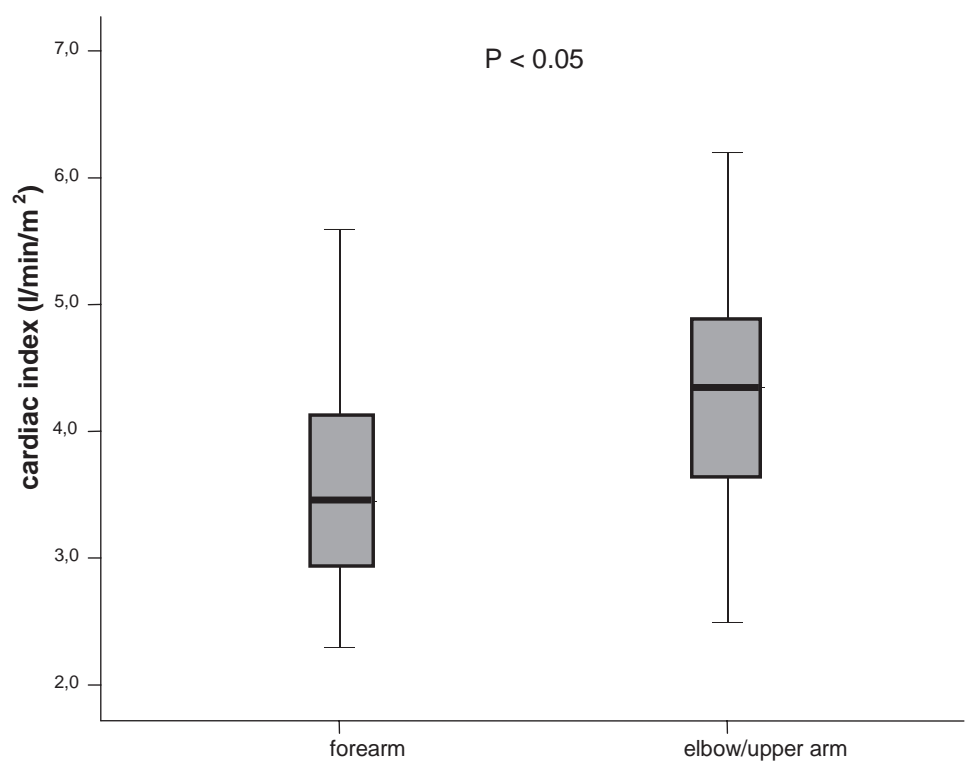

Figure 7.2: Difference in cardiac index between patients with forearm access and elbow/upperarm access in patients without cardiac failure. Notes: Box indicates $25^{\text {th }}$ and $75^{\text {th }}$ percentiles (thick line is median value]. Capped bars indicate minimum and maximum value [excluding outliers]. 
tral blood volume (indexed for body weight) $(\beta=0.40 ; t=4.4 ; p<0.001)$, age $(\beta=-0.36 ; t=-3.5 ; p=0.001)$, and $Q a(B=0.48 ; t=4.8 ; p=0.001)$ were independently related to $\mathrm{Cl}$, whereas after exclusion of age from the model, presence of pre-existent cardiac failure became a significant predictor $(\beta=-0.30 ; t=-2.8 ; p<0.01)$.

PVR and PVRI were significantly lower in patients with elbow/upper arm access compared to patients with forearm access, whereas $\mathrm{Qa}$ and the Qa:CO ratio were significantly higher (Table 7.2). $\mathrm{CO}$ and $\mathrm{Cl}$, in the overall group, was not significantly different between patients with forearm and elbow/upper arm access types. However, when patients with cardiac failure were excluded, $\mathrm{Cl}$ was significantly higher in patients with elbow/upper arm access (Table 7.2, Figure 7.2).

\section{DISCUSSION}

This study showed a significant relation between $\mathrm{Qa}$ and systemic haemodynamics, and significant differences in systemic haemodynamics between patients with elbow/upper arm and forearm access. Qa was significantly and positively related to $\mathrm{CO}$ and $\mathrm{Cl}$, and inversely to PVR. Multiregression analysis showed that CBV, an index of systemic filling, presence of cardiac failure, and $\mathrm{Qa}$ were important determinants of $\mathrm{Cl}$. The strong relation between $\mathrm{Qa}$ and $\mathrm{CO} / \mathrm{Cl}$ is in agreement with previous studies on this subject7,9. Of course, systemic haemodynamics per se may also influence $Q a$, as also shown by the relation between $\mathrm{Qa}$ and systemic blood pressure in the present study. However, this would not explain the higher $\mathrm{CO}$ in patients with elbow/upper arm fistula, as described below, despite comparable blood pressure values.

As expected, Qa was significantly higher in patients with elbow/upper arm fistula. Whereas in the overall group, $\mathrm{CO}$ or $\mathrm{Cl}$ were not significantly higher in patients with elbow/upper arm access compared to patients with forearm access types, this is probably due to the presence of confounding variables, such as pre-existent cardiac failure. The prevalence of pre-existent cardiac failure was higher in patients with elbow/upper arm access, which is likely due to the impaired quality of blood vessels in these patients, which necessitated the construction of other access types than standard radial-cephalic arteriovenous fistulas. Indeed, when patients with systemic cardiac failure were excluded from the analysis, $\mathrm{CO}$ and $\mathrm{Cl}$ were significantly higher in patients with elbow/upper arm fistula. 
The parameter which was most clearly different between patients with forearm and upperarm fistula was the Qa:CO ratio, a parameter introduced by Pandeya and Lindsay7. As mentioned previously, it has been suggested that a ratio of Qa:CO ratio above 0.3 is a risk factor for high output cardiac failure ${ }^{5}$. In our study in which patients with pre-existent cardiac failure were also included, only $11 \%$ of patients with elbow/upperarm fistula and none of the patients with forearm access had a $\mathrm{Qa} / \mathrm{CO}$ ratio above 0.3 , whereas the highest measured $\mathrm{Qa} / \mathrm{CO}$ ratio was 0.32 .

A drawback of the study is the cross-sectional design with measurements obtained during a single dialysis session, and the absence of echocardiographic data. Longitudinal studies with echocardiographic measurements are needed to assess the influence of $\mathrm{Qa}$ and different access types on cardiac structure. Moreover, radial-cephalic arteriovenous fistulas and PTFE grafts were not analyzed separately, nor were brachial-cephalic and transposed brachialbasilic arteriovenous fistulas. However, no difference in Qa was observed between the different forearm access types, nor between brachial-cephalic and transposed brachial-basilic arteriovenous fistulas.

Lastly, although only a small percentage of the patients with upperarm/elbow fistulas appeared to be in the risk zone for development of high-output cardiac failure, it should be acknowledged that the proposed Qa:CO ratio of 0.3 has not yet been validated in prospective trials 5 .

\section{CONCLUSION}

Qa is strongly related to systemic haemodynamics in dialysis patients. In patients without cardiac failure, $\mathrm{CO}$ and $\mathrm{Cl}$ are significantly higher in patients with elbow/upper arm access compared to patients with forearm access. However, only a small percentage of patients with elbow/upperarm fistulae appeared to be in the risk zone for development of high-output cardiac failure. However, longitudinal studies are needed to assess the influence of different access types on structural cardiac changes. 


\section{REFERENCES}

1. III. NKF-K/DOQI Clinical Practice Guidelines for Vascular Access: update 2000. Am J Kidney Dis. Jan 2001;37(1 Suppl 1):S137-181.

2. Murray BM, Rajczak S, Herman A, et al. Effect of surgical banding of a high-flow fistula on access flow and cardiac output: intraoperative and long-term measurements. Am J Kidney Dis. Dec 2004;44(6):1090-1096.

3. Dikow R, Schwenger V, Zeier M, et al. Do AV fistulas contribute to cardiac mortality in hemodialysis patients? Semin Dial. Jan-Feb 2002;15(1):14-17.

4. Engelberts I, Tordoir JH, Boon ES, et al. High-output cardiac failure due to excessive shunting in a hemodialysis access fistula: an easily overlooked diagnosis. Am J Nephrol. 1995;15[4]:323-326.

5. MacRae JM, Pandeya S, Humen DP, et al. Arteriovenous fistula-associated highoutput cardiac failure: a review of mechanisms. Am J Kidney Dis. May 2004;43[5]:e17-22.

6. Anderson CB, Codd JR, Graff RA, et al. Cardiac failure and upper extremity arteriovenous dialysis fistulas. Case reports and a review of the literature. Arch Intern Med. Mar 1976;136(3):292-297.

7. Pandeya S, Lindsay RM. The relationship between cardiac output and access flow during hemodialysis. Asaio J. May-Jun 1999;45(3):135-138.

8. Besarab A, Lubkowski T, Vu A, et al. Effects of systemic hemodynamics on flow within vascular accesses used for hemodialysis. Asaio J. Sep-Oct 2001;47[5]:501-506.

9. Polkinghorne KR, Atkins RC, Kerr PG. Determinants of native arteriovenous fistula blood flow. Nephrology (Carlton). Aug 2004;9(4):205-211.

10. Beerenhout C, Dejagere T, van der Sande FM, et al. Haemodynamics and electrolyte balance: a comparison between on-line pre-dilution haemofiltration and haemodialysis. Nephrol Dial Transplant. Sep 2004;19(9):2354-2359.

11. Krivitski NM. Theory and validation of access flow measurement by dilution technique during hemodialysis. Kidney Int. Jul 1995;48(1):244-250.

12. Krivitski NM, Depner TA. Cardiac output and central blood volume during hemodialysis: methodology. Adv Ren Replace Ther. Jul 1999;6[3]:225-232. 
Brachial artery thrombosis due to haemodialysis arteriovenous fistula

X.H.A. Keuter, R.N. Planken, F.M. van der Sande, J.H.M. Tordoir

Nephrol Dial Transplant 2006; 21: 829-830. 
Arterial dilatation proximal of dialysis vascular access is induced by large blood flows through the arteriovenous fistula (AVF). Aneurysmal clot formation and subsequently thrombosis can initiate distal embolism and ischaemia of the hand. We describe a patient with symptomatic hand ischaemia due to a thrombosed brachial artery and a previous vascular access in the same extremity.

A 49-year old male was presented with a painful swelling in the left upper arm and claudication of the hand. Medical history showed end-stage renal disease with renal replacement therapy by haemodialysis treatment. Vascular access was obtained through a radial-cephalic arteriovenous fistula (RC-AVF) at the left wrist for four years. After a successful renal transplant the AVF was ligated. At that time the brachial artery diameter was $14 \mathrm{~mm}$ and access blood flow was $2.2 \mathrm{I} / \mathrm{min}$. Immunosuppressive medication was used to prevent rejection.

At time of admission the angiography showed a dilated brachial artery, with thrombus formation obstructing the lumen almost completely with prolongation into the proximal radial and ulnar artery (Figure 8.1). The dilated and thrombosed brachial artery was decompressed by declotting and subsequent-

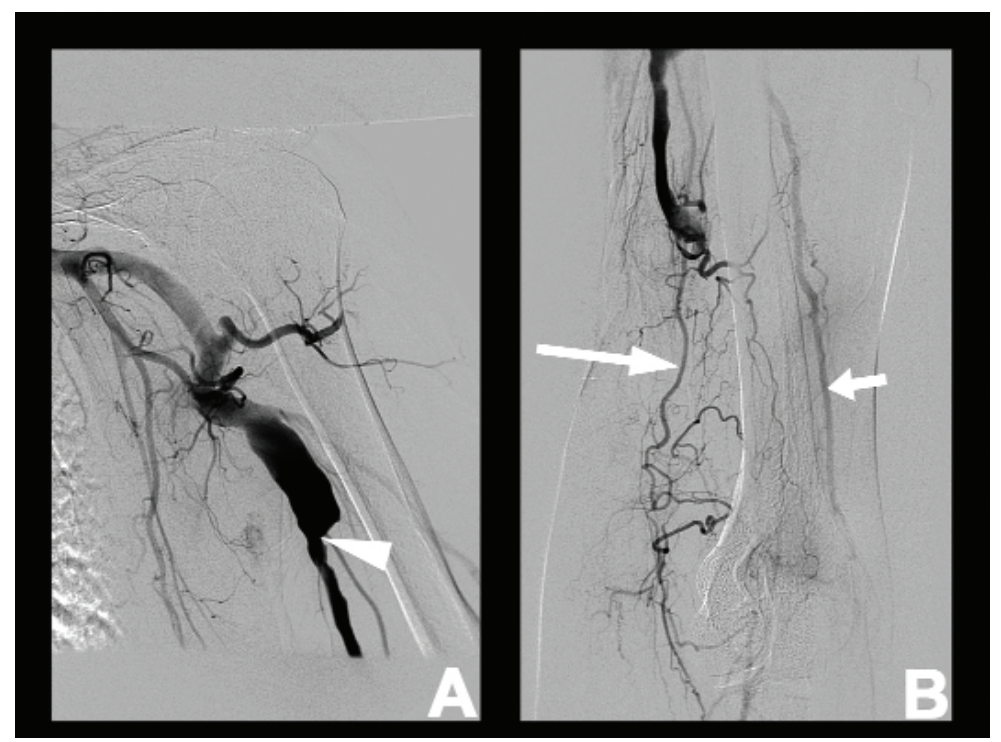

Figure 8.1: Digital Subtraction Angiography recordings of the brachial artery: (A) the arrowhead points at tapering of the brachial artery due to thrombus with a compete occlusion distally (B). Collaterals [arrows] preserve the perfusion to the radial and ulnar arteries. 
ly ligated. Revascularisation by a reversed saphenous vein bypass from the axillary to the brachial artery was executed. Postoperatively, pulsations at the wrist reappeared and the hand perfusion recovered.

Arterial dilatation proximally to an AVF may increase over time and is correlated to high flow and shear stress. Flow triggers the release of relaxing substances from vascular endothelial cells which have characteristics similar to the endothelium-derived relaxing factor released by acetylcholine ${ }^{1}$. Fragmentation of elastic tissue, atrophy of vascular smooth muscle cells, increased fibrosis, intimal thickening and calcifications have been reported in the arterial wall of aneurysms proximal to AVFs? ${ }^{2}$. Also thrombus formation in the aneurysmatic artery may cause vessel occlusion and/or emboli jeopardizing the distal perfusione,3.

Eugster et al. reported that the dilatation is more a local rather than a systemic effect ${ }^{3}$. Furthermore, arterial dilatation is known to develop earlier and more frequently in patients receiving steroids for autoimmune disease ${ }^{4}$.

We hypothesize that the arterial vessel wall has degenerated due to altered haemodynamics during the presence of the forearm RC-AVF. After surgical closure of the AVF the bloodflow will return to normal values. This relatively low flow may result in stasis and clot formation in the aneurysmatic sac and subsequently thrombosis with distal perfusion impairment and peripheral ischaemia. Treatment by means of ligation of the aneurysm and creation of an arterial bypass has been shown effective in this case and other reports 5 .

In summary, late aneurysm formation, after surgical closure of a dialysis AVF may occur. Although a high blood flow, shear stress and immunosuppressive therapy may play a major role in the aneurysm formation, the exact mechanism is not clear.

\section{REFERENCES}

1. Rubanyi GM, Romero JC, Vanhoutte PM. Flow-induced release of endothelium-derived relaxing factor. Am J Physiol. Jun 1986;250(6 Pt 2):H1145-1149.

2. Sako Y, Varco RL. Arteriovenous fistula: results of management of congenital and acquired forms, blood flow measurements, and observations on proximal arterial degeneration. Surgery. Jan 1970;67(1):40-61. 
3. Eugster T, Wigger P, Bolter S, et al. Brachial artery dilatation after arteriovenous fistulae in patients after renal transplantation: a 10-year followup with ultrasound scan. J Vasc Surg. Mar 2003;37(3):564-567.

4. Sato 0, Takagi A, Miyata T, et al. Aortic aneurysms in patients with autoimmune disorders treated with corticosteroids. Eur J Vasc Endovasc Surg. Oct 1995;10(3):366-369.

5. Melliere D, Hassen-Khodja R, Cormier JM, et al. Proximal arterial dilatation developing after surgical closure of long-standing posttraumatic arteriovenous fistula. Ann Vasc Surg. Jul 1997;11(4):391-396. 
General discussion and conclusions 
Renal replacement therapy and the role of secondary vascular access procedures for chronic intermittent haemodialysis treatment

In end stage renal disease (ESRD) patients the irreversible loss of endogenous renal function makes the patient permanently dependent upon renal replacement therapy. This therapy can be achieved by haemodialysis, peritoneal dialysis and renal transplantation. In the Netherlands about 45\% of the ESRD population relies on dialysis treatment ${ }^{1}$. To facilitate connection to the artificial kidney for blood withdrawal and purification a functional vascular access is mandatory. The dialysis population increases in size and has a higher age with associated co-morbidities and increased life expectancy. In this population it will be frequently impossible to create a functional primary autogenous radialcephalic wrist fistula, forcing vascular access by means of second and third choice operative procedures. International guidelines 2 , 3 do prefer autogenous fistulas not only as a primary, but also as secondary vascular access, because of superior (long-term) patency rates and low incidence of thrombosis. Although numerous, usually retrospective, studies on the performance of autogenous fistulas have been published, randomised controlled clinical trials are scarce, particularly about the outcome of second or third choice vascular accesses like the brachial-basilic arteriovenous fistula (BB-AVF) and forearm prosthetic graft implantation2-4. Major drawbacks of the creation of brachial artery-based vascular accesses may be the high volumes of shunted blood, initiating cardiac output increase leading to high-output cardiac failure, and steal of blood from distal tissues leading to hand ischaemia. These phenomena are less common in radial artery-based AVFs ${ }^{5-9}$, because of lower access flows without compromised collateral blood supply to the hand.

The aim of this thesis was to investigate autogenous upper arm fistulas and forearm prosthetic graft implants as a secondary vascular access for haemodialysis in a randomised controlled clinical trial.

Chapter 2: Review on autogenous arteriovenous fistula options as secondary \& tertiary vascular access

Diseased and/or small arteries and veins may preclude successful creation of distal radial-cephalic (RC) AVF, but they do not exclude the possibility of creation of proximally located AVFs with anastomosis to the mid-forearm or elbow/upper arm artery 10,11 . This implies that autogenous AVFs are also possible in elderly, co-morbid and obese patients, in particular when innovative surgical techniques are employed like elevation and/or transposition of deeply 
or dorsally positioned veins ${ }^{12-14}$. These veins are protected against iatrogenic damage and can be detected by pre-operative clinical and ultrasound duplex investigation. Whenever forearm access options are not possible or when they have failed, access options remain at the elbow and upper arm site, with the anastomosis between brachial artery and cubital or cephalic vein (brachial-cubital = Gracz fistula and brachial-cephalic), or between the brachial artery and basilic vein $11,15-19$. The deeply and medially located basilic vein is inaccessible for cannulation and needs therefore to be superficialised. This procedure is done in either a one- or a two-staged operation. The patency rates of basilic vein superficialisation are similar for either a transposition or elevation technique and a one- or a two-staged operation20. Alternative upper arm options are the brachial-brachial vein superficialisation AVF and the brachial-axillary translocated superficial femoral vein harvested from the thigh21,22. Whenever upper arm or thorax AVF sites (ipsilateral subclavian artery to subclavian vein loop access or contralateral subclavian artery to subclavian vein straight access) are not possible, autogenous AVF with the use of saphenous and superficial femoral veins in the thigh may be opted for. These usually high flow accesses are associated with steal and high incidence of ischaemia and infection. The role of prosthetic graft material is an option whenever autogenous fistulas or autologeous grafts have failed.

The innovative surgical procedures, required for secondary and tertiary access, need experience and good preoperative clinical and duplex vessel assessment. Especially in patients with a longer life expectancy, it is worthwhile to investigate these exotic options before moving to a more proximal level. In older patients with limited life expectancy the need for a proper functioning fistula is usually for a shorter period and options with prosthetic graft implantation at familiar sites may be used as there is more experience with the latter operations.

\section{Chapter 3: Brachial-basilic vein transposed fistulas: retrospective study} indicates high maturation and patency rates

In a retrospective study the results of one-staged basilic vein transposition were evaluated. Despite previous vascular access failure in $80 \%$ of the patients, excellent maturation rates and secondary patency rates were achieved. Literature reports non-maturation and early failure in 38\% of patients, in particular in patients over 60 years of age $23-25$. In the current study only one out of 32 patients (3\%) had non-maturation and required another vascular access. The enlarged basilic vein diameter, initiated by pre- 
vious ipsilateral forearm vascular access with associated increased blood flows, may explain our high maturation rate. On the other hand, high maturation rates are also reported in diabetic patients, of which only $15 \%$ had a previous ipsilateral access 25 . Other explanations for high non-maturation rates in the literature may be the learning curve for the operation and poor preoperative vessel assessment by duplex scanning.

The excellent assisted-primary and secondary patency rates in our patient population are explained by close monitoring and pre-emptive intervention in case of access flow decline in the dialysis facility. Nowadays, vascular access monitoring is mandatory and advised in most guidelines and do result in increased assisted-primary patencies. The surgical strategy regarding one- or two-staged BB-AVF creation results in similar outcomes 20,26 , although El Mallah showed better results of the one-staged procedure in a randomised trial27. The advantage of a two-staged procedure may be vein arterialisation and dilatation which could favour secondary superficialisation with low risk of vessel damage. Hossny et al. have shown similar performance of transposition and elevation techniques20. Due to its medial location, the elevated basilic vein may be difficult to cannulate, making it prone to miscannulation, haematoma and aneurysm formation, and thrombosis. The practice of only one operation is more convenient for the patient, cost-effective and results in excellent assisted-primary and secondary patency rates with a very low early failure percentage to maturation.

Chapter 4: Randomised controlled trial shows better primary patency of brachial-basilic AVF compared to forearm prosthetic arteriovenous graft

In chapter 4, the results of a randomised multicenter controlled trial between the one-staged BB-AVF and the prosthetic forearm loop arteriovenous graft (AVG), as a third choice vascular access, are described. BB-AVFs needed fewer interventions to prevent access failure compared to prosthetic AVGs.

Basilic vein quality and suitability as access conduit are usually excellent. Due to the deep location of the basilica vein it is not damaged by repeated iatrogenic vein punctures and intravenous lines 28 . Although the construction of a BB-AVF may be a challenging operation, inability to create a BB-AVF occurred only in $3.9 \%$ of patients due to a small diameter of the basilic vein. In a similar percentage it was not possible to create a forearm prosthetic AVG due to insufficient arterial inflow associated with low blood pressure. Thus, in $4 \%$ of patients we were unable to create BB-AVFs or prosthetic AVGs. This is in con- 
cordance with the literature reporting 5 to $7 \%$ of the basilic veins as inadequate because of small calibers $23,28,29$. Short basilic veins can be transposed together with adjacent segments of the deep venous system to gain sufficient length for cannulation. Non-maturation may be an important drawback of BBAVF, but in this randomised study it occurred in only $4 \%$ of the patients. Published early failure rates of up to 38\%, even for primary accesses like RCAVFs, corroborate that our results are very good considering a tertiary vascular access option24,30,31. Hakaim et al. have shown in diabetics better maturation rates of BB-AVFs compared to RC-AVFs25. The incidence rates of thrombosis and infections were significantly lower in the randomized patients with BB-AVFs as compared to the literature, which reflects the importance of monitoring and pre-emptive intervention22,28,32.

The primary patency rates of both groups were lower as compared to the literature 20,23-25,33-40. Pre-emptive interventions in fistulas at risk for thrombosis becomes standard and results in lower primary but higher assisted-primary and secondary patency rates. We prefer the BB-AVF as the choice for tertiary access because fewer interventions with better primary and assisted-primary patency rates compared to the prosthetic implant group are achieved. In addition when BB-AVFs do fail, it remains possible to construct prosthetic AVGs in most patients ${ }^{41}$. The question remains how to manage old patients, with limited life expectancy and multiple co-morbidities, needing urgent vascular access. One may argue that in these high risk patients prosthetic graft implantation with immediate accessibility for cannulation is preferred, as these patients do probably not need a second access because of life expectancy. Moreover, for timely referrals to the vascular surgeon the maturation period is of less importance. In a relatively old population (mean age $64 \mathrm{yrs}$ ), we did find significantly more complications and interventions in patients with prosthetic AVGs. A non-randomised study focussing on elderly patients showed that grafts had better secondary patency even after three years compared to autogenous AVFs 42 . The latter study, however, contained a majority of autogenous RC-AVFs and brachial-axillary grafts. It would be more applicable to consider the results of a forearm loop AVG and BB-AVF in an older population of over 70 years of age, as this is a fast growing dialysis group with multiple co-morbidity and thus frequently in need for a third choice vascular access.

The limitation of our randomised study is the short follow up time. Prosthetic AVG do have low long-term patency and thus secondary patency will be significantly better in BB-AVF after a longer follow up time. 
Chapter 5: Ischaemia in brachial-basilic AVF and prosthetic AVG is hard to predict

Minor or major amputations due to ischaemia have been reported after vascular access creation in ESRD patients $7,8,43$. Ischaemia occurs more frequently in brachial-based fistulas compared to forearm fistulas ${ }^{9}$. Up to $25 \%$ of patients with an upper arm fistula may develop hand ischaemia43-46. Reported predictors for ischaemia are age, diabetes, multiple previous vascular access, hypertension, peripheral arterial obstructive disease, coronary artery disease, and female gender8,47-51. In chapter 5, we investigated possible clinical and non-invasively measured parameters for the prediction of ischaemia and incidence rates in BB-AVFs and prosthetic AVGs. In a multivariate backwards Cox-regression, a high radial artery volume flow before operation and history of peripheral arterial reconstructions in the leg were identified as independent predictors for ischaemia. Also age showed a tendency to statistical significance. The digit-brachial index (DBI) might be an important surveillance method and can indicate whether a patient will develop ischaemia or not, although there is still no agreement about cut-off values for the DBI [0.60 to 1.00$)^{4,48,49,52-54}$. Sequential DBI measurements seem to be more accurate to detect ischaemia than a single measurement at any time point. We could not find any difference in incidence of ischaemia between the BBAVF and AVG, while published data usually show greater percentages of ischaemia in BB-AVF accesses 55 . Because of a $28 \%$ incidence of ischaemic symptoms in this population, close monitoring is mandatory and interventional treatment is advocated when grade 3 to 4 ischaemia occurs ${ }^{3}$.

\section{Chapter 6: Cardiac performance after creation of brachial-basilic AVF and prosthetic AVG}

High-output cardiac failure may be induced by haemodialysis vascular access and may have a devastating outcome ${ }^{5,6}$. Up to $75 \%$ of pre-dialysis ESRD patients have left ventricular hypertrophy $(\mathrm{LVH})^{56}$. LVH is an adaptive response to increased cardiac load, but may lead to systolic or diastolic cardiac failure, and is strongly related to mortality in dialysis patients. We hypothesized that high volume flows in upper arm BB-AVFs lead to a greater increase in cardiac load as compared to forearm AVG. To investigate the expected difference in cardiac load, pre- and postoperative echocardiography was performed in both groups; surprisingly various left ventricular parameters for cardiac load did not increase significantly after operation. This observation is in contrast with similar short-term studies, showing significant 
increase in several cardiac function parameters $57-59$. We conclude from these publications and our studies that cardiac response after arteriovenous fistula creation might be strongest directly after operation but returns to baseline values within several months60. From our data it appeared that changes in left ventricular parameters were generally small, although incidentally high output cardiac failure might occur in patients with extreme high-flow AVFs and/or cardiac compromised patients. The use of magnetic resonance imaging (MRI) or real-time 3D echocardiography to assess left ventricular performance might improve measurements with possibly a different outcome regarding cardiac workload after access operation ${ }^{61}$. Furthermore, it would be useful to have several measurements during the follow up of the vascular access.

Chapter 7: Access flow and cardiac output in fore- and upper arm vascular access

To assess the relationship between access flow and cardiac function and to compare the haemodynamic effects of elbow/upper arm fistula with forearm vascular access types, we measured access flow and systemic haemodynamic parameters, like cardiac output (CO), Cardiac Index (CI), central blood volume (CBV), and peripheral vascular resistance (PVR) by the saline dilution technique. A significant relation between access flow and $\mathrm{CO}, \mathrm{Cl}$, stroke volume, PVR and resistance index, systolic and diastolic pressure was shown: both $\mathrm{Qa}$ and the $\mathrm{Qa} / \mathrm{CO}$ ratio were significantly different for patients with elbow/upper arm and forearm access. A recent study indicates that vascular access flow above $2.0 \mathrm{I} / \mathrm{min}$ has a higher predictive value for cardiac failure than $\mathrm{Qa} / \mathrm{CO}$ index calculation62. Prospective studies are needed to better outline access flow thresholds in relation to high-output cardiac failure. The literature suggests a complex relation between $\mathrm{Qa}$ and $\mathrm{CO}$ but we found a linear relation between both114. An explanation could be that in the study of Basile et al. the mean access flow was higher and the range of the access flow was wider and more diverse than in our study62. Indeed if our range of access flows is projected into the graph of Basile of al., then the relevant range also has a linear correlation between $\mathrm{CO}$ and $\mathrm{Qa}$.

Chapter 8: Ischaemia and brachial artery thrombosis after vascular access

In chapter 8, the case of a patient with an RC-AVF with brachial artery dilatation and thrombosis, leading to ischaemia, is described. The literature sug- 
gests that brachial artery dilatation is caused by high flow, triggering the release of substances which resemble endothelium-derived relaxing factor 63 . This is seen in patients with patent as well as occluded fistulas, although the dilatation is less explicit in occluded fistulas ${ }^{64}$. The fistula in our patient was ligated after kidney transplantation with the same haemodynamic effect as an occluded fistula, making the 'high flow theory' still possible but probably less plausible. Literature also points out a probable effect on brachial artery dilatation of immunosuppressive agents patients receive after kidney transplantation and the use of corticosteroids, similarly to the effect of steroid agents on development and rupture of aortic aneurysms ${ }^{64}$. Although to date the effect on aortic aneurysm development is only shown for steroids and only in mice and the exact mechanism is not clear, it might be a valid explanation for the development of brachial artery dilatation 65,64 .

This case report shows that AVFs can cause complications, even after access closure, and that not all changes caused by AVF creation are reversible.

\section{Future perspectives}

A recent meta-analysis showed better patency rates in brachial cubital or Gracz fistulas compared to RC-AVFs in an elderly population, and preferred the BC-AVF as first choice vascular access in elderly patients66. However, the flow direction in brachial-cubital AVFs is difficult to predict since either the basilic or the cephalic vein or both may develop as the main flow circuit. Prospective studies comparing brachial-cubital (BC) and brachial-basilic (BB) AVFs in elderly patients would be useful as BB-AVFs have been proven to have excellent patency rates with low non-maturation percentages.

As the precise mechanism of steal phenomenon and cardiac adaptation is not well understood, a closer monitoring at frequent time points, with the use of $\mathrm{MRI}$, will be helpful.

Stenosis formation, due to intimal hyperplasia $(\mathrm{IH})$, remains a major problem in autogenous and prosthetic AVFs and frequently restenosis occurs after interventional treatment in failing accesses. The use of drug-eluting stents or wraps can also be employed in vascular accesses and may have a significant impact on $\mathrm{IH}$. The need for in depth studies in this field is obvious. 


\section{CONCLUSIONS OF THIS THESIS}

1. Upper extremity secondary/tertiary autogenous access conduits with transposed/elevated veins have patency rates comparable to primary radial-cephalic arteriovenous fistulas.

2. Brachial-basilic arteriovenous fistulas have significantly better one-year primary and assisted-primary patency rates compared to the forearm prosthetic arteriovenous grafts. Furthermore, in the first year after creation, fewer interventions are needed in brachial-basilic arteriovenous fistulas compared to the forearm prosthetic arteriovenous grafts.

3. There is no difference in occurrence of hand ischaemia in patients with brachial-basilic arteriovenous fistulas and prosthetic forearm arteriovenous grafts; in these accesses $28 \%$ of patients have symptomatic ischaemia.

4. A history of peripheral arterial reconstruction and a high radial artery volume flow are predictors for the development of symptomatic ischaemia of the hand after tertiary vascular access creation. Furthermore, higher age tends to be a predictor of development of hand ischaemia.

5. Brachial-basilic arteriovenous fistula and prosthetic forearm loop arteriovenous graft creation induce similar and limited changes in cardiac structure after three months.

6. Access flow is strongly related to systemic haemodynamics in dialysis patients. In patients without cardiac failure, cardiac output and cardiac index are significantly higher in patients with elbow/upperarm access compared to patients with forearm access.

\section{REFERENCES}

1. Haase BJJM, Hoitsma AJ, Kooman JP, et al. Statistisch Jaarverslag 2007, Renine. Rotterdam: Stichting Renine; 2007.

2. Besarab A, Work J, Brouwer D, et al. Clinical Practice Guidelines for Hemodialysis Adequacy, Update 2006. Am J Kidney Dis. 2006;48:Suppl 1:S176-247.

3. Tordoir J, Canaud B, Haage P, et al. EBPG on Vascular Access. Nephrol Dial Transplant. May 2007;22 Suppl 2:iï8-117. 
4. Tordoir JH, Mickley V. European guidelines for vascular access: clinical algorithms on vascular access for haemodialysis. Edtna Erca J. Jul-Sep 2003;29(3):131136.

5. Anderson CB, Codd JR, Graff RA, et al. Cardiac failure and upper extremity arteriovenous dialysis fistulas. Case reports and a review of the literature. Arch Intern Med. Mar 1976;136[3]:292-297.

6. MacRae JM, Pandeya S, Humen DP, et al. Arteriovenous fistula-associated highoutput cardiac failure: a review of mechanisms. Am J Kidney Dis. May 2004;43(5):e17-22.

7. Levine MP. The hemodialysis patient and hand amputation. Am J Nephrol. NovDec 2001;21(6):498-501.

8. Morsy $\mathrm{AH}$, Kulbaski $\mathrm{M}$, Chen $\mathrm{C}$, et al. Incidence and characteristics of patients with hand ischemia after a hemodialysis access procedure. J Surg Res. Jan 1998;74(1):8-10.

9. Tordoir JH, Dammers R, van der Sande FM. Upper extremity ischemia and hemodialysis vascular access. Eur J Vasc Endovasc Surg. Jan 2004;27(1):1-5.

10. Bonforte G, Zerbi S, Surian M. The middle-arm fistula: A new native arteriovenous vascular access for hemodialysis patients. Ann Vasc Surg. Jul 2004;18(4):448452.

11. Bender MH, Bruyninckx CM, Gerlag PG. The Gracz arteriovenous fistula evaluated. Results of the brachiocephalic elbow fistula in haemodialysis angio-access. Eur J Vasc Endovasc Surg. Oct 1995;10(3):294-297.

12. Silva MB, Jr., Hobson RW, 2nd, Pappas PJ, et al. Vein transposition in the forearm for autogenous hemodialysis access. J Vasc Surg. Dec 1997;26[6]:981986; discussion 987-988.

13. Gefen JY, Fox D, Giangola G, et al. The transposed forearm loop arteriovenous fistula: a valuable option for primary hemodialysis access in diabetic patients. Ann Vasc Surg. Jan 2002;16(1):89-94.

14. Cull DL, Taylor SM, Carsten CG, et al. The fistula elevation procedure: a valuable technique for maximizing arteriovenous fistula utilization. Ann Vasc Surg. Jan 2002;16(1):84-88.

15. Cantelmo NL, LoGerfo FW, Menzoian JO. Brachiobasilic and brachiocephalic fistulas as secondary angioaccess routes. Surg Gynecol Obstet. Oct 1982;155(4):545-548.

16. Dagher FJ, Gelber RL, Ramos EJ, et al. Basilic vein to brachial artery fistula: a new access for chronic hemodialysis. South Med J. Nov 1976;69(11):14381440.

17. Elcheroth J, de Pauw L, Kinnaert P. Elbow arteriovenous fistulas for chronic haemodialysis. Br J Surg. Jul 1994;81(7):982-984. 
18. Murphy GJ, Nicholson ML. Autogeneous elbow fistulas: the effect of diabetes mellitus on maturation, patency, and complication rates. Eur J Vasc Endovasc Surg. May 2002;23(5):452-457.

19. Rubens F, Wellington JL. Brachiocephalic fistula: a useful alternative for vascular access in chronic hemodialysis. Cardiovasc Surg. Apr 1993;1(2):128-130.

20. Hossny A. Brachiobasilic arteriovenous fistula: different surgical techniques and their effects on fistula patency and dialysis-related complications. J Vasc Surg. Apr 2003;37[4]:821-826.

21. Bazan HA, Schanzer H. Transposition of the brachial vein: a new source for autologous arteriovenous fistulas. J Vasc Surg. Jul 2004;40(1):184-186.

22. Huber TS, Carter JW, Carter RL, et al. Patency of autogenous and polytetrafluoroethylene upper extremity arteriovenous hemodialysis accesses: a systematic review. J Vasc Surg. Nov 2003;38(5):1005-1011.

23. Murphy GJ, White SA, Knight AJ, et al. Long-term results of arteriovenous fistulas using transposed autologous basilic vein. Br J Surg. Jun 2000;87(6):819823.

24. Rao RK, Azin GD, Hood DB, et al. Basilic vein transposition fistula: a good option for maintaining hemodialysis access site options? J Vasc Surg. May 2004;39(5): 1043-1047.

25. Hakaim AG, Nalbandian M, Scott T. Superior maturation and patency of primary brachiocephalic and transposed basilic vein arteriovenous fistulae in patients with diabetes. J Vasc Surg. Jan 1998;27[1]:154-157.

26. Zielinski CM, Mittal SK, Anderson P, et al. Delayed superficialization of brachiobasilic fistula: technique and initial experience. Arch Surg. Aug 2001;136(8):929-932.

27. El Mallah S. Staged basilic vein transposition for dialysis angioaccess. Int Angiol. Jun 1998;17(2):65-68.

28. Coburn MC, Carney WI. Comparison of basilic vein and polytetrafluoroethylene for brachial arteriovenous fistula. Journal of Vascular Surgery. December 1994 1994;20(6):896-904.

29. Rivers SP, Scher LA, Sheehan E, et al. Basilic vein transposition: an underused autologous alternative to prosthetic dialysis angioaccess. J Vasc Surg. Sep 1993;18(3):391-396; discussion 396-397.

30. Dix FP, Khan Y, Al-Khaffaf H. The Brachial Artery-basilic Vein Arterio-venous Fistula in Vascular Access for Haemodialysis-A Review Paper. Eur J Vasc Endovasc Surg. Oct 132005.

31. Rooijens PP, Tordoir JH, Stijnen T, et al. Radiocephalic wrist arteriovenous fistula for hemodialysis: meta-analysis indicates a high primary failure rate. Eur J Vasc Endovasc Surg. Dec 2004;28(6):583-589. 
32. Perera GB, Mueller MP, Kubaska SM, et al. Superiority of autogenous arteriovenous hemodialysis access: maintenance of function with fewer secondary interventions. Ann Vasc Surg. Jan 2004;18(1):66-73.

33. Coburn M.C. CWI. Comparison of basilic vein and polytetrafluoroethylene for brachial arteriovenous fistula. Journal of Vascular Surgery. December 1994 1994;20(6):896-904.

34. Dammers R, Planken RN, Pouls KP, et al. Evaluation of 4-mm to 7-mm versus 6$\mathrm{mm}$ prosthetic brachial-antecubital forearm loop access for hemodialysis: results of a randomized multicenter clinical trial. J Vasc Surg. Jan 2003;37(1):143-148.

35. Fitzgerald JT, Schanzer A, McVicar JP, et al. Upper arm arteriovenous fistula versus forearm looped arteriovenous graft for hemodialysis access: a comparative analysis. Ann Vasc Surg. Nov 2005;19(6):843-850.

36. Keuter XH, van der Sande FM, Kessels AG, et al. Excellent performance of onestage brachial-basilic arteriovenous fistula. Nephrol Dial Transplant. Oct 2005;20(10):2168-2171.

37. Lemson MS, Tordoir JH, van Det RJ, et al. Effects of a venous cuff at the venous anastomosis of polytetrafluoroethylene grafts for hemodialysis vascular access. J Vasc Surg. Dec 2000;32[6]:1155-1163.

38. Rooijens PP, Burgmans JP, Yo TI, et al. Autogenous radial-cephalic or prosthetic brachial-antecubital forearm loop AVF in patients with compromised vessels? A randomized, multicenter study of the patency of primary hemodialysis access. J Vasc Surg. Sep 2005;42(3):481-486; discussions 487.

39. Taghizadeh A, Dasgupta P, Khan MS, et al. Long-term outcomes of brachiobasilic transposition fistula for haemodialysis. Eur $J$ Vasc Endovasc Surg. Dec 2003;26(6):670-672.

40. Tordoir JH, Hofstra L, Leunissen KM, et al. Early experience with stretch polytetrafluoroethylene grafts for haemodialysis access surgery: results of a prospective randomised study. Eur J Vasc Endovasc Surg. Apr 1995;9(3):305-309.

41. Matsuura JH, Rosenthal D, Clark M, et al. Transposed basilic vein versus polytetrafluorethylene for brachial-axillary arteriovenous fistulas. Am J Surg. Aug 1998;176(2):219-221.

42. Staramos DN, Lazarides MK, Tzilalis VD, et al. Patency of autologous and prosthetic arteriovenous fistulas in elderly patients. Eur $J$ Surg. Oct 2000;166(10):777-781.

43. Odland MD, Kelly PH, Ney AL, et al. Management of dialysis-associated steal syndrome complicating upper extremity arteriovenous fistulas: use of intraoperative digital photoplethysmography. Surgery. Oct 1991;110(4):664-669; discussion 669-670.

44. Zerbino VR, Tice DA, Katz LA, et al. A 6 year clinical experience with arteriovenous fistulas and bypass for hemodialysis. Surgery. Dec 1974;76[6]:1018-1023. 
45. Zibari GB, Rohr MS, Landreneau MD, et al. Complications from permanent hemodialysis vascular access. Surgery. Oct 1988;104(4):681-686.

46. van Hoek F, Scheltinga MR, Kouwenberg I, et al. Steal in hemodialysis patients depends on type of vascular access. Eur J Vasc Endovasc Surg. Dec 2006;32(6):710-717.

47. Mattson WJ. Recognition and treatment of vascular steal secondary to hemodialysis prostheses. Am J Surg. Aug 1987;154(2):198-201.

48. Tynan-Cuisinier GS, Berman SS. Strategies for predicting and treating access induced ischemic steal syndrome. Eur J Vasc Endovasc Surg. Sep 2006;32(3):309-315.

49. Valentine RJ, Bouch CW, Scott DJ, et al. Do preoperative finger pressures predict early arterial steal in hemodialysis access patients? A prospective analysis. J Vasc Surg. Aug 2002;36(2):351-356.

50. Suding PN, Wilson SE. Strategies for management of ischemic steal syndrome. Semin Vasc Surg. Sep 2007;20(3):184-188.

51. Yeager RA, Moneta GL, Edwards JM, et al. Relationship of hemodialysis access to finger gangrene in patients with end-stage renal disease. J Vasc Surg. Aug 2002;36(2):245-249; discussion 249.

52. Besarab A, Work J, Brouwer D, et al. Clinical practice guidelines for vascular access. Am J Kidney Dis. Jul 2006;48 Suppl 1:S176-247.

53. Goff CD, Sato DT, Bloch PH, et al. Steal syndrome complicating hemodialysis access procedures: can it be predicted? Ann Vasc Surg. Mar 2000;14(2):138-144.

54. Papasavas PK, Reifsnyder T, Birdas TJ, et al. Prediction of arteriovenous access steal syndrome utilizing digital pressure measurements. Vasc Endovascular Surg. May-Jun 2003;37(3):179-184.

55. Lazarides MK, Staramos DN, Kopadis G, et al. Onset of arterial 'steal' following proximal angioaccess: immediate and delayed types. Nephrol Dial Transplant. Nov 2003;18(11):2387-2390.

56. Foley RN, Parfrey PS, Sarnak MJ. Clinical epidemiology of cardiovascular disease in chronic renal disease. Am J Kidney Dis. Nov 1998;32(5 Suppl 3):S112-119.

57. Iwashima Y, Horio T, Takami Y, et al. Effects of the creation of arteriovenous fistula for hemodialysis on cardiac function and natriuretic peptide levels in CRF. Am J Kidney Dis. Nov 2002;40(5):974-982.

58. Ori Y, Korzets A, Katz M, et al. Haemodialysis arteriovenous access-a prospective haemodynamic evaluation. Nephrol Dial Transplant. Jan 1996;11(1):94-97.

59. Unger P, Wissing KM, de Pauw L, et al. Reduction of left ventricular diameter and mass after surgical arteriovenous fistula closure in renal transplant recipients. Transplantation. Jul 15 2002;74(1):73-79.

60. Ori Y, Korzets A, Katz M, et al. The contribution of an arteriovenous access for hemodialysis to left ventricular hypertrophy. Am $J$ Kidney Dis. Oct 2002;40(4):745-752. 
61. Mor-Avi V, Sugeng L, Weinert L, et al. Fast measurement of left ventricular mass with real-time three-dimensional echocardiography: comparison with magnetic resonance imaging. Circulation. Sep 28 2004;110(13):1814-1818.

62. Basile C, Lomonte C, Vernaglione L, et al. The relationship between the flow of arteriovenous fistula and cardiac output in haemodialysis patients. Nephrol Dial Transplant. Oct 172007.

63. Rubanyi GM, Romero JC, Vanhoutte PM. Flow-induced release of endotheliumderived relaxing factor. Am J Physiol. Jun 1986;250(6 Pt 2):H1145-1149.

64. Eugster T, Wigger P, Bolter S, et al. Brachial artery dilatation after arteriovenous fistulae in patients after renal transplantation: a 10-year follow-up with ultrasound scan. J Vasc Surg. Mar 2003;37[3]:564-567.

65. Reilly JM, Savage EB, Brophy CM, et al. Hydrocortisone rapidly induces aortic rupture in a genetically susceptible mouse. Arch Surg. Jun 1990;125(6):707-709.

66. Lazarides MK, Georgiadis GS, Antoniou GA, et al. A meta-analysis of dialysis access outcome in elderly patients. J Vasc Surg. Feb 2007;45(2):420-426. 


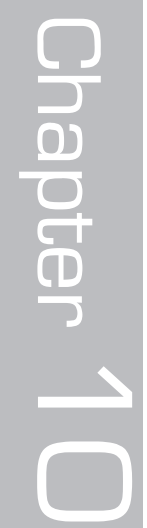

Samenvatting 


\section{SAMENVATTING}

Het verloren gaan van de nierfunctie bij patiënten met eindstadium nierfalen heeft tot gevolg dat patiënten afhankelijk worden van nierfunctie-vervangende therapie zoals hemodialyse, peritoneaal dialyse (buikspoeling) en niertransplantatie. In Nederland krijgt ongeveer 45\% van de patiënten met eindstadium nierfalen dialyse. Voor hemodialyse is het noodzakelijk om een goede vaattoegang tot de bloedbaan te hebben (grote diameter bloedvat, hoge bloedstroom]. Om dit te bewerkstelligen wordt er een verbinding gemaakt tussen een slagader en ader (arterie en vene), ook wel arterioveneuze fistel (AVF) genoemd. Hierdoor krijgt men een gecontroleerde kortsluiting in het vaatbed en neemt de bloedstroom en daaraan gekoppeld de vaatdiameter toe. De bloedbaan kan nu door middel van twee naalden worden aangeprikt en via slangen naar en van de kunstnier vervoerd worden. Volgens verschillende richtlijnen is de pols (radio-cephalica) arterioveneuze fistel (RC-AVF) de eerste keuze als vaattoegang. Echter omdat de dialyse populatie steeds ouder wordt met veel bijkomende ziekten, en de levensverwachting toeneemt, wordt het moeilijk om daar een goed functionerende vaattoegang te creëren. Dientengevolge zal steeds vaker een tweede of derde keuze vaattoegang, zoals de brachio-cephalica (BC), vena basilica arterioveneuze fistel (BB-AVF) in de bovenarm of het gebruik van prothese materiaal noodzakelijk zijn.

De kwaliteit van AVFs kan men onderling vergelijken door middel van de overlevingskansen. Er wordt onderscheid gemaakt tussen primaire, geassisteerdprimaire en secundaire overleving. De primaire overlevingskans zegt iets over het interval tussen het aanleggen van de fistel en de eerste interventie of het uiteindelijk falen van de fistel. De geassisteerd-primaire overlevingskans zegt iets over het interval tussen aanleggen van de fistel en eerste trombose van de fistel of uiteindelijk falen van de fistel. Hierbij mogen in de tussentijd wel interventies ten behoeve van het behoud van een disfunctionerende fistel worden uitgevoerd. Secundaire overlevingskans zegt iets over het interval tussen aanleggen en uiteindelijk falen van de fistel. In de tussentijd kunnen eventuele interventies voor de behandeling van trombose worden uitgevoerd.

Er bestaat geen wetenschappelijke indicatie voor de keuze van ofwel een BBAVF of het gebruik van prothese materiaal ten behoeve van het aanleggen van een AVF. Uit retrospectief onderzoek blijkt wel dat autogene fistels een betere (lange termijn) overleving hebben en dat er minder tromboses in optreden. Er is echter geen gerandomiseerde studie die verschillende vaattoegangen met elkaar vergelijkt. 
In dit proefschrift worden de vena basilica arterioveneuze fistel in de bovenarm (BB-AVF) en de onderarms protheseloop graft (AVG) in een gerandomiseerde studie met elkaar vergeleken. Behalve naar overlevingskansen hebben we ook gekeken naar voorspellers voor complicaties zoals zuurstoftekort in de hand en verhoogde hartbelasting na het aanleggen van de vaattoegang.

Hoofdstuk 2 biedt een overzicht van de opties voor vaattoegang als conventionele fistels niet mogelijk zijn of als deze hebben gefaald. Te kleine of beschadigde slagaderen en aderen verhinderen vaak het succesvol aanleggen van een pols (radio-cephalica) arterioveneuze fistel; dit hoeft echter een AVF ter hoogte van de mid-onderarm of de elleboog niet in de weg te staan. Hierdoor kunnen ook in oudere patiënten met co-morbiditeit of in patiënten met overgewicht, AVFs worden gecreëerd middels nieuwe operatietechnieken zoals omhoog brengen (elevatie) en/of omleggen (transpositie) van diep of aan de achterzijde van de arm gelegen aderen. Deze zijn vaak juist goed beschermd gebleven tegen beschadiging door infusen en vene puncties. Deze diepliggende aderen kunnen het beste worden geëvalueerd met preoperatief geluidsgolven (duplex) onderzoek.

Er zijn meerdere opties voor vaattoegangen ter hoogte van de elleboog, zoals de brachio-cephalica AVF, de brachio-cubiti (Gracz) fistel, en de brachio-basilica AVF. De vena basilica is een diep en mediaal gelegen ader in de bovenarm en is daardoor niet rechtstreeks toegankelijk voor aanprikken, tenzij deze ader oppervlakkig wordt gelegd. Dit kan in één of twee aparte operaties plaatsvinden. Er zijn verschillende operatietechnieken mogelijk, met ongeveer dezelfde uitkomst.

Indien deze opties niet mogelijk zijn of hebben gefaald bestaat de mogelijkheid van een vena brachialis superficialisatie of van een verbinding tussen de arterie brachialis en de vena axillaris met behulp van de vena saphena magna uit het bovenbeen. Een andere optie is het aanbrengen van een fistel in het bovenbeen.

Uit de retrospectieve studie (hoofdstuk 3), met daarin de resultaten van de vena basilica transpositie die in één operatie ["one stage-procedure"] werd aangelegd, bleek dat met deze methode uitstekende rijpingspercentages en geassisteerd-primaire en secundaire overlevingskansen behaald werden. Dit ondanks het gegeven dat $80 \%$ van deze populatie al eerder een AVF fistel heeft gehad. 
In hoofdstuk 4 wordt de gerandomiseerde studie tussen de vena basilica transpositie in de bovenarm en de prothese onderarms lus als derde keuze vaattoegang gepresenteerd. De BB-AVF blijkt minder interventies nodig te hebben dan de prothese loop om falen van de vaattoegang te voorkomen. De vena basilica blijkt meestal van goede kwaliteit omdat hij beschermd is tegen iatrogeen letsel door zijn diepe mediale ligging in de bovenarm. Slechts in 4\% van de patiënten bleek het onmogelijk een vena basilica transpositie aan te leggen vanwege een te kleine diameter. Het was eveneens bij eenzelfde percentage niet mogelijk een prothese onderarmsloop aan te leggen vanwege een te lage bloeddruk. Niet rijpen van de BB-AVF trad slechts in $4 \%$ van de gevallen op. In de literatuur worden non-maturatie percentages gemeld tot $38 \%$, zelfs voor RC-AVFs ( = eerste keuze vaattoegang). In onze studie waren de primaire overlevingskansen voor beide groepen lager dan die gerapporteerd in de literatuur. Men verklaart dit door de preventieve interventies om trombose van de vaattoegang te voorkomen. Dit beleid resulteert in een lagere primaire en hogere geassisteerde en secundaire overlevingskansen. $\mathrm{Er}$ traden significant minder complicaties (m.n. infecties en trombose) en interventies op in de BB-AVF groep in vergelijking met de prothese AVG groep. De primaire en geassisteerd-primaire overlevingskansen zijn significant beter in de BB-AVF groep, terwijl de secundaire overlevingskansen vergelijkbaar zijn voor beide groepen.

Onvoldoende bloeddoorstroming van de hand wordt vaak gezien na het aanleggen van een vaattoegang ter hoogte van de arteria brachialis. Volgens de literatuur treedt in 25\% van de patiënten met dit type fistel ischemie op. In hoofdstuk 5 is gekeken naar de klinische en niet-invasief (met behulp van duplex] gemeten parameters welke ischemie kunnen voorspellen alsook naar de incidentie van ischemie. Met behulp van een multivariate backwards Coxregression analyse blijkt dat een hoge bloedstroom door de arteria radialis en een voorgeschiedenis van perifere arteriële reconstructies onafhankelijke predictoren voor ischemie zijn. Een hoge leeftijd is eveneens een risico factor voor het ontwikkelen van ischemie. De vinger/armbloeddruk index is geschikter om patiënten met ischemie te vervolgen dan voor het voorspellen van de ischemie. Er was geen verschil in de incidentie van ischemie tussen de BBAVF en prothese onderarmslus.

Hartfalen door een hoge bloedstroom door de arterioveneuze fistel kan ernstige gevolgen hebben. Van alle pre-dialyse patiënten heeft $75 \%$ linker ventrikel hypertrofie (LVH). Dit is een compensatiemechanisme van het hart als gevolg van verhoogde hartbelasting en kan leiden tot systolisch en diastolisch 
hartfalen. LVH is sterk gerelateerd aan mortaliteit in de dialyse-populatie. Onze hypothese in hoofdstuk 6 was dat de cardiale belasting bij patiënten met BB-AVFs groot is ten gevolge van een hogere bloedstroom door de AVF. Echocardiografisch onderzoek liet echter geen verschil zien in linker ventrikel eind diastolische parameters vóór en drie maanden na het aanleggen van beide type vaattoegangen. In tegenstelling tot wat in de literatuur wordt vermeld was bij ons de volumeflow in beide fistels niet verschillend en was deze zelfs lager in de BB-AVF groep. Verder viel op dat de toename in linker ventrikel eind diastolische parameters nihil was in tegenstelling tot wat hierover in de literatuur gemeld wordt. Mogelijk is de cardiale respons het sterkst direct na het aanleggen van de arterioveneuze fistel en keert daarna weer terug naar de basiswaarden. Tevens kan de meetfout van echocardiografie zodanig zijn dat het moeilijk wordt om significante verschillen te ontdekken. Een dergelijk onderzoek met bijvoorbeeld MRI, waarmee gedetailleerdere opnames mogelijk zijn, zou mogelijk andere uitkomsten laten zien.

In hoofdstuk 7 wordt de relatie tussen de cardiale functie en de volumestroom door de fistel onderzocht. De hemodynamische effecten van elleboogs/bovenarmsfistels en onderarmsfistels zijn met elkaar vergeleken. Er is een significante relatie tussen de bloedvolumestroom door de fistel en de verschillende hemodynamische parameters. De volumestroom door de fistel [ $\mathrm{Q} a$ ] en $\mathrm{Qa} / \mathrm{CO}$ (met CO = Cardiac Output) zijn significant verschillend voor beide vaattoegangen (elleboogs/bovenarmsfistel vs onderarmsfistel). Een Qa boven de $2.0 \mathrm{I} / \mathrm{min}$ blijkt een hoge predicatieve waarde te hebben voor het voorspellen van hartfalen. De exacte relatie tussen $\mathrm{Qa}$ en $\mathrm{CO}$ blijkt complex te zijn.

In hoofdstuk 8 wordt een patiënt beschreven met in de voorgeschiedenis een RC-AVF welke werd opgeheven na een geslaagde niertransplantatie. Enkele jaren later ontwikkelt zich een arteria brachialis dilatatie resulterend in trombosering met hand ischemie. Dilatatie van de arteria brachialis kan worden veroorzaakt door de hoge bloedstroom of door immunosuppressiva welke patiënten gebruiken na niertransplantatie. Ook na het onderbinden of falen van een AVF kunnen er nog complicaties ontstaan en men dient zich dus te realiseren dat niet alle veranderingen veroorzaakt door een AVF omkeerbaar zijn.

Hoofdstuk 9 geeft een algemene discussie over de bevindingen van dit proefschrift, vergelijkt deze met de literatuur, gevolgd door de belangrijkste conclusies. Aansluitend worden er aanbevelingen gedaan voor mogelijke studies in de toekomst. 


\section{CONCLUSIES:}

1. Tweede en derde keuze eigen vaten vaattoegangen met ader transpositie of elevatie hebben vergelijkbare overlevingskansen met de eerste keuze (radio-cephalica arterioveneuze fistel) vaattoegang.

2. De brachio-basilica arterioveneuze fistel heeft een significant betere éénjaars primaire en geassisteerd-primaire overleving in vergelijking met de onderarmsprothese lus. Daarnaast zijn binnen één jaar na het aanleggen van de arterioveneuze fistel minder interventies nodig in de brachio-basilica arterioveneuze fistel groep in vergelijking met de onderarmsprothese lus groep.

3. Het optreden van ischemie is vergelijkbaar voor de brachio-basilica arterioveneuze fistel en de onderarmsprothese lus; symptomatische ischemie treedt bij 28\% van deze vaattoegangen op.

4. Een perifere arteriële reconstructie in de voorgeschiedenis en een hoge flow door de arteria radialis zijn predictoren voor het ontwikkelen van symptomatische ischemie van de hand na aanleggen van een derde keuze vaattoegang. Een hogere leeftijd neigt naar predictie voor ischemie van de hand.

5. De veranderingen in cardiale structuren drie maanden na aanleg van de fistel zijn minimaal en vergelijkbaar voor de brachio-basilica arterioveneuze fistel en de onderarmsprothese lus.

6. Bloedvolume flow door de fistel is sterk gerelateerd aan systemische hemodynamica in dialyse patiënten. In patiënten zonder hartfalen met een elleboogs/bovenarmsfistel is de cardiac output en de cardiac index significant hoger vergeleken met patiënten met een onderarmsfistel. 
Dankwoord 
In de euforie dat "het af is", moet ik niet vergeten iedereen te bedanken die eraan heeft bijgedragen dat dit proefschrift nu voor u ligt. Hoewel ik de meeste mensen reeds in persoon bedankt heb, hebben onder andere de volgende personen op de een of andere manier een belangrijke bijdrage geleverd aan mijn proefschrift.

Ik wil natuurlijk beginnen met mijn promotoren en co-promotoren. Prof. Kitslaar, bedankt voor u zeer waardevolle kritische en open blik op mijn wetenschappelijk werk. Prof. Hoeks, u was degene die mij letterlijk een bureau gaf om aan te werken en dit werk vervolgens met een doortastende blik gevolgd en gecorrigeerd heeft. Dank voor alles! Dr. Tordoir, beste Jan. Niet voor niets ben je het brein geweest achter dit project, als toonaangevend clinicus én wetenschapper op het gebied van de vaattoegangschirurgie in Europa, zo niet de wereld. Ik heb veel geleerd van de soms losse hand waarmee je mij begeleidde ook al heb ik daar in het begin wel eens moeite mee gehad -, en van je talrijke adviezen en correcties ten aanzien van mijn manuscripten. Bedankt voor de samenwerking! Dr. van der Sande, dank voor het zetten van de puntjes op de i, zonder uitzondering snel en vriendelijk.

Naast mijn promotoren ben ik uiteraard dank verschuldigd aan de beoordelingscommissie van dit proefschrift, voor de snelle en vakkundige beoordeling: Prof. Dr. Leunissen, Prof. Dr. Moll, Dr. de Haan en Dr. Hofstra, ik dank u. Dr. Kooman en Dr. Cheriex, u beider bijdrage aan hoofdstuk 6 van mijn proefschrift is van ongekende waarde. Hetzelfde geldt voor Jos Habets, welke de echo's vervaardigde voor dit hoofdstuk.

Deze multicenter studie was nooit mogelijk geweest zonder de enthousiaste samenwerking met verschillende mensen. Dr. Yo, deze studie kwam voort uit uw COP-Trial. Bedankt voor de introductie in het MCRZ. Patrick, bedankt voor de vele inzichten. Succes met het afronden van de COP-Trial, moge het een mooi feest worden! Dr. de Smet, dankzij u een goede inclusie in het MCRZ en een dubbelpresentatie van ons werk in mei 2006 in Veldhoven en Phoenix. Dr. Welten, waarschijnlijk omdat u pas op een later tijdstip bij deze multicenter trial betrokken bent, heeft $u$ het predicaat "hofleverancier" net niet gehaald. Echter uw centrum is van zeer grote waarde geweest bij het behalen van het benodigde aantal patiënten voor de studie. Bedankt voor de adviezen en steun, ook naast het wetenschappelijk werk. Fons, jij was degene die me door de moeilijkste periode van mijn proefschrift heen trok, en me de kneepjes van het (SPSS-) vak leerde. Hopelijk treffen we elkaar nog vaak onder water. Yvonne, Evelien en Johanna bedankt voor alle ondersteuning. 
Van ongekend belang voor het slagen van deze studie zijn de medewerkers van de verschillende dialyse afdelingen, vaatlab afdelingen en chirurgie poli's van het Atrium MC in Heerlen, het MCRZ in Rotterdam en het azM in Maastricht geweest. Van al deze medewerkers ben ik in het bijzonder veel dank verschuldigd aan Hanneke, Jane, Marga en Louise uit het MCRZ, Willy, Marjo en Linda uit het Atrium en Edwin (veel succes met je promotie!), Laura, Marjon, Evelien, Sandra, Simone, Bianca en Monique uit het azM. Magda, fijn dat we af en toe van gedachten konden wisselen. Veel succes met jouw promotie.

Jeroen, dankzij het stand-by zijn van jou konden technische problemen vaak ad hoc worden opgelost, bedankt.

Mijn kamergenoten wil ik bedanken voor de mooie tijd die ik met hen heb doorgebracht. Rick, het was moeilijk om jou te leren kennen tussen je filosofieën en ondervragingsstrategieën door, maar de race-momenten met een biertje zullen me zeker bijblijven. Succes met de verdediging van je proefschrift. Andrei, jouw hyperactiviteit/opgewektheid en filmpjes waren vaak een welkome afwisseling in de onderzoeks"sleur". Blijf vooral geloven in jezelf en je onderzoekslijn zal zeker slagen! Femke, jij bracht de vrouwelijke noot aan in de mannenkamer, al waren we niet blij met het vooruitzicht dat een vrouw ons kwam bemoederen. Jouw introductie van de vrijdagmiddag-kamer-lunch was echter een groot succes voor de teamspirit en zorgde voor een goede bodem voor de vrijdag(avond) kamer-borrel. Succes met je onderzoek en carrière! Stella, jij tipte me altijd als er een patiënt voor mijn onderzoek op de afdeling was en er tijd was voor mijn metingen. Gefeliciteerd met je physician-assistent titel! Tot op de volgende vaatborrel!

De heren van Carrera, ambiteus en pijlsnel als altijd. Boesch, relaxed maar ambitieus, jij floot ons altijd terug als we te veel zaten te blaten over patiënten, onderzoek en carrières. Bedankt daarvoor en succes met je (golf?)baan! Robbert en Nils, nadat onze interesse voor het wetenschappelijk onderzoek gewekt was in ons bestuursjaar bij het MMSRC, gingen we ieder ons wetenschappelijk pad, al hebben deze paden elkaar meerdere malen gekruist. Ik denk dat we veel van elkaar geleerd hebben en hoop dat we daar nog lang van kunnen profiteren. Hopelijk kan ik jullie glansrijke verdediging van jullie proefschrift evenaren, al wordt dat een zware taak. Fred, bij jou kan ik altijd terecht voor advies of gewoon een praatje over iets anders dan werk. Ik vind het super dat onze wegen elkaar nu af en toe professioneel kruisen, maar nog veel belangrijker dat we daarbuiten nog veel contact hebben!

Coen, jij was de eerste van ons jaar die promoveerde en dus een lichtend voorbeeld. Ik hoop dat ik nog vaak van je kookkunsten mag genieten! Mascha, 
vaak denk ik nog terug aan de bestuursvergaderingen bij Ko-beraad. Je had een doortastende blik en wist een goede koers uit te zetten. Zo vastberaden ben je ook naar Rotterdam vertrokken, ik weet zeker dat je daar een mooie carrière tegemoet gaat. Anouk, hopelijk kunnen we binnenkort wat vaker afspreken, bedankt voor je luisterend oor en gezelligheid tijdens onze eetafspraken.

Joep en Guido, ik vind het een eer dat jullie mij willen flankeren op deze voor mij zo spannende dag. Ik denk dat het symbolisch is voor de voorbije jaren waarin we elkaar ter zijde stonden, maar vooral veel leuke dingen samen deden. Ik hoop dat we dit nog lang zo kunnen voortzetten. Alvas bedaank!

Theo, bedankt voor het kritische commentaar op de belangrijke delen van mijn proefschrift.

Mam en Pap, jullie zullen het niet geloven maar het is nu echt af. Bedankt voor jullie luisterend oor, steun en vertrouwen. Yvo en Melvin, do not try this at home. Oma's en opa, dank voor het onvoorwaardelijke geloof. Lieve Sanne, jij bent degene die alles van dichtbij heeft meegemaakt. Jij zorgde ervoor dat er in de privé tijd zowel tijd was voor het afronden van mijn proefschrift als voor de nodige ontspanning! Ik kijk ernaar uit nu hetzelfde voor jou te doen, het was namelijk van ongekende waarde! Ik hou van je! 
Curriculum vitae 
Xavier H.A. Keuter was born June 28, 1978 in Tongeren, Belgium. He attended the Stedelijke Scholengemeenschap Maastricht (Atheneum), where he graduated from in 1997. Immediately thereafter he started his medical training at the faculty of Medicine of the University of Maastricht. During his medical training he served as a research assistant at the Department of Ophthalmology, University Hospital Maastricht. Furthermore, he was a member of the board of the $4^{\text {th }}$ Maastricht Medical Students Research Conference (MMSRC) and treasurer of Ko-beraad (the association of medical interns). He obtained his medical degree in August 2003. Thereafter he became a $\mathrm{PhD}$ student at the Department of Vascular Surgery of the University Hospital Maastricht working on a study funded by the Dutch Kidney Foundation resulting in this thesis. In January 2007 he started his surgical residency in Viecuri Medical Center Venlo (Dr. H.M.J. Janzing). 